Florida International University FIU Digital Commons

$11-13-2015$

\title{
You Crit Like a Girl: the Performance of Female Identity in the Virtual Gaming Community World of Warcraft
}

Connie M. Viamonte

Florida International University, cviam001@fiu.edu

DOI: $10.25148 /$ etd.FIDC000170

Follow this and additional works at: https://digitalcommons.fiu.edu/etd

Part of the Gender and Sexuality Commons

\section{Recommended Citation}

Viamonte, Connie M., "You Crit Like a Girl: the Performance of Female Identity in the Virtual Gaming Community World of Warcraft" (2015). FIU Electronic Theses and Dissertations. 2273.

https://digitalcommons.fiu.edu/etd/2273 


\section{FLORIDA INTERNATIONAL UNIVERSITY}

Miami, Florida

YOU CRIT LIKE A GIRL: THE PERFORMANCE OF FEMALE IDENTITY IN THE VIRTUAL GAMING COMMUNITY WORLD OF WARCRAFT

A dissertation submitted in partial fulfillment of the

requirements for the degree of DOCTOR OF PHILOSOPHY

in

COMPARATIVE SOCIOLOGY

by

Connie M. Viamonte

2015 
To: Dean John Stack

School of International and Public Affairs

This dissertation, written by Connie M. Viamonte, and entitled You Crit Like a Girl: The Performance of Female Identity in the Virtual Gaming Community World of Warcraft, having been approved in respect to style and intellectual content, is referred to you for judgment.

We have read this dissertation and recommend that it be approved.

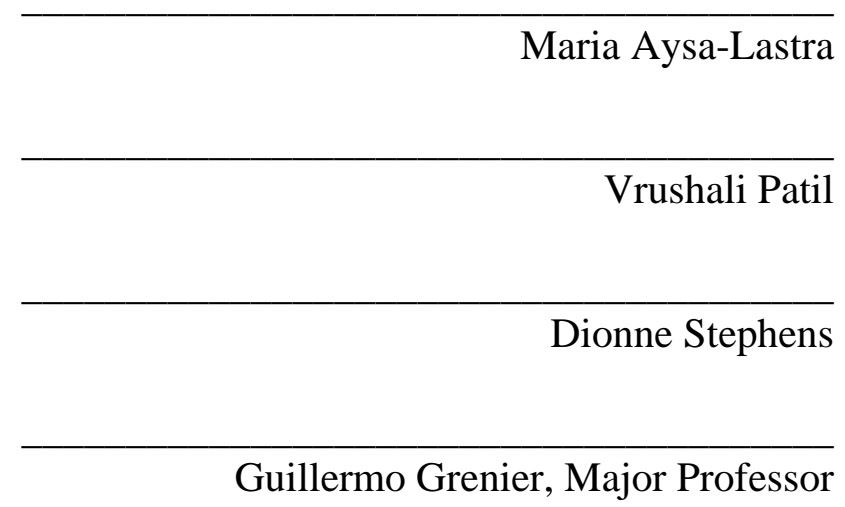

Date of Defense: November 13, 2015

The dissertation of Connie M. Viamonte is approved.

Dean John Stack

School of International and Public Affairs

Dean Lakshmi N. Reddi

University Graduate School

Florida International University, 2015 


\section{DEDICATIONS}

To my son, my light and my joy, I love you and this is for you (as is everything I do).

To my parents, for all their love and support through these many years and these many trials. 


\section{ACKNOWLEDGMENTS}

I want to thank Dr. Guillermo Grenier for all his support through this long process and for being my inspiration. Without him, I would never have gone down this path. I want to thank my committee members: Dr. Maria Aysa-Lastra, Dr. Vrushali Patil, and Dr. Dionne Stephens, for always being there to give me feedback and advice.

I want to thank my parents, Reinaldo and Concepcion Viamonte, for pushing me through this process, and through all the trials that I faced. They are the wind at my back that tells me to keep going and if it were not for them, I would not have gotten to this point. And I want to thank my heart, my son, Tristan, for being the hope and joy in my life. I'd like to thank my brother, Luis Castano, for his positivity and encouragement in the darkest of moments. I'd also like to thank Melissa Burt, who was the only person to believe in me when I had lost my way and if not for her constant encouragement, this would never have been finished.

Finally, I want to thank all the people who I reached out to and who responded to surveys, to interviews, and to countless questions. I want to thank my friends and all the people who, through the years, have helped me shape this project into what it became.

This is for those of us trying to find a place in this mad world. 
ABSTRACT OF THE DISSERTATION

YOU CRIT LIKE A GIRL: THE PERFORMANCE OF FEMALE IDENTITY IN THE VIRTUAL GAMING COMMUNITY WORLD OF WARCRAFT

\author{
by
}

Connie M. Viamonte

Florida International University, 2015

Miami, Florida

\title{
Professor Guillermo Grenier, Major Professor
}

This dissertation examines how gender is expressed and performed in the virtual gaming community of World of Warcraft. Players were approached through the medium of the game and through various on-line bulletin boards to answer surveys and openended interview questions about their experiences as a female player or with female players in this virtual society. In addition to answering questions, this project involved participant observations within several different types of realms or servers in World of Warcraft in order to gain a better understanding of community dynamics. The premise for this research is working through an idealistic notion that virtual communities might break down gender lines through allowing members to pick their gender or doing away with biological differences in gender altogether. This research hopes to dissect this idea and, furthermore, fill an important gap in existing sociological studies about virtual societies and games by making the argument that gender stereotypes carry over from the physical world into virtual spaces and, consequently, affect the vabried interactions of players within this virtual community as well as the gender performance of female players, in particular. Observations and game design suggests that many of the aesthetic 
principles of the female avatars available in World of Warcraft cater to attracting heterosexual male players. Clothing and armor is revealing and female avatars are highly sexualized not just through appearance, but through programmed behaviors in the game. This research examines the effects of such pre-conditioned parameters on the population of this top ranked game. 


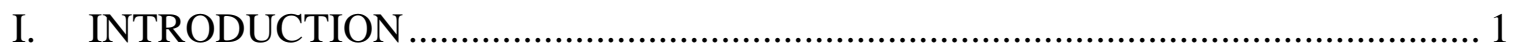

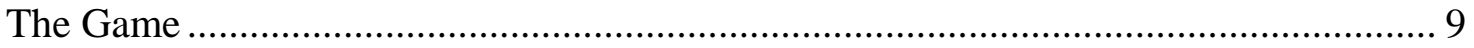

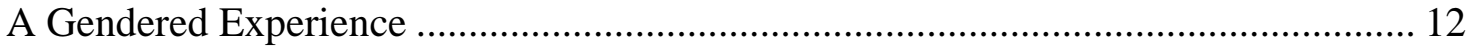

Glossary of Terms …………………………………..................................... 16

Statement of Problem ............................................................................................. 18

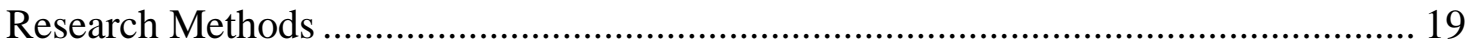

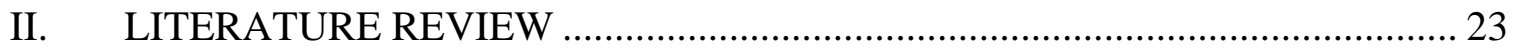

Self-actualization in Virtual Worlds ..................................................................... 23

Understanding Virtual Interactions by Gender ............................................................ 26

Understanding Virtual World Culture and its Effect on Gendered Interactions ............ 34

Understanding Motivations of the Players by Gender ................................................... 38

Social Science Research in Virtual Worlds.......................................................... 50

Nick Yee: Daedalus and Proteus ............................................................................... 54

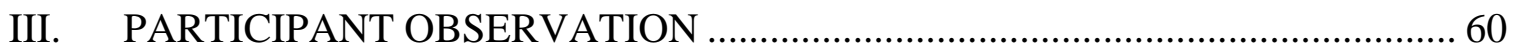

Player versus Player Servers: Guilds are Serious Business ........................................... 62

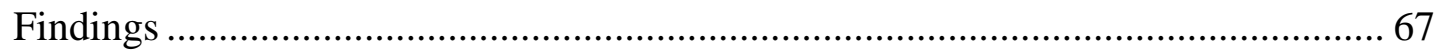

Gendered Interactions Online and at Home: My Husband Plays Better........................ 68

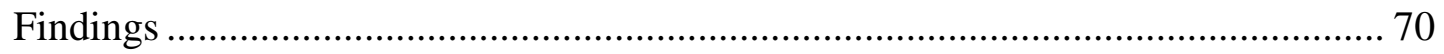

Player versus Environment: Not so Serious Business................................................ 70

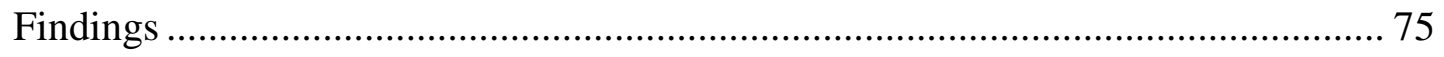

Gender and the Avatar: Speak Softly but Carry a Very Manly Staff............................ 76

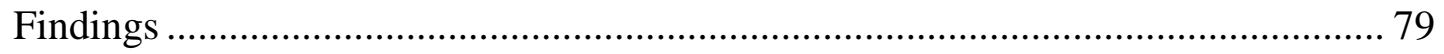

Gender and the Voice: You Sound Hot! .............................................................. 79

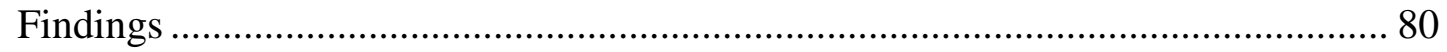

Gender and Power: The White Knight Syndrome ...................................................... 81

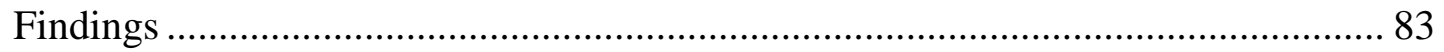

Role Play Servers: Less Than Serious Business ………………………...................... 84 


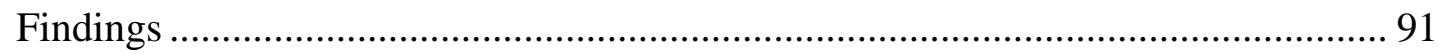

Trade Chat: The Foremost Authority in World News............................................. 92

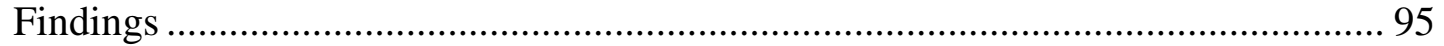

Trade Chat: Lessons on Spotting a Real Girl............................................................ 96

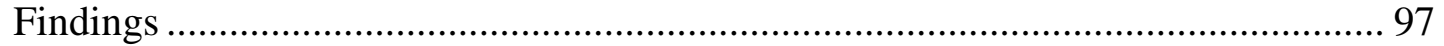

Guild Chat: How to be Offensive in 10 Chat Lines ................................................ 97

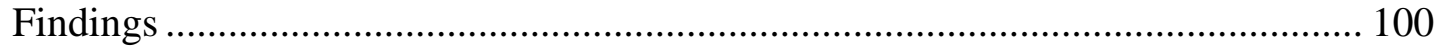

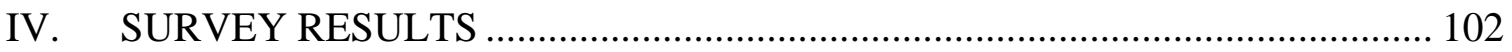

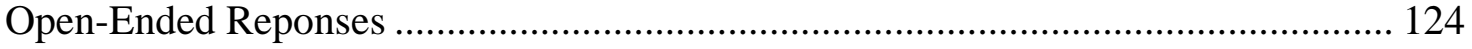

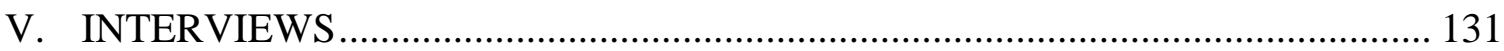

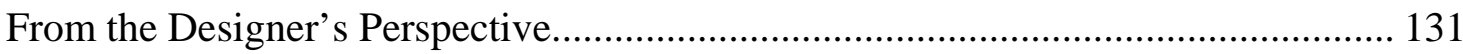

From the Gamer's Perspective ........................................................................... 132

VI. DISCUSSION AND CONCLUSIONS ...................................................... 158

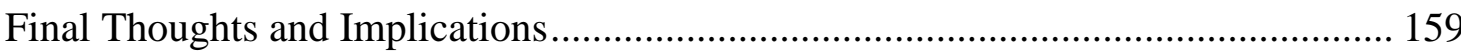

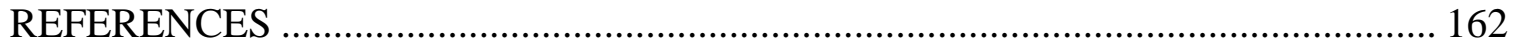

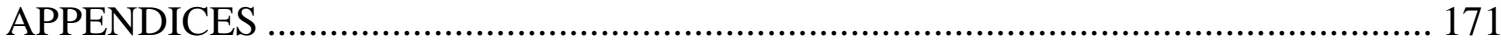

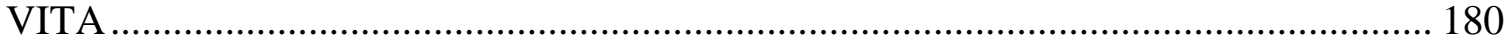




\section{LIST OF TABLES}

TABLE

PAGE

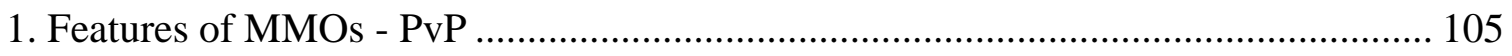

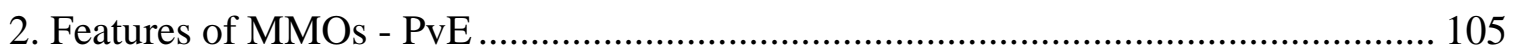

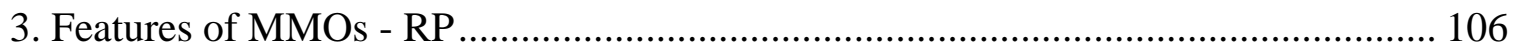

4. Features of MMOs - Avatar Customization................................................................ 107

5. Features of MMOs - Gaming Interface................................................................ 107

6. Features of MMOs - Gaming Environment ........................................................... 108

7. Features of MMOs - Difficulty/Challenge of Game..................................................... 108

8. Features of MMOs - Player Community .................................................................. 109

9. Features of MMOs - Player Co-operation .............................................................. 109

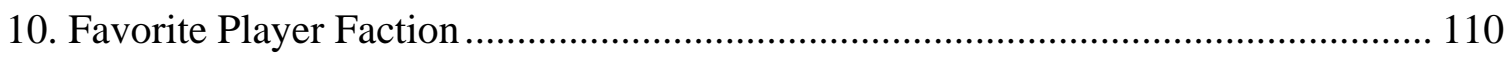

11. Favorite Player Class …………………………………..................................... 111

12. Best In-Game Healer......................................................................................... 112

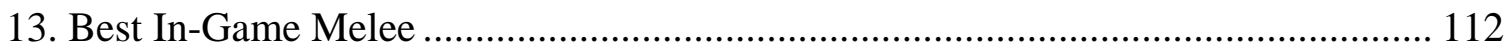

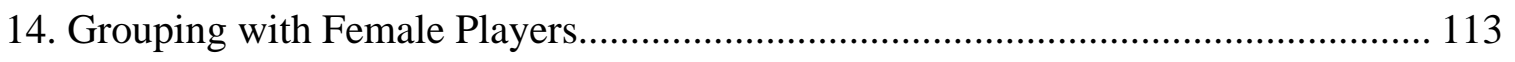

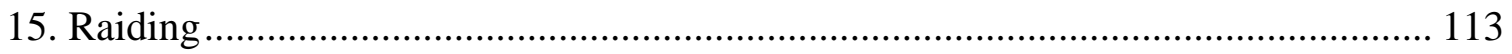

16. Gender Assumptions - Avatar................................................................................. 114

17. Gender Assumptions - Player ............................................................................ 114

18. Gender-Bending - Other Players............................................................................. 116

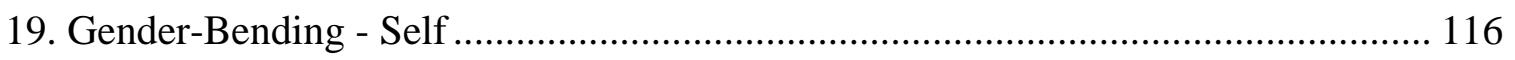

20. Aesthetically Pleasing Avatars - Female Gamers ...................................................... 117 
21. Aesthetically Pleasing Avatars - Young Gamers .................................................. 117

22. Aesthetically Pleasing Avatars - Self ......................................................................... 118

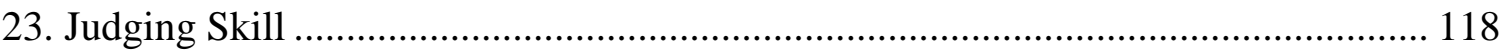

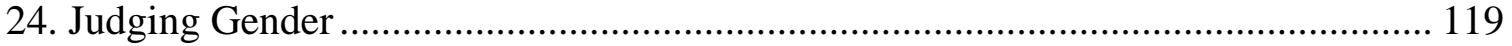

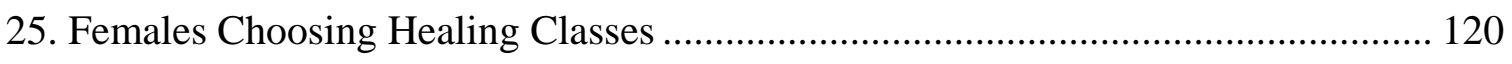

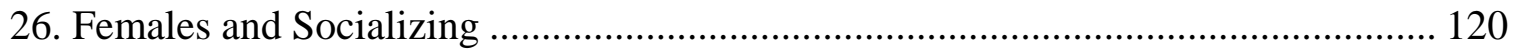

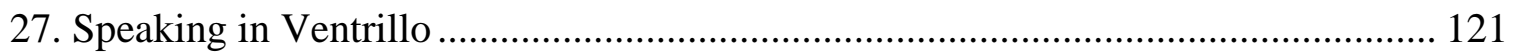

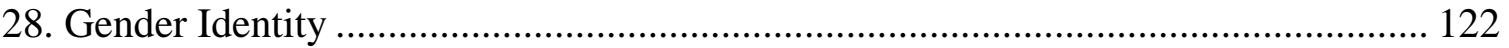

29. Aggressive MMO Communities ......................................................................... 122

30. The WoW Forums - Asking Questions............................................................... 123

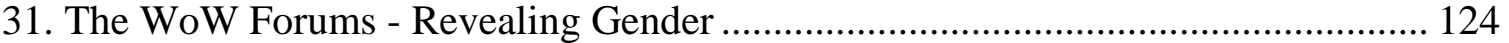




\section{LIST OF FIGURES}

FIGURE

PAGE

1. Women on Internet Meme

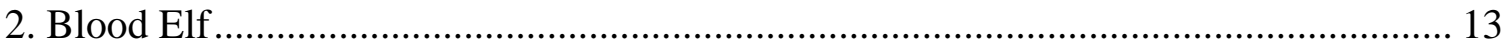

3. Yee, Nick. I Think of my Avatars as Idealized Versions of Myself............................ 56

4. Characteristics associated with gamers that are negative ...................................... 125

5. Characteristics associated with gamers that are positive ..................................... 128 


\section{INTRODUCTION}

All of a sudden the world around me blurs and there is only the screen. Seventeen inches of high definition graphics and this is my point of view now. I have left my life to enter another. My avatar is my vehicle, my virtual self, helping me to transcend my physical existence and navigate an imagined world, a programmed reality. I am not alone in my journey. Millions join me every day, every hour, every minute. The numbers of virtual selves grow almost as rapidly as the imagined spaces in which we travel.

This investigation, this journey, is to the land of Azeroth. A universe in which dragons still rule the skies and war has torn asunder much of the land. Magic is as powerful a tool as physical force. And you can still sit down to fish if the mood strikes you, though it is often just as frustrating as it is in the physical world. In Azeroth, there are humans as there are on Earth. But humans share their land with other bipeds of equal or greater intelligence. Creatures of myth, like orcs and trolls, elves and goblins. They share meals, adventures, and their lives with humans. Best of all, when you step into Azeroth you can choose to shed your humanity and adopt the persona of any of these varied races.

As I leave my life behind, I step into the shoes of a Night Elf. Descended from a long line of nature-loving druids, I am one of the many, fighting to save my people from their own hubris and carve a niche in this ages-long war. I am female, tall, elegant, and slender. My hair is white and my skin is a dark violet hue. I have long ears and dramatic lavender markings on my face. My eyes glow bright, framed by long eyebrows and lashes. It cannot be denied that I am attractive, muscular, and quite a catch! Who 
wouldn't be drawn to a powerful being that can wield magic and turn into a panther at will?

This type of escape into virtual worlds is experienced by millions every day. The escape, it seems, is invaluable to many. When investigating the psychology of player motivations, Nick Yee (2006) writes the following:

When respondents were asked whether the most positive experience they had experienced over the period of the past 7 days or the past 30 days occurred in an MMO or in real-life, $27 \%$ of respondents $(n=2170)$ indicated that the most satisfying experience over the past 7 days occurred in the game, and $18 \%$ of respondents indicated the same when the wording was changed to "over the past 30 days”. With regards to the most negative event, 33\% of respondents indicated that the most negative experience over the past 7 days occurred in the game, and $23 \%$ of respondents indicated the same when the wording was changed to "over the past 30 days”.

Given the role the Internet plays in the average American's daily life, these numbers are not surprising. After a grueling day at work, shedding your corporate skin to step into someone else's and blow off steam by shooting down a few enemies or building a fortress seems like an excellent way to unwind. We can bog ourselves down in discussions of virtual violence as a form of leisure and what that says about our society, but that is not the focus of this research. Here, my concern is identity. And, more specifically, feminine identity. How do females navigate virtual, and still patriarchal, 
worlds? How is female identity expressed and how is this expression associated with sex and power virtual relations?

Virtual worlds and video gaming have been predominantly male territory since their inception. I will exhaustively lay this out in the pages that follow. It is only very recently that the female "gamer" population has come forward, controller in hand, shouting that we enjoy violence too, we like to build fortresses that are just as large, and we don't mind wielding a hammer that would put Thor's to shame! This has left the male population of virtual communities with little recourse but to turn to self-deprecating humor. Popular catch phrases such as "There are no women on the Internet" (See Figure 1) to discredit claims of femininity, have suddenly lost credit themselves, used now as sarcastic, dark humor. However, fans of virtual games and pioneers of virtual gaming sub-culture are not known for taking themselves overly serious and when presented with sensitive topics like gendered discrimination, the response is almost always riddled with satire. 


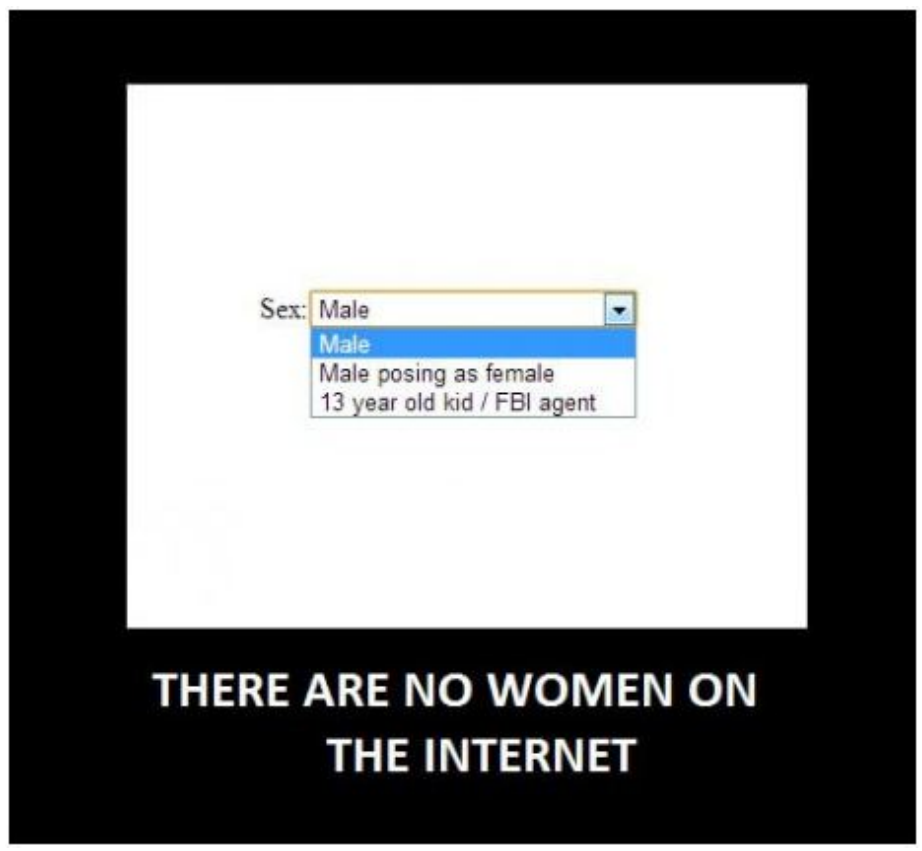

Figure 1 Women on Internet Meme. Retrieved from URL http://www.comicvine.com/forums/off-topic/5/besst-looking-girl-on-the-vine/741986/ on Mar 2013.

As with all carefully woven tales, background is important. This investigation has been nearly a decade in the making. As an idealistic undergraduate finding my way into graduate school at the start of this century, I was intensely interested in the Internet. Even earlier, as a 13 year old boldly exploring racy chat rooms, the Internet always held an allure I could never quite explain. Faceless anonymity, limitless potential for interaction. It was the ideal playground for a sheltered teenager. I devoured every corner of the World Wide Web I could access, and even some I shouldn't have accessed (hard lessons, well learned). When it came time to use my knowledge for the advancement of the social sciences, I looked at budding Internet trends. At the time, sites like Match.Com were making ripples. Suddenly, singles were not meeting each other in person anymore. They were custom shopping and custom ordering partners based on profiles published on the Internet - that amorphous behemoth where all things are permanent. There are no 
secrets on the Internet and our lives become ever more open to scrutiny. Any kid with a keyboard can play the part of a private investigator if they know how to "'Google' you".

To see how our love affair with the Internet evolved into the tawdry, drawn-out romance it is today, some of the first bits of research from on-line communications and relationships are important to re-visit, as they hold the key to virtual interaction. In Diane K. Wysocki’s doctoral dissertation, $\underline{\text { Somewhere Over the Modem: Interpersonal }}$ Relationships Over Computer Bulletin Boards, the author investigates the questions of how, why and in what way people develop relationships on-line. She begins by presenting the fact that relationships developed over the Internet evolve much faster than face-to-face relationships because of self-disclosure without fear of rejection based on appearance. Attraction is not based on aesthetics, but on shared personal interests, adding to the quality of the relationship (Wysocki, 1996). The author also looks at sexual activity on the Internet as a safe outlet of sexual fantasy. One can get almost any fantasy they desire fulfilled over the Internet and there is no risk of disease, social stigma or personal danger, such as rape (The latter contention complicated by Julian Dibbell's (1993; 1998) exploration of a virtual rape, where he goes about detailing that a virtual rape can be possible so long as the individual feels victimized.) There is no physical involvement whatsoever, a benefit in this age of deadly diseases. One can escape to a world of sexual fantasy that may not be possible in one’s typical, daily life. However, this concealment of identity for sexual satisfaction could lead to deception, as Wysocki points out. Though some take comfort in being anonymous, others may use and manipulate their faceless-ness to find victims. For example, there is a large problem with 
adults pretending to be children in order to lure actual children into face-to-face meetings (Whysocki, 1996). These people are not looking for companionship, as much as they are hunting for prey.

Wysocki (1996) does quantitative analyses of a particular BBS to discover the reasons why people go on-line, thereby establishing relationships through frequent use. The four most frequent respondent answers were loneliness, sickness, fear of rejection or shyness, and lack of time. The author states, "individuals could gain gratification by joining other people on-line, thus gaining relief from feelings of isolation and the feeling of being alone.” Sickness may result in not being able to leave your home, which thereby leads to loneliness. Being shy or fearing rejection is another isolating factor. And, finally, with very little spare time because of work, children or other obligations, relaxing in front of a computer screen in your own home and conversing with others seems like a more convenient alternative. All of these responses are interrelated and make the Internet a valuable tool for many individuals to avoid isolation or relieve social anxiety by taking away the public social context, yet retaining the human contact (Wysocki, 1996).

Erich R. Merkle and Rhonda A. Richardson (2000), take computer-mediated relationships (CMR) and compares them to face-to-face relationships (p. 187). Following Wysocki they make the points that "internet users can extend their social networks, create virtual on-line communities, find prospective marital partners, and even fulfill their most veiled sexual desires (Merkle and Richardson, 2000, p. 188).” The authors make a vital comparison between Internet dating and traditional dating. In traditional dating, physical 
attraction is important in determining whether or not the relationships will even continue. It is the first step to a successful union between two individuals, therefore, there is always anxiety concerning one's appearance. After that initial spark, the two parties look for similarity of interests and social life. And then, finally, if the relationship has survived for that long, there is intense personal self-disclosure that brings the parties closer together. But this is not the case for Internet relationships. Most CMR progress through an inverted model, with the intense self-disclosure beginning the relationship and physical attractiveness no longer playing a role in the durability of the union. And with the building of trust, individuals often meet "with highly sexualized outcomes” (Merkle and Richardson, 2000, p. 189).

And so this was where I began my journey into investigating virtual relationships, Internet dating. How did couples meet and connect? I too had dated on the internet, met boyfriends through real-time chatrooms and ultimately taken many failed relationships off-line. But very soon, something else caught my eye. Text-based virtual interactions were becoming a thing of the past. In this age of technology, something new can become old in months, weeks, minutes. I had moved on to massively multi-player on-line roleplaying games. What a mouthful! Today, the genre is mercifully referred to as MMOs, Massive-Multiplayer Online games. For this analysis the role playing dimension of the virtual experience is important so I will continue to refer to them as MMOs. These graphic rich sensations were worlds unto themselves with quests, monsters to slay, damsels (not always female) in distress, and other players to interact with. The interaction element intrigued me and seemed to lend continuity to my interest in virtual 
relationships. Surely relationships start in places like this, when you are arm-in-arm with your virtual partners fighting the injustices of this imagined world. Indeed they did.

World of Warcraft, the MMO I frequented and the subject of this investigation, had an entire website dedicated to matching up enthusiasts for romantic "questing". Datecraft.Com and similar sites sprang up to provide easier channels for players to meet and find partners that shared their love of slaying dragons and virtual fishing. I was mesmerized by this innovation and I began investigating immediately. With little to no scholarly research to back me up, I was on my own. However, the very existence of this gamer dating site had to be predicated on a fact that is still needs to be defended. It turns out there were women on the Internet and they were playing the same games their male counterparts were playing! And this led me to the breadcrumb that began the journey that I present in this research. How do female players, clearly of greater numbers than even the marketing geniuses at the very top of the video game food chain managed to miss, navigate the minefield of sexism in this industry and in these virtual communities?

It is at this point that I lost interest in the relationship and became drawn to the experiences of the female player. Through simply playing the game, without having begun any formal investigation, I could already see that there was a division within the community of female players. Studies of sexuality and identity show a very pervasive and completely dichotomous heteronormative ideal within our society (Western society for the purposes of this investigation). These ideals seem to be upheld in the virtual sphere, particularly in MMOs where there is a concept of skill and ability. This concept, 
this power, though absent of the boundaries of physicality, is still one very much linked to the masculine (Cassell and Jenkins, 2000).

The Game

Before I recount my experiences as a typical player and then, subsequently, as a scholarly investigator within World of Warcraft (hereafter, WoW), it is important to provide an overview of the game being discussed. The game is set in the fictional world of Azeroth, split into continents and into two warring factions, the Alliance and the Horde. When this investigation formally began there were 12 playable races with male and female avatar options (options that are purely cosmetic and have no bearing on the skills or abilities of the avatar). There has since been one new race addition, a race that plays on both the Horde and Alliance side, thus the number of playable races has increased to 13. The Alliance is arguably the representative of "good", though moral concepts are complicated within story lore. Races within the Alliance are typically aesthetically pleasing. There are humans, with both the male and female avatars exhibiting idealized physical builds. There are Night Elves, the female avatars of which are highly sexualized, their character dance being a seductive writhing of the body. The Draenei are an alien race that worships beings of light, the male avatar with overly muscular bodies and the females resembling the Night Elf females in their traits and physicality. Other races attributed to the Alliance are Dwarves, Gnomes, and Worgen (a race of werewolves). Now, onward towards the other faction, the Horde, arguably the "evil" side. The Horde's structures are littered with war-torn huts and make-shift encampments. Their races are rougher, less of a Western idealized aesthetic and littered 
more with what our culture might typically consider monsters or frightening beings. Races include the Orcs, eternal enemies of the humans. Hulking, green-skinned people with gruff voices and drooling fangs. Trolls are long-eared, long-toothed, furry humanoids with angry, sloping foreheads. Tauren resemble minotaurs, with humanoid bodies and the heads of bulls. Undead, zombie-like creatures are also contained within the Horde's line up, as well as green-skinned, goblins with a lust for gold. The Blood Elf (added with the Draenei on the Alliance side) seemed an ill-fit (as far as looks were concerned) with the Horde. The Blood Elves resembled the Night Elves, the females highly sexualized and the males of the race drawn with what could be classified as feminine characteristics, if one is bound by the assumptions that come with a heteronormative society, and it will become plainly obvious that these assumptions are also in the minds of the programmers when they write and design these games. The running joke amongst gamers and within the coding for the avatar of the Blood Elf male was that he was a metro-sexual of sorts, his appearance being of the utmost importance, conjuring up images of Narcissus worshipping himself at the water's edge. The Blood Elf's lore was written in such a way that the race often questioned their own allegiance to the Horde. These points will be taken up again later in this investigation, but the background is integral to understanding all aspects of this virtual community. It is also important to mention that the most recent addition, the Pandaren, added to both the Alliance and Horde's roster, is a large Panda-like creature with influences of Asian culture and a propensity towards the martial arts. 
Different races have different powers or abilities. There are groups of classes for each race, including warriors, mages, rogues, priests, paladins, sorcerers, hunters, shamans, monks, and druids. There are currently 11 total class choices. Classes can be used within four different roles. These roles are essential when fighting difficult monsters in the game. They include a tank, a difficult position in which the player is meant to keep the target in position, moving depending on the abilities of the monster and positioning for the group of attacking players. Attacking (or DPS) players can be ranged, including hunters with long ranged bows or guns and mages with long ranged spells, or they can be melee using weapons like axes or swords and attacking up close. The last role is that of the healer, another integral role in which the player's sole job is to keep everyone alive during a battle.

Class choices are the same for both factions. When the choice is made to play either the Alliance or the Horde, players cannot communicate with players of the other faction. When viewing messages typed into the local chat box from a player of the opposing faction, the words are garbled. Players from the same faction can view messages through different text-based chat channels. Players also sometimes use Ventrillo (Vent for short) a voice chat system to coordinate quests or dungeon raids. Players can form guilds, large specialized groups of players with similar intentions towards game-play. Guilds often work together to defeat difficult dungeons or monsters. Some guilds come together based on nationality, some based on simple questing through the game. There are all manner of guilds. 


\section{A Gendered Experience}

It was on one very typical day of play that I encountered the gendered ideals of the physical world within WoW. The general thesis and structure of my dissertation was still very much ambiguous in my mind, and incredibly hard to grasp with very few tools under my academic belt with which to solidify it and give it context. And so it was that on this day a very dear male friend of mine was assisting me in making an avatar for the Horde. Being that I was unfamiliar with any assumptions made about me based on my choices, I chose a female Blood Elf (pictured below in Figure 2). Why did I make such a choice? Well, looking back, I wanted an attractive avatar. At the time, I never bothered to ask myself why. Up until that point, I'd played female Night Elves almost exclusively. Therefore, when my friend wanted me to play with him on the Horde side, I chose the most similar race. Once I'd made my warlock (a type of sorcerer), I was excited to get started playing and my friend was showing me the ropes of the Horde, as I'd been so used to the landscape of the main Alliance areas. 


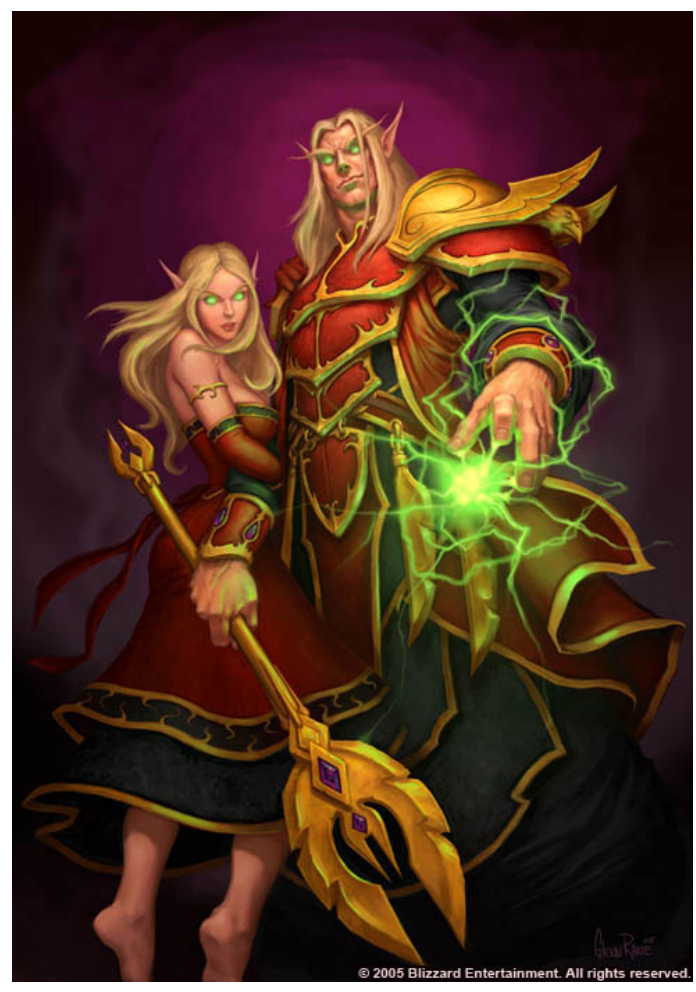

Figure 2 Blood Elf Retrieved from URL http://www.wowwiki.com/Blood_elfon December 2014.

"Janx is going to hate you," he says to me on Vent. We've been friends a long time so we talk on voice chat whenever possible. Perplexed, I ask, "who? Why?" He goes on to explain that Janx is part of the guild he is in, a guild into which he is bringing my nascent avatar. I can't imagine why this person would hate me and Ryan, my friend, elaborates that Janx is militantly anti-Blood Elf. Ryan dodges any further inquiry with a vague "you'll see" and I am taken into the guild voice chat with the infamous Janx, another female player, Ryan, and myself. Immediately, I am treated to a tirade of antiBlood Elf rhetoric. Janx informs me that she plays a male Troll and that she finds this to be a very respectable avatar for a female player. "I know Ryan knows you and all so I don't mean you, but anytime I see a girl Blood Elf I'm just like... this must be a newbie, you know." 
A "newbie" is a term born from the very inception of internet gaming. The newbie/noobie/noob is the most dreaded of positions and the most commonly flung insult when one wants to undermine another player. The fear of being labeled as such is intrinsic to every gamer, both casual and experienced alike. All in-game actions are dominated by a haunting fear of being labeled a "noob" if tasks are not completed as quickly, efficiently, and correctly as possible. And so, with this one phrase I was a little afraid that she would make those assumptions about me. I wasn't the best of players and I was full of insecurities already. It was disheartening to have already been judged. Janx went on to say that she believed that the "real" female gamers were those that chose to play one of the four original Horde races: an Orc, a Troll, an Undead, or a Tauren. Choosing a Blood Elf was, for Janx, an affront to experienced female gamers that had worked so hard to earn their respect within this virtual community, a community dominated by men. Suddenly, I understood Janx's animosity. After further analysis of the entire situation, I began to speculate about the motives of adding an avatar such as the immaculate, bejeweled Blood Elf to the Horde's traditionally gruff, dirt-covered, war-torn exterior. Was the marketing department responding to their growing female fan-base? Were they working under the assumption that girls like pretty things? Was the current female fan-base responding to this the same way Janx was? Did they feel undermined after what they perceived to be a hard-won place amongst their male gamer counterparts? This was what I set out to investigate and this was the moment that my dissertation changed its course. 
A recent op ed piece on CNN, written by Peggy Drexler (2013) makes the point that it is not only in virtual worlds that women seek to attack or belittle other women for expressions of exaggerated femininity. Drexler recounts a study in which groups of women were shown to be aggressive towards women that were displaying their sexuality, such as short skirts, small tops, clothing that accentuated their bodies. However, in the study she cites, the provocatively-dressed female was placed in an academic environment, where such clothing is widely considered inappropriate. Therefore, she concludes that it is not fair for social research to suggest that our modern society is one of "mean girls" versus "slutty girls". There is no doubt that "slut shaming" and similar trends that find vast outlets over social media are simply reinforcing gender stereotypes, but is it always the case that, as Drexler (2013) questions in her title, "women [are] mean" when it comes to competition with other women. How much does the context influence this type competitive and aggressive behavior? For my research, I asked if this type of study helped us understand Janx's animosity towards other female players that chose sexualized avatars rather than the male troll she took pride in playing?

As I will discuss, my interviews revealed that when heterosexual gaming couples play within the same room, there is still the need by the female to strive to be more "masculine", while still following the direction of her male partner. The male tends to want to shape his partner because there is the assumption that this will make her a better player... a stronger player. In a world where strength is irrelevant to gender. In a situation such as this, there is no direct competition with other females, no need to be hostile or aggressive to earn ones place. Deception is out of the question because one's 
partner is in the room. Therefore, why the continued need to prove oneself through masculine heteronormative ideals?

The question of why is problematized significantly when we look at this virtual problem as a result of either intragender competition or, as one interviewee later puts it, a need to belong within a "pirate's clubhouse". It is not easy to carve out a niche in a world that is predominantly male and has been seen and marketed as such since the inception of Internet gaming. Therefore, it would make sense to say that these long-time female gamers are attempting to shed anything that would identify them as female in order to belong, to be seen for their playing and not for their gender and to navigate the rich landscape of dichotomous stereotypes that are recreated even in a setting where the culture is very much up to a community of essentially faceless players.

\section{Glossary of Terms}

Before attempting to answer some of these questions, there are key terms that need to be defined. These will be used often throughout this paper and it is important for general understanding of the concepts being discussed to first begin with basic terminology. Gender identity and gender bias are terms that will be used throughout this investigation.

Gender identity is defined as an individual's sense of their own identification of either male or female based on appearance, behavior or other aspects of their lives.

Gender bias as it relates to relationships between players is defined as any gendered or sexually suggestive language, as well as behaviors that fall outside of the immediate 
goals of the game (i.e. gifts from one player to another based on the perceived gender of the recipient)

There are also several terms that will spring up throughout the course of the discussion, including acronyms that will be used liberally.

WoW will be used in reference to World of Warcraft, the game being studied within the pages of this dissertation.

SL will be used in reference to Second Life, a virtual world that will be briefly discussed in reference to certain findings.

RL stands for real-life and refers to a person's physical reality.

MMO stands for massively Multi-Player On-line Game and is the type of game that represents WoW. These games typically weave together questing, lore, elements of story-telling, and often role play by the players within fictional landscapes.

FPS stands for First-Person Shooter. These are games like the Halo series and Call of Duty where players simply point and shoot, often taken from one scene to the next on a track-like setting. The game involves minimal story and is mainly focused on shooting as many enemies or targets as possible.

CMC stands for computer-mediated communication and will be used when discussing any kind of chat, bulletin board, e-mail or other mode of communication via the Internet.

BBS stands for Bulletin Board System, also known as Discussion Forums, where people post messages and read replies that can sometimes come years after the original post. 
IRC stands for Internet Relay Chat, and refers to real time chat messages posted live, involving two or more people. IRC is popularly referred to today as IM or Instant Messaging. Several modern clients allow for IRC through phones and Internet capable tablets in addition to computers.

Trolling refers to the malicious actions of a person or group of people within social media. Trolls specifically cause trouble or insult other chatters, members, players, etc. depending upon the virtual world or community they are inhabiting. Trolls can be found in nearly every virtual gathering of people, small or large.

Statement of Problem

This research explores specifically how females perform their gender in WoW, where avatar gender plays no part in the abilities and skills of the character in game and is purely an aesthetic choice. Do women who choose female avatars rely on aesthetics for a conscious reason (that is, because they want to feel attractive or want the attention of male players within the game) or because of social pressure or both? Conversely, do women who choose a male or unconventional avatar (i.e. an unattractive female) do so consciously and why? How do these conscious or socially-driven decisions affect their interactions with other players? Are they more or less reluctant to share vital social information based on the physical appearance of the avatar? Do they use their avatars physical appearance to their advantage? Further, this research hopes to fill a gap in understanding how gender is performed in a world where one can choose what they want to be from a wide variety of playable races and characters. How does our own social understanding of the performance of gender in the real world translate to the virtual 
world? Are gender biases exhibited between players? Additionally, it would be important to examine the interactions between men and women within WoW more closely, with respect to female performance of their perceived gender in-game. How do female players hold their own in an industry dominated by male players and masculine hegemonic ideals? Do female players feel the need to gender bend in order to be taken seriously? What does all this information suggest and what really happens in this virtual society?

\section{Research Methods}

This research hopes to specifically explore how females perform their gender in WoW, where gender plays no part in the abilities and skills of the character in the game and is purely an aesthetic choice. These explorations will seek to understand if women who choose female avatars rely on aesthetics for a conscious reason (that is, because they want to feel attractive or want the attention of male players within the game) or because of social pressure. Conversely, do women who choose a male or unconventional avatar (i.e. an unattractive female) do so consciously and why? How do these conscious or socially-driven decisions affect their interactions with other players? Are they more or less reluctant to share vital social information based on the physical appearance of the avatar? Do they use their avatars physical appearance to their advantage? Further, this research hopes to fill a gap in understanding how gender is performed in a world where one can choose what they want to be from a wide variety of playable races and characters. How does our own social understanding of the performance of gender in the real world translate to the virtual world? Are gender biases exhibited between players? 
Additionally, it would be important to examine the interactions between men and women within WoW more closely, with respect to female performance of their perceived gender within the game. How do female players hold their own in an industry dominated by male players and masculine hegemonic ideals? Do female players feel the need to gender bend in order to be taken seriously? What does all this information suggest and what really happens in this virtual society?

There are two major goals for this project. The first is to understand how gender is performed within this virtual society. The second is to discover whether or not the medium of a virtual world has any effect on that performance. Based on the literature and data available, the following hypotheses will be tested through this research:

H1: Players using female avatars experience gender-biased behavior from other players.

H2: Perceived gender-bias behavior from other players affects the avatar choices of female players.

H3: Perceived gender-bias behavior from other players affects the communicative and behavioral habits of female players.

H4: Male players that choose female avatars often do so based on the perceived genderbias of other players.

This research was conducted over 15 months and began with participant observation of the game environment and population. Characters were established on both sides of the two factions in three separate servers (realms) of differing types. (Some servers specialize in player versus player combat, others in role play and the last group in 
player versus the environment.) The participant observation includes accounts of how players interact with each other and with the game environment. These accounts were codified in order to determine how best to tailor the surveys and open-ended interview questionnaires toward the hypotheses being tested.

Surveys were conducted using the website SurveyMonkey.com. The population sampling for this was purposive, based on both the convenience of contacting players and the specificity of the communities through which they were contacted. Links to the survey were distributed through the official WoW BBS and through gaming communities such as MMO.org as well as specialized communities in LiveJournal.com and Facebook. Survey numbers were based on the gaming population. An adequate sample could be anywhere from 400-500 surveys, but the end total was well over 1000 . Survey respondents were given a choice to voluntarily submit their e-mail address to participate in the open-ended semi-structured interview portion of this research. Those participants volunteering their e-mail were then asked a series of open-ended questions. The interviews were first done through a virtual medium, Skype. In some cases snowball sampling resulted in additional interviews. Interviewees consisted of five females and one male. Interview and survey respondent demographics were tested against Yee’s (2005) demographics which show the real life player population of WoW as being 84\% male and 16\% female. Since Yee’s (2005) study was based on voluntary self-sampling, from visitors to his website, it is likely that the demographics may change. This is the only demographic available to the public. The game's manufacturer has yet to release an accurate census of the real life identity of its players. Survey responses were then 
analyzed using SPSS quantitative analysis software. Interview transcripts were analyzed using NVivo qualitative analysis software. 


\section{LITERATURE REVIEW}

The following is an exploration of the literature of gaming as it relates to gender, community and technology. With this exploration, I hope to provide some context to my own ideas and observations considering WoW and other MMOs. Because the field is still so new, many of these authors have cited one another and continue to be heralded as pioneers in the field. However, it is first important to lay some groundwork using more traditional studies of human interaction in face-to-face societies.

\section{Self-actualization in Virtual Worlds}

Psychological theory speaks to human motivations and is useful for larger studies of society. Sociological tradition has taken so much from psychology, Freud, Jung, etc. For the purposes of this paper, I used Maslow's theories about motivation as a useful framework (Maslow, 1943). According to Maslow, human beings have a hierarchy of needs, basic needs like food and shelter being primary and necessary before one can pursue other needs, like socialization, friendship, relationships. Maslow states that, "[a] person who is lacking food, safety, love, and esteem would most probably hunger for food more strongly than for anything else." Without food, the body places all energies into acquiring this most basic of needs. Conversely, as basic needs are met, the individual begins to fulfill needs that do not necessarily affect survival, but do affect mood, happiness, emotional fulfillment (Maslow, 1943).

How does this relate to virtual communities? It can be theorized that if someone is involved in a virtual community several basic needs have already been met. However, if we isolate the avatar itself, it has no basic needs to speak of in the world in which it is 
created. In WoW, specifically, while there is food, it is not essential to survival. An avatar needs only to be created to survive as a virtual entity. To thrive the avatar needs to only to complete tasks assigned to all avatars equally. Recall for a moment the idea of Internet dating and the inverted model relationship. Can the same be said of a virtual existence? Instead of the goal being self-actualization, as Maslow suggests for human motivations, one begins with self-actualization. The avatar knows its place. As a player, one knows the ultimate goal. One goes into the game having set that ultimate goal. (e.g. I will get to the highest level.; I will beat the hardest dungeon.; I will do nothing but fish on this avatar.) In fact, the very design of the game is all about pre-determining the role that avatar will have. Will you be a warrior or a rogue or a priest? What specialization of warrior? Will you be a healing priest? All this is decided and determined early in the game and, thus, the avatar is self-actualized from its inception.

Is this the draw we have to video games? All the fun of purpose and meaning in life without all the hardships and struggles? Knowing where you belong and who you are without wondering if you'll lose your job or where your next meal is going to come from or whether or not you sent the electricity bill in on time? If we think about that for a moment, one can see why these virtual communities become powerful parts of people's lives. It goes beyond escapism in the traditional sense. We think of escapism as reading a book, watching a movie, losing ourselves in the lives of a character for a brief time. In games like WoW, you're not just losing yourself in the character, you ARE the character. You get to be that person, live that life, direct it as you see fit. You are in charge of this pre-determined destiny. You can change it at your whim. Your free will is not lacking, 
you still own this virtual body, you still guide and move it the way you guide and move your own.

Now, this begs the question, is self-actualization gendered? This would be of help when we consider the idea of "girl-spotting", finding a "real girl" in a virtual world dominated by male players. If the self-actualization of an avatar in WoW is their class, then if stereotypes hold true, the virtual destinies of female players lie within the healing (nurturing) classes. Indeed, these stereotypes are not exclusive to the virtual communities and active players, they permeate into academia and social research. Hayes (2005) writes about a study done with two female graduate students who were required to play the roleplaying video game, The Elder Scrolls III: Morrowind. The author found that both women dealt with challenges that were present in the game using methods that coincided with characteristics of their real life identity. For instance, one participant chose a healing class character because she enjoyed science in her real life. This choice of class became a challenge when she encountered hostile situations that required combat, because she believed that combat conflicted with her desire to be a healer (Hayes 2005). Although the study revealed interesting insight into the two subjects' choices within the game world, it probably was not an accurate depiction of females who choose to play video games, particularly interactive games like WoW. Since both subjects were playing the game as part of a class assignment, their performance of their identity within the gaming world was almost entirely influenced by their behaviors in their non-virtual lives. Additionally, the students were going into nursing and caretaking careers, skewing the results significantly. It might seem obvious that a female that had never played a MMO 
would choose a class she felt familiar with, in this case a healer. It would be of greater relevance to study a larger group of females who are voluntarily involved in virtual gaming worlds and who might consider it a hobby, like the long-time female players who inspired this investigation. Perhaps their influences on in-game identity stem from other sources (i.e. trying to perform well in game events and competitive interactions). This would give a more accurate account of female identity and how it is performed within a virtual society, something that the current literature does not effectively address.

\section{Understanding Virtual Interactions by Gender}

Many new studies have begun to suggest that interactions within virtual societies are vital to understand, not only because of their significance to our changing social world, but for therapeutic and educational value as well. A 2004 University of Michigan Master's Thesis written by Kaitlan C. Chu, examines gender differences among fifth and eighth grade children when playing educational games. According to Chu (2004), both genders enjoyed customizability within the virtual world as well as open-ended game content. In short, the ability to explore and exact some sort of free will over the virtual world was of equal importance to both genders. This is a vital characteristic of games like WoW where the player is free to choose which places to visit and which quests to undertake. However, the author emphasizes that (consistent with male stereotypical behavior), boys enjoyed games with, “action, weapons, [and] challenging difficulty level” among other aspects (Chu 2004). Girls preferred "storylines, multiple difficulty levels, and sufficient instructions” (Chu 2004). Chu (2004) therefore conjectures that, "[p]references for player avatars and game themes conform to traditional gender roles." 
Does this remain true as males and females age? Is it a characteristic of those who have chosen to play a game like WoW for entertainment or leisure? Later in this investigation of the literature, other research is presented which affirms the adherence to gender role stereotypes with respect to the motivations of older male and female gamers.

Taking a less stereotypical view of children and gaming, Cassell and Jenkins (2000) make the claim that our cultural backgrounds influence children at a young age to distinguish between what is a "girls' game" and what is a "boys' game”. They believe that a more gender neutral gaming industry should be implemented. Further, marketing should not be targeted to one specific gender, but to a wider and more neutral audience. The authors declare that, "we might use the computer as the very site for children to make meanings, express themselves, and play out the range of identities that will constitute themselves" (Cassell and Jenkins, 2000). The authors draw on this idea of multiple selves within virtual worlds and allude to the fact that socially constructed binaries are part of what keeps people in these gendered boxes. "[R]eality as described in language is given more weight than any objective reality” (Cassell and Jenkins, 2000). So, when online games are marketed towards a particular group and exhibit language and stereotypes of Western hegemonic masculine culture, those dichotomies become even more deeply ingrained and serve to repeat themselves. This gets to the heart of the issue in gendered relations within virtual communities. While some scholars, like Rheingold (1993), take a light-heartedly hopeful view of virtual communities as veritable blank slates where identity performance can be whatever the user wishes, the evidence suggests 
that we bring our cultured language and gendered distinctions with us into the virtual space.

In 2003, T.L. Taylor wrote about a two-year ethnography that was conducted to explore the emerging female population in the game EverQuest, another popular massivemulti-player on-line game. The author concludes by saying that although MMOs were likely originally designed with male players in mind, they really provide an all-inclusive environment and are essentially gender neutral (Taylor 2003). Although women have been categorized in the literature as being attracted to the social aspects of games like these, it is clear that they are finding pleasure in every other aspect of the games as well, including the ability to dominate or exact power (Taylor 2003). The author also reiterates a major gap in gaming research literature when it comes to issues of gender. When we take this back to our characterization of a "real girl" it starts to complicate the stereotypes we bring with us from our own cultures, the stereotypes we see that abound within this virtual world as well.

Jenson and de Castell (2010) lay out the issues with gender and video game research as being a problem because of its recurrence in the literature. Firstly, research of gender and gendered relations in virtual interactions is often dismissive of gender as a relevant factor, choosing sex over gender or a combination of the two and downplaying its significance. Secondly, as referenced above, researchers tend to lump playing into types or patterns that are sex-specific based on assumptions about evolutionary biological predispositions. In fact, Nick Yee (2015) writes “[w]hen we look at gender similarities instead of gender differences, we find that claims of dramatic differences between men 
and women are often inflated.” This isn't to say gender is insignificant, but there is no evidence available to date confirming that men and women play any differently.

Howard Rheingold (1993) provides gaming researchers with an invaluable foundation when he describes MUDs (multi-user dungeons or dimensions) as the forefathers of today's graphic rich MMOs. MUDs were the first online gaming communities, where participants created their characters and the worlds within which they role played. The author notes that MUD users, circa 1993, were typically male college students, ages ranging from 17 to 23. He mentions that "tinysex", "net.sleazing” and "gender deception" are rampant in MUDs. Tinysex is more popularly referred to as cybersex, engaging in sexual discussions through textual mediums. Net.sleazing is the act of coaxing another party into engaging in cybersex and then logging the conversation to use later as a form of virtual blackmail. In MUDs many of the users are male, even those presenting themselves as female. MUD users will try to "seduce" new MUDers to join in textual sex and then post the encounter for the community to share, effectively humiliating the newcomer. Because of the general belief that most MUDers are male, all new players presenting themselves as females are called upon to prove that they are actually female. This is not something required of those players that present themselves as male. When tackling deception and gender bending, Rheingold (1993) makes it clear that "[a]lthough the technology of CMC provides the instrument of deception, the special importance we place on gender roles and the prevalence of swindlers in a population are both rooted in questions that extend far beyond the technology that brings them into focus” (1993). 
When I asked what they considered gendered textual cues, users of the popular WoW-themed forum, MMO-Champion.com, echoed the idea that one should usually assume that whomever they are interacting with is male until that person manages to prove otherwise, typically through voice confirmation. Snowraven (2013), a European poster that (at the time) used a caricature of a female character as his distinct avatar, cites that the reverse can very often be true:

In WoW, I never said my gender, and in general didn't talk much about my real life. One day I found out half of my guild thought I was a guy and the other half that I was a lady. I never said I as [sic] either, I never tried to convince anyone I was a lady, but people thought that. I couldn't stop laughing when I told everyone I was a dude lol.

It would be reasonable to guess that the community is taking notice of the growing female population, resulting in many players making assumptions that their playing partners are of either gender. As far as semantics, posters in the WOW forum did not seem to recognize any specific gendered textual cues apart from a few sporadic mentions of excessive emoticon use, though this may have been as a result of probing on the part of this investigator to elucidate more in-depth answers. Maybe spotting a "real girl" is much more difficult than the chat conversations would suggest.

Kendall (2002) takes Rheingold's (1993) conclusions one step further when she discusses masculinity in the BlueSky MUD, an active virtual community frequented by tech-savvy participants. This author's analysis supports the idea that misogynistic hegemony is enacted and constructed through language. She affirms that on both MUDs 
and other virtual spaces, the question of gender is frequently brought up. Additionally, exaggerated gender performance is sometimes an indication of gender bending, something the Trade chat conversation I outlined earlier certainly seemed to confirm. However, not enough accentuation of gendered textual cues can elicit assumptions that one is not “acting" to their gender (Kendall, 2002). In the author's own experiences, she was told she did not "act female" because she did not go out of her way to "emphasize a gendered identity” (Kendall, 2002). This discussion is reminiscent of Butler (1999; 2004) and her ideas about gender performativity, where doing gender is socially constructed and repetitive. Both the women and men in this community find that it is better to distance themselves from all things feminine because it is such a masculine environment. The highly technical and computer literate speech is something associated with masculinity, therefore, it sets the tone of the environment. And although the men in BlueSky do not see themselves as "traditionally" masculine or fitting with hegemonic masculine ideals outside this virtual space, they do still exact a kind of control based on textual expertise (i.e. extensive technical knowledge). Further, when discussing a woman outside the MUD, the chatters will often portray her as a sex object, using words like "babe” to refer to the woman and speech patterns saturated with "traditionally" masculine overtones (Kendall, 2002). In her discussion with one gender bending participant, the author comes to the conclusion that the user "both reinforces and calls into question stereotypical assumptions about femininity and masculinity” (Kendall, 2002) by being female and trying to pass as male. Yet, believing that because she makes no effort to exaggerate the male-ness of her character, many perceive him as gay. "Her passing as a male becomes irrelevant to her own gender identity as long as she passes as only an 
imperfect or wimpy male” (Kendall, 2002). This leads the author to assume that “caricatured” gendered interactions may be “more 'real' online than less stereotypical portrayals” (Kendall, 2002). According to Butler (1999; 2004) it is in the act of genderbending where gendered binaries are more clearly visible and Kendall (2002) seems to agree. It is clear that the textual interactions of participants and the use of gendered language serves to both re-affirm stereotypes and immeasurably complicate them.

In an earlier investigation by Kendall (1996), she briefly describes the atmosphere of MUDs that cater to role playing above anything else. One such MUD is AniMUCK, a MUD where players role play as anthropomorphic animals. She notes that AniMUCK is significantly different from BlueSky in that it is less masculine. However, it complicates femininity just as often. The female characters are highly sexualized, so much so it can often be an uncomfortable experience for women unfamiliar with this particular sub culture. The "tone" of this virtual community is, as the author puts it, "set by men" (Kendall, 1996). For those MUDers deciding to set a neutral gender, Kendall (1996) believes that other participants simply see the designation as a "mask", a tactic for hiding ones "true gender", because we cannot deal with the possibility of a neutral gender. As discussed earlier, gender always comes into question when dealing with femininity and, in this case, ambiguity.

Beyond the idea of questioning gender, there is the discussion of gender-bending as an act of self-exploration. Like Kendall (1996), McRae (1996) reports that MUDers enjoy experimentation with things that are not possible for them to experience in real life, such as animal sex play and gender-swapping. For one male participant that masquerades 
as a woman, the author writes that "[w]hat she experiences as her female side seems to be part of herself that her socialization as a male somehow excluded” (McRae, 1996). For many gender-benders, exploring the opposite gender allows them a means of dealing with issues surrounding power and their own emotions. For one participant, he believed “[o]ne of the ways for him to work out his own complex and sometimes problematic associations with masculinity and power was to experiment with being dominated as a woman by another woman” (McRae, 1996). Through experimentation in virtual settings, many players find that sexual identity is immeasurably complex, more so than they might have previously perceived it to be (McRae, 1996). Perhaps this is indicative of the simplistic dichotomies our culture assigns to gender, and how very limiting they are to the discovery of individual identity. The author writes, "we can experience for ourselves, inside ourselves, the kinds of things that we associate with female or male, and realize that those aspects are not, after all, something Other and outside of us” (McRae, 1996). Those that experience deceit through gender-bending on MUDs, are often shocked because they are socialized to believe that gendered behaviors are fixed (McRae, 1996). The same kinds of "shock” are reported amongst the MMO players of today when they discover that play partners are of one or another gender that did not conform to their initial perceptions.

The question of gender and gendered behavior naturally leads to questions dealing with both individual identity and the identity of others. Turkle $(1997 ; 1999)$ looks at CMC and virtual identity. She believes that through these medium, identity can be recast as something flexible. Through her work with MUDs, she claims that participants 
"become authors not only of text but of themselves, constructing selves through social interaction” (Turkle, 1997). She reports that different people feel differently in response to the creation of a virtual identity. In one example, she cites a man who plays a female identity in a MUD because he sees modern women as assertive and men incapable of being that assertive because it would label them insensitive or "bastards". She claims that his "gender swapping has enabled the different aspects of his inner world to achieve self-expression without compromising the values he associates with his "whole person" (Turkle, 1997). Turkle’s optimism in her discussions mirror that of Rheingold (1993), though they are among the few that believe CMC will transform gendered distinctions significantly. For others, these binary distinctions are pervasive and so ingrained that they are unlikely to fade from the virtual space until they fade from the physical space.

Understanding Virtual World Culture and its Effect on Gendered Interactions

In her seminal book, The Second Self (2005), Turkle discusses the differences between children raised in a computer culture and their adult counterparts. While children seemed almost naturally adept at engaging with technology, many adults found it challenging to adjust their lives to a culture with a growing technological emphasis. The computer provided a new frontier to many adults that had before felt removed from technology. It provided both practical applications and personal enjoyment to new users, quickly sucking them into a new world, particularly with the world wide connections afforded by the Internet. Turkle (2005) mentions that the "first-generation personal computer owners were for the most part men who had always been interested in technical things and had a long history of involvement with computers.” This is important because 
it feeds into the assumptions and associations about technology and gender that still persist today. The second generation of owners was different, more attracted to the dropping prices of computers and the advertisements that invited even the non-technical to embrace the computer. Even the purchase of the machine invites the potential user to immerse him or herself in the language of the culture, in the particular knowledge that will be useful to the decision making process. Turkle (2005) then illustrates the metamorphosis of the computer from machine to "more than a machine". Users develop personal relationships with their computers, anthropomorphizing them in many instances (Turkle, 2005). Therefore, it is not hard to see how one can immerse oneself in created or imagined spaces within the computer, within the Internet and become an entirely different identity.

For a moment, let us isolate gender from the technology so that we see what we carry over from our physical realities when we assume these virtual personas. Scholars like Shari L. Thurer (2005) suggest that we have come to the end of gender in society. According to the author, postmodernist theory assures us that we will never be able to understand sex and gender through rationalization or traditional methodology. It is a social construct and, thus, does not actually exist (Thurer, 2005). What are the implications of this in virtual societies where gender is merely an aesthetic trait within the parameters of the game? How do human beings, as social animals, define gender within a world that has been programmed to remove the physical inequalities that we associate with biological gender? Postmodernist scholars say that we have come to the end of gender through a breakdown of the binaries in our society. Looking at virtual societies 
where gender is incidental could provide vital information to researchers who have been constantly perplexed with the nature of gender and gender relations. Why do people feel the need to re-enact gender? Further, answers to these questions can be integral to understanding gender relationships in contemporary society. If human beings feel the need to reenact gender within an imaginary world, perhaps there is something inherent within human nature to establish and uphold binaries. Why is it that the virtual setting does not remove our arrogance in presuming that we can tell the genders apart, that we are sure who that person is on the other side of our screen, just as we are sure of who we are?

Donna Haraway (2004) writes about the cyborg as a metaphor for postmodern feminism in which the cyborg has no desire for any part of the human condition and has shed the confines of a binary life (p. 9). Thus, too, postmodern feminists should break from the Oedipal complex and the patriarchal rhetoric that shapes our gender discourse (Haraway, 2004). Haraway's assertion is that, even in our attempts to rid ourselves of these binary oppositions -male, female, black, white, in, out - we continue to speak and think in these terms. So, perhaps imaginary worlds in their effort to create a kind of gender neutrality fall short because those very creators think and act in our binary gendered world. And in our constant questioning of gender and consciousness of gender performance, we fall into the same traps that plague our non-virtual lives.

Often, when one thinks of a virtual world, one is immediately inclined to consider it “not real” or, for lack of a better description, “less real”. Etzioni and Etzioni (1999) make the case that CMC do indeed meet the prerequisites of building a "real" community 
and, as technology advances, can only improve in giving rise to "full-fledged communities”. Further, the authors posit that a combination of CMC and face-to-face (F2F) relationships can overcome the weaknesses both mediums have individually and build an even stronger community bond. This is seen in WoW where guilds will have "guild meets" where members will meet face-to-face to celebrate their victories as a virtual group or simply to socialize with other like-minded individuals with whom they have shared significant moments in the game. To take this farther as it relates to sexual expressions and, thus, expressions of gender, Etzioni and Baris (2005) make the claim that through the communitarian approach, "in principle a society cannot function if it allows unfettered sexual expression, nor can its members lead a contented, let alone flourishing, life...” This type of contextualization might be put forth as speculation for the reason why gender binaries hold true in genderless virtual spaces.

Rellstab (2007) affirms that the virtual space does not rid us of binary absolutes. Using elements from liberal and post-modern feminism as backdrops for his argument, he draws on the work of O’Brien (1999) to bolster the idea that virtual community members "need [their] communication partners to have fixed identities, and that [they] cannot communicate with an un-gendered or even multi-gendered opponent”. Because CMC is so text-rich, textual and language cues are invariably important. Users attempt to determine the gender of others through the social cues evident in their use of language (Rellstab, 2007). Through analyzing the communication of male and female participants, marked differences present themselves. One can make the assumption that, particularly in Western society, our psyche is deeply ingrained with gendered conventions and, thus, 
differences in communication persist whether we are conscious of it or not (Rellstab, 2007). In the author's analysis of real-time Internet Relay Chat rooms (IRCs), he emphasizes that when participants of a perceived gender violate gender norms either willingly or through interactions with other members, they tend to then re-affirm their originally intended gender. For example, in one instance a presumably male and female chatter engage in an argument where the female establishes clear dominance. At the end of the argument, the male chatter announces that he will retire to have sexual relations with a female, thereby asserting his masculinity (Rellstab, 2007). The male chatter felt compelled to re-establish dominance by invoking sexual imagery, because that is the stereotypical association with masculinity, the hypersexual. These clear distinctions again serve to remind us that our language is undeniably dichotomous, influenced by social distinctions of “doing” gender.

Understanding Motivations of the Players by Gender

Yee (2005) furthers this through exploration of player motivations in MMOs, although he invokes some of the earlier gendered assumptions we saw in Chu's (2004) analysis of children. He tells us that male players tend to be driven by achievements, such as character advancement, game mechanics and competition. Female players tend to favor relationships and character customization. As previously mentioned, there are stereotypical gender distinctions coming to the surface, seemingly reinforcing studies that exhibit marked differences between female and male gamers. And although Yee later claims partial responsibility for perpetuating these assumptions in his 2015 book, The Proteus Paradox, his evidence-based claim holds when he states, "male players socialize 
just as much as female players but are looking for very different things in those relationships” (Yee, 2005). Female players will spend time within the game trying to build and strengthen personal relationships, while male players will spend more time trying to advance in levels, acquire better items or understand the game mechanics to improve (Yee, 2005). In short, female players are more socially driven in their motivations to build relationships, while male players are more practical. However, because female players spend more time building strong relationships, they are also more likely to be involved in longer raids (Yee, 2005) - special dungeons where players must band together in large, tactical groups to defeat difficult monsters. The author then presents different perspectives on MMOs from the gamers themselves, lending more insight into the quantitative aspect of this analysis. It would seem that many of the players that value relationships within the virtual environment are not opposed to the further development of those ties offline. This would suggest that for many players, the offline and online worlds tend to meld, and we bring with us all the conceptions and misconceptions of our cultural understandings.

Although discredited by modern video game research (Yee, 2015; Jenson and De Castell, 2010) it is still important to examine studies such as those of Williams et. al. (2009) examining video games and gender. In accordance with gender role theory as well as the general consensus at the time about video games and gender, this study found that females were more socially motivated than males to play MMOs and males were more achievement oriented (Williams et. al., 2009). However, this does not take into account the ways in which female players might choose to abandon what is considered 
inherently female within the gaming environment. In fact, the study goes on to say that female players played more often than male players and were classified as more highintensity players (Williams et. al., 2009). Although Williams et. al. (2009) suggest this may be in keeping with the social interaction motivation stated earlier, I argue that this might also suggest that female players choose to become more devoted to the game play in order to combat the gendered stereotypes they encounter within the gaming environment. Because this study does not touch upon the avatars played in-game nor the experiences of the players in-game it is difficult to back up such an assumption based only on these results.

MacCallum-Stewart (2008) writes about gender bending in MMOs, taking Yee’s (2005) explorations one step further. This author makes the point that, while the video game market was traditionally targeted towards the young male demographic, genderbending in video games is nothing new. Games like Tomb Raider and Metroid allowed their predominantly male audience play as a female character. Specific to MMO genderbending, players (both male and female) often argue that they like to look at the figure of the opposite sex on screen as a reason why they gender-bend (MacCallum-Stewart, 2008). MacCaullum-Stewart (2008) writes, in reference to WoW, “[h]eterosexual males specifically stated they were appreciating the female form whilst playing it, thus setting themselves in a sexual dichotomy in regards to their adopted avatar. Women who played women also broadly agreed with these ideas; in particular arguing that some avatars gained more attention than others.” The author also cites that female player sometimes chose male avatars to avoid unwanted attention (MacCallum-Stewart, 2008). These are 
important points because it again illustrates a need or desire by female players to adopt masculinity (in this case aesthetically) to be able to play the game comfortably.

Another point brought up by MacCallum-Stewart (2008) - and often ignored by other MMO researchers - is that “[p]layers, by and large, feel that the skinnier, or overtly sexualised [sic] female characters are the domains of younger, more sexually immature players. Conversely, players who like curves also style themselves as older and more mature.” This illustrates what was mentioned earlier and what many female players of WoW who choose to play non-aesthetically pleasing female avatars or male avatars will often elaborate is part of their motivation. These female players tend to feel as though their choice in a non-traditionally feminine avatar offsets them as a more seasoned or veteran player. While this is not proven by any social scientific means, it is something that can be explored based upon the findings of MacCallum-Stewart (2008).

One other point that is often reiterated in other studies is, "players feel that women avatars are given more help, given more social leeway, and are allowed to make gameplay mistakes with fewer consequences, another common subject for the WoW Forums [WoW Forums, 2006; 2007]. 'Real' female players therefore do not like this perception and frequently resist it” (MacCallum-Stewart, 2008). Additionally, the author points out that, "men like the female avatars, women want to avoid undue, gendered attention and be regarded as gaming equals. These reaffirmations serve not only to normalise cross-gendering, but also to render it safe, heterosexual and emancipating rather then [sic] associated with homosexual desire or transgendered desires” (MacCallum-Stewart, 2008). This is seminally important to the research that follows this 
literature investigation because it exposes what has been rarely commented upon when analyzing female gender-bending practices in virtual worlds.

Klastrup and Tosca (2009) discuss an even rarer subject of investigation, that of avatar clothing in WoW. Through qualitative investigation, it is apparent that both male and female players are aware of the importance of in-game gear that provides the player with the best possible stats improvement for end-game progression. Both male and female respondents felt compelled to attain gear that would provide them with status as a respected or significant player. Both male and female respondents felt the desire to look "awesome” (Klastrup and Tosca, 2009). While the superficiality of fashion is something traditionally linked with the feminine, in this context it is absolved of gendered restrictions. Therefore, it might be fair to surmise that traditional assumptions made about female and male priorities cannot be successfully applied when in the context of MMOs. This further complicates earlier assumptions about gendered motivations of play. If gear (good-looking gear) is such a coveted achievement for players of all genders, then what does that say about the research that would lead us to believe that female players prefer the social and males the practical? In short, there are always new findings that serve to complicate our assumptions about gendered distinctions in virtual worlds.

Perron (2003) writes, “[a]s human beings are social creatures, they are thus able to determine their own identity only in reference to others (comparison or identification with the group).” It is only when faced with the competitive and perceivably masculine nature of the WoW environment, female players often feel a need to exert masculine 
characteristics to either appear "tougher" or even appear male. This coincides with many postmodern ideals about the self and, as Perron (2003) notes, “[t]he postmodern man’s personality is not quite definite, its final form is never reached, and it can be manipulated.” As the environment is changed, or as it calls for changes in aspects of personality, the human being adapts. Nowhere else is this as easy as a virtual world, where the user is in complete control of how they appear to other inhabitants of the virtual space.

Salazar (2009) talks about the social identity of players in MMOs, and how many researchers work under the assumption that players carry with them social identities. By examining these identities closely, Salazar (2009) claims that while there is an in-group, there are three gradations of out-group status. The author believes that in order for a researcher to be able to identify a player's in-game social identity, the researcher must not only look at what the player says, but also the context in which they are saying it the speech act and the speech event, respectively (Salazar, 2009). In fact, Salazar (2009) argues that even more emphasis needs to be placed upon the speech event to better understand the in-game social identities of players. This can be applied to the research contained in this study as it is important to understand that events such as high-level dungeons and raids are integral for the social status of players. Events like thess are often highly energetic and highly stressful for some players, as they require a high measure of skill and concentration. Because these events are so vital to the social status of WoW players, the inherently militaristic organization of a high-level dungeon group can be seen as something traditionally masculine. Thus, more serious female players may feel added 
pressure to "man up" as some players would say - or to shed that which is considered inherently feminine in order to fit within the confines of a perceived masculine environment. These are not theoretical leaps being taken by a researcher involved in the environment she is analyzing, but something that female researchers have long been witnessing in face-to-face society. A truly poignant participant observation written in the 1990s, undertaken by Irene Padavic (1991) recounts her experiences as a worker in an industry dominated by blue-collar males, largely regarded as the paragon of masculinity in the hearts and minds of American contemporary society. Padavic (1991) writes that in response to how she was sometimes treated, "[she] was reluctant to call for help in potentially hazardous situations because [she] did not want to perpetuate a sense that [she] could not perform the job.” Indeed, she found herself attempting to outdo her male counterparts, filling her shovel with more than she could physically handle "so as not to arouse suspicions that [she] wasn't 'pulling [her] weight'” ( Padavic, 1991). This is startling when compared to some of the findings of this and other research where female players feel the need to underplay their perceived femininity, which is characterized by stereotypes of helplessness. However, Padavic (1991) found that if a woman is regarded as "unfeminine” or violates the stereotypes of femininity too much, she is excluded. She is, essentially, an "other" because no one is quite sure how to interpret such a violation of gendered norms. Does this make the job of "spotting a real girl” easier in the virtual world? Would one even know the degree (if such a thing exists) to which gender norms were being "violated" when the player is sitting behind his or her avatar? 
Lina Eklund (2011) also uses Butler's theories of gender performance to describe doing gender in MMOs, specifically WoW. Because Butler sees gender as performative and the spaces in which players group together are, essentially, "performance(s) of the space", it is easy for players to slip into traditional gendered roles. All of Eklund's (2011) informants were women playing female avatars for which she suggests the reasoning is simply that they are women wishing to be identified as such. It is my argument that the tradition of gender-bending in avatar creation does not necessarily equate a female avatar to a female player. And, furthermore, female players wishing to simply play the game will often under-represent their femininity. Eklund (2011) touches upon this when she states that one of her informants did not name her avatar an overtly female name to avoid being seen as a female. Still another informant chose to create what she considered an "ugly" avatar to escape her reality, in which she felt others classified her as "cute". That same informant indicates she is also reluctant to reveal that she is a woman for fear of other players' preconceived notions about female players. The author also mentions the dynamic between female gamers who expect special favors from male gamers as described in a heterosexual context. The informants felt that these special favors would not be gained from players they thought to be female. In my own investigations, my informants elaborate on a mistrust of other female gamers. It is as if they are re-creating the gendered stereotypes of their male counterparts, perhaps as part of their struggle to be less feminine. The respondents the author interviewed highlighted the fact that women and men begin on equal footing when they create characters on WoW. Gender makes no difference in regards to the power and abilities of the character. Through play, female gamers become experts in their own right, though it is evident that they are still reluctant 
to declare themselves experts in an area they remain convinced is run by their male counterparts. Eklund (2011) declares, "[t]he gamers point out that being good at the game is not something that is expected of them, but they play anyway. By gaming, the women claim a certain position; they create themselves as gamers. They integrate the game technology into their lives and take control of it." In other words, the author claims that through the gaming experience, these women come into their own as gamers. However, the author makes it seem as if these women come to this state of gamer nirvana nearly haphazardly. It is my argument that these female gamers actively perform gender in a way so as to achieve what they perceive to be the accepted gamer status as "one of the boys". The author alludes to this but because her sample was largely female gamers that had gained access to the game through their male counterparts, it leaves out those female gamers that have gamed on their own. And so, the article presents a very dim picture of what is really happening when female gamers choose to play a game that predominantly appeals to males. Even Yee (2015) presents statistics on female gamers' introductions to MMOs, citing that data gathered through his Daedalus Project revealed “that a romantic partner introduced 27 percent of female players to online games, whereas only 1 percent of male players were introduced to an online game this way. And 60 percent of women in these online games regularly play with a romantic partner, compared with 15 percent of men.” So, again, the predominant research in the field is not capturing the motivations and assumptions of those female players that are not reliant on a male counterpart for a reason to play. 
Royse et. al. (2012) makes an interesting observation when discussing the work of Schott and Horrell (2000). Female gamers in the latter study felt that they had less time for game play because of domestic duties, a problem they felt did not extend to their male counterparts. Those female gamers identified as "power gamers" or those that played over 10 hours a week were found to integrate technology and gaming into their lives. It is among the "power gamers" that the study found women deliberately choosing violent combat games and challenging gender norms. Royse et. al. (2012) note that "several of the power gamers interviewed take tremendous pleasure in challenging gender norms through their choice of genre.” The authors mention the paradox of embodied "femininity" and performed "masculinity", where the female gamer is outwardly assertive of her femininity while specifically choosing to challenge that femininity in the virtual environment. Additionally, in those environments where avatars can be created to be highly sexualized, female gamers will often choose to exploit that option and create deliberately sexy avatars. Thus, the juxtaposition between their real world femininity and their virtual world masculine performance becomes complicated to add a virtual world element of the feminine ideal. The article goes on to speculate that this stems from a need for control. Controlling the sexuality of their own avatar lends another element of power to the female gamer. "For power gamers, technology encourages them to enact new definitions of the gendered self" (Royse et. al., 2012).

Ethnographies are often invaluable to understanding how virtual worlds, particularly gaming worlds, are experienced by the players. While the following investigation is focused on the aspects of role-play, many of the points discussed earlier 
can be gleaned from Copier’s (2007) dissertation. It specifically investigates role-playing in WoW through an autobiographical narrative of Copier's (2007) adventures in a roleplaying server. She describes her avatar as "a character I paradoxically experience as having both her own identity as well as being part of myself. Like an improvisation actor or a puppet master I am the one performing her role and making her into a character for both myself and other player-characters.” Although Copier’s (2007) role-play experiences can be seen as following traditionally gendered interactions, her actual gender comes into question. She details her role-play with one other player-character with whom her character shares a romance. After a forum post where her role-play partner asks for help in locating a muffin (in-game food) for her character, another poster asserts that " $80 \%$ of the female characters has a guy playing it." While this was not personally relevant for Copier (2007) as her role-play partner expressed interest in only her role-play ability and not her actual gender, it is relevant for this study because it illustrates again that even in today's graphical MMO role-play environments gender is questioned. And even in a role-play environment where we find ourselves playing a part (i.e. that of a Troll or an Elf, or a Goblin, etc.) and working under the assumption that we are not in our physical lives either a Troll, or an Elf, or even a Goblin, then why are we so concerned that our avatar or in-character gender match that of our physical gender and biological sex?

One must consider the paradox of the concept of imaginative role-playing coupled with the idea of deception should one choose to play a character of a different gender from one’s own. This deception (though, again, arguably, not deception at all 
considering the very nature of role-play) is almost intrinsic to on-line situations where gender is a factor - such as an in-character romantic relationship in a MMO. Copier (2007) also talks about imagined and re-imagined boundaries in play. In role-play, for instance, there are no official in-game rules or regulations on how to role-play. Therefore, it is up to the players to decide how they should play out their characters. Because of differing styles, this leads to many different forms of action and interaction between player-characters, sometimes enjoyable and other times volatile. It can be said that on non-role-playing servers, the same kinds of characters are created, although perhaps in a less conspicuous nature. The way the player presents himself is entirely up to the player. Is that not too a form of role-play? As previously discussed, female players may wish to shed that which sets them apart as female, while male players may adopt more feminine aspects to garner special favors in-game. These are players playing a game for the purposes of playing the game and not to participate in any kind of play acting, only to play with their own perceptions of gendered identity - and perhaps not necessarily aware that they are doing so. As Shakespeare was famed to have said, "All the world's a stage, and all the men and women merely players: they have their exits and their entrances; and one man in his time plays many parts, his acts being seven ages." The "real girl" cannot win and neither can the male pretending to be the "real girl" for while one is defined by pre-conceived notions and gendered stereotypes, the other is shunned for deception... in a world that can arguably be defined as, itself, a deception. However, let us not see it as such. Let us see a virtual world as an escape, as a frontier, as an alternate reality, a mental playground. Because it is a playground of our minds, we 
are then subject to the rules we set up in our physical realities. To that point, let us move back to the realm of sexuality in the physical world.

Foucault (1978) talks about our sexuality being controlled through power structures that people use in order to themselves exact forms of control. In MMOs, those who control the environment and make the rules are the programmers and game designers. They make the decisions, they shape the stage on which the players perform. And these "politicians' of the virtual world are themselves shaped by the political powers that be in our physical society. Therefore, a vicious cycle is enacted. Foucault (1978) mentions transforming desire into discourse. This idea that he elaborates upon again and again takes on new meaning when we consider that at the heart of a graphic-rich video game is line after line of written code. If the power of oppression and repression lies within the nuances of discourse, what is to be said of a world created entirely from language? Participation in such a world, the continued engagement in the discourse, continues to define and re-define the dichotomies experienced in the physical world within the confines of the virtual.

\section{Social Science Research in Virtual Worlds}

One of the peculiarities of working on a dissertation dealing with virtual communities is that one's observable population is, by and large, in the form of digitally rendered images. While presenting the researcher with a great many opportunities that would otherwise not be available thanks to geographic constraints, it can also include a number of limitations. Boellstorff (2006) was pivotal in formatting what was to be my first endeavor, participant observation. In this case, an ethnographic approach is best 
when trying to analyze the part of virtual worlds and games for the purposes of study. Boellstorf (2006) remarks that anthropologists often equate ethnography with participant observation and that the latter "implies a form of ethical yet critical engagement that blurs the line between researcher and researched..." (p. 32). This is never more true than in the case of a video gaming researcher. For this dissertation, I had to play and immerse myself in the WoW community. How else was I to learn the norms, the distinct vernacular, and the issues that affect the community (whether programming problems or in-game challenges)? It would be almost impossible to depict an accurate reflection of a gaming community without having played the game. And while one toes the line between the observer and the observable, it becomes key to the researcher's own understanding and integral when one moves to interviews with other players.

In addition, demographic representations of surveys and interviews may not be accurate, as there is currently no way to determine the real-life population demographics of this game. And because some interviews were conducted through the Internet, I was not be able to assess the demeanor or mannerisms of those particular respondents and, thus, they may not have been as candid in their responses. Surveys taken on-line may also yield multiple responses from the same respondent or attract respondents that wish to sabotage the study through false responses. Steps were taken to limit the former by blocking the same IP address from re-taking the survey. However, this is not full proof as the Internet is an amorphous and vast place with endless possibilities. Further limitations include the realms chosen in which to conduct participant observation. 
Higher populated realms may attract a different type of player than those with lower populations and may affect the outcome of my observations.

Armed with this basic knowledge long before the start of this dissertation, my journey inevitably began with the WoW login screen. As an idealist and in my initial draft of my proposal, I really wanted to get a sense of how avatar choice affected the way a player was treated in-game. However, it was not feasible to try every single possible race and gender avatar combination. I began with the perceived fan favorite, the Night Elf female. A highly sexualized creature with a slim, yet muscular build, legs for days, glowing eyes, long lashes, and flowing hair. What's not to like? I chose a Druid because, as I was a long-time player already, I knew from experience that the rhetoric favored the notion that females always played healers and a Druid was a particularly attractive healing class because one could transform oneself into different animals depending on what needed to be done. If you wanted to attack something, you had a sleek panther-like cat form that specialized in massive amounts of damage. If you wanted to play a defensive role, you could turn yourself into a hulking bear. If you wanted to run fast, cheetah form was your best friend (that is, if you could not use your much speedier land or flying mount (i.e. a horse, a large tiger, a gryphon, etc... the list of mount types is nearly limitless). As a player, I got the general sense from this predominantly male community that the ability to turn into an animal was somehow much more appealing to a female. The logistics behind this general assumption was never explained beyond of vague sense of animals being "cute" and "cute" being something that women strive for on a regular basis. 
And so, my choice was made. And then as I played I had to be honest with myself, as a researcher and as a person. I didn't want to be a healer, I hated healing, but the reason was not as a rebellion against the female gaming status quo. I'd like to say that it was. In reality, healing is intense in groups. You are responsible for keeping everyone alive and I feared that responsibility. I never considered myself a great player and it was always easier to hide my true skills with a DPS/damage type of class. And, while I was being honest with myself, it was time to admit the heart of the matter. I like cats. I think cats are cute. Thus, ripping into stuff while prowling around as a panther sounds pretty great. Okay, time to scrap this whole Night Elf thing, right?

I was conflicted and more than a little disappointed that I was falling into these stereotypes. I needed to explore this, but first I needed some sort of alternate avatar to start my investigation. I decided on a female Draenei Shaman. I still did not want to be a healer, but a shaman can do major damage wielding two weapons and I liked the image of a shaman. Since the Draenei are Alliance-side characters, this was where I began, as a member of the "good" side. The conformists and capitalists, fighting for gentrification and organization. The Alliance is the starting point of most newcomers to WoW and even more attractive to those that are using WoW as an introduction to on-line gaming, what is sometimes jokingly referred to as My First MMO. So, I had my female Draenei and my female Night Elf. My plans of making a male avatar started to seem grim based on the amount of time I would have to invest in these characters. And I still had the Horde to tackle. The Horde side are populated with bestial humanoids and undead dwelling in caves, sewers, huts and all manner of crude structures. In terms of aesthetic, 
where the Alliance is the Renaissance, the Horde are the Dark Ages. Let me clarify that I have no negative thoughts in regards to the Horde. I rather liked playing an Undead and that was what I chose for my investigation on this side, a female Undead Rogue. As far as justifications for choosing female avatars, I felt that it would be sufficient if I played what I wanted to play, what I felt most comfortable playing. I went into my investigation with the idea that whatever I was going to discover from wandering the virtual world of Azeroth, I would get no matter what avatar I chose to embody. Nuances of how players treated one another, I felt that I would ultimately discover from observations of interactions between the players around me and within the guild.

At the time, I was married to a WoW player and he and I played together. I always felt as if he was a much better player than myself and, indeed, he felt more confident in his skills, often making comments (that ranged from suggestions to shouted commands) as to how I could improve. Under his varied tutelage, I saw an improvement in the amount of damage I did and my reaction times. This aspect of my experience became part of my participant observation, an unintended consequence that later came to light in my interviews. I found that when you played with a partner or others in the room, the experience was two-fold. One's identity was being acted upon by both the real world and the virtual one.

Nick Yee: Daedalus and Proteus

While playing with my Draenei, I began to formulate the questions that would make up my survey. For this survey I used Nick Yee's (2003) Daedalus Project as my inspiration. While not quite as monumental a task as that particular survey, I decided I 
needed a survey that looked at more specific aspects of avatar choice and game play. Building upon what even Yee (2003) identified as points of expansion, I asked about avatar choices and perceptions of the choices of their fellow players. I wanted to get at the heart of what they thought the avatar said about the individual behind the screen.

Nick Yee (2005) and his monumental Daedalus Project captured data that informs the observations of researchers studying virtual worlds. It is also Nick Yee and Jeremy Bailenson (2007) who coined for the world of video gaming research the term "The Proteus Effect”, whereby the player can take aspects of the avatar into the physical world. Thus, while our physical realities act on us in games, our gaming avatars and personas also affect our physical world. It is important for this dissertation research to explore Yee’s (2005) findings in order to frame the discussion that follows and give the reader a better sense of the culture of video gaming and video gamers. Yee’s (2005) introduction into his monumental project first discusses the pervasive mainstream idea that video games are primarily an activity engaged in by youth alone.

The truth is that the average age of MMO players is around 26. In fact, only $25 \%$ of MMO players are teenagers. About 50\% of MMO players work full-time. About $36 \%$ of players are married, and $22 \%$ have children. So the MMO demographic is fairly diverse, including high-school students, college students, early professionals, middle-aged home-makers, as well as retirees (Yee, 2005).

Yee (2005) also notes that “[o]n average, MMO players spend 22 hours a week in these environments and usage is not correlated with age.” He seeks to break further stereotypes by addressing a common assumption that video game players are, as he says 
"solitary hermits", when in fact, "the data on MMO players show that 80\% of MMO players play with someone they know in [real life] (a romantic partner, family member, or friend) on a regular basis” (Yee, 2005). Further, 36\% of MMO players are married, particularly important because female players (26.9\%) reported starting the game because of a significant other (Yee, 2005).

Yee (2005) also tackles identity and this is an important aspect of this dissertation research. Early in his research and before The Proteus Effect, Yee (2005) explores the avatar's effect on the personality of the player and vice versa. The graph below (See Figure 3) displays that "female players are more likely to see their characters as idealized version of themselves, and age has a greater effect on male than on female players” (Yee, 2005).

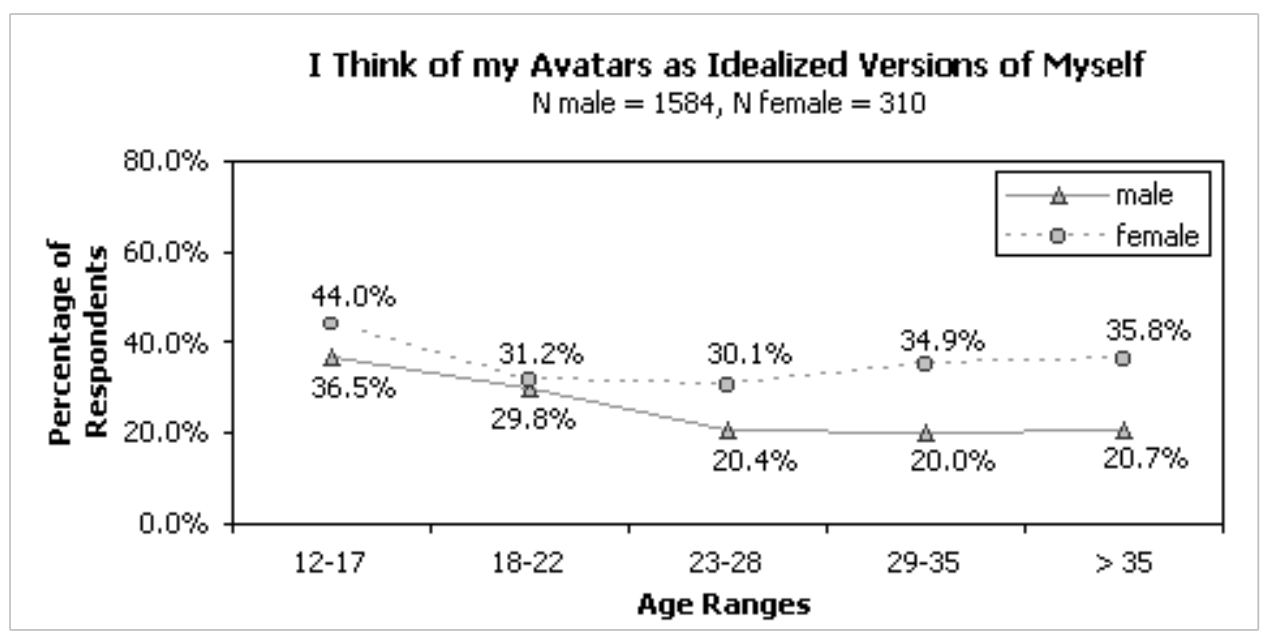

Figure 3 Yee, Nick. I Think of my Avatars as Idealized Versions of Myself. Retrieved from URL http://www.nickyee.com/daedalus/ on Mar 2013.

Additionally, while those players that responded in the affirmative to the above question did not spend any more time on the game, they did express "a greater 
willingness to stay with the game indefinitely... probably due to personal and emotional investment in their characters" (Yee, 2005). Yee (2005) illustrates that, "female players are more likely to behave and interact in an MMO very similarly to how they behave and interact with others in real life when compared with male players.” This certainly lends credibility to the assertion that behaviors of females in virtual settings are modified to fit a predominantly male environment, the same way these behaviors are modified in physical reality.

While gender did not make much of a difference when players “were asked whether they felt that they were more of 'who you really are' in the MMO than in real life” (Yee, 2005), the results indicate that those players using the game for social or escapist reasons feel that their online personas are truer representations of who they are. Yee (2005) adds that this was also true of introverts, who were also more likely to act differently online, indicating that these individuals might feel more comfortable expressing what they consider to be their true natures in a virtual setting, overcoming socially dictated barriers and stigma that might not allow for them to easily express who they are in the physical world.

Yee's (2005) discussion of gender bending, that is a player choosing to play an avatar of the opposite gender, is unprecedented. Before Yee's (2005) work, this issue had not been discussed in other gaming literature. The following findings were from Everquest (EQ), a MMO that was extremely popular, likened to WoW and very much a predecessor to WoW in the devotion of the players. One of the more intriguing points for Yee (2005) was the fact that male players were more likely than females to gender bend. 
However, in order to explore this finding further, Yee (2005) looked at the age of those players and discovered that gender bending is more frequent amongst older male players, a finding that he has no concrete theories to set against. His only explanation was that older male players had far more avatars than did their female counterparts and that, perhaps, this was the reason behind the data.

Since Yee (2005) was mainly interested in player motivation, he went further in asking why players were gender bending. Most of the reasoning was attributed to role play. Again this is in EQ, thus, it is not a part of the WoW virtual world, but still relevant to the discussion. Role play is just that, assuming a role and playing it out, a role that is apart from the reality. One might argue that it is a role within a role. There is the avatar and the characterization the player assigns to the avatar. Role play is a world unto itself that this investigation did not and will not delve into with much detail, but it does play a large role in gender bending. Aesthetics is the second likeliest motivation, playing a greater part for male players than it does female players.

To further explore this fascinating point, Yee (2005) looks at reactions to gender bending, because that is what is at the crux of motivations and of the stereotypes players encounter. Below is the presentation of the results of a set of questions from Yee's (2005) study, where he investigated how bothered other players were by gender-bending.

Participants were asked to rate on a 5 point scale how much this bothered them, ranging from "Not At All" (1) to "A Lot" (5). There was a significant effect between the genders of the participants $(F[1,666]=5.83, p=.01)$, and it was found that female EQ players were significantly more bothered by gender-bending than 
male EQ players were (Tukey HSD, Mmale(584)=1.64, Mfemale(86)=1.89, $\mathrm{p}=.01$ ). The direction of the gender-bending also produced a significant effect $(\mathrm{F}[1,666]=5.38, \mathrm{p}=.02)$, and it was found that male-to-female gender-bending was significantly more troubling than female-to-male gender-bending (Tukey HSD, Mm-to-f(317)=1.89, Mf-to-m(353)=1.64, $\mathrm{p}<.001)$. There was also an interaction effect between gender of participant and direction of gender-bending $(F[1,666]=15.29, \mathrm{p}<.001)$. In particular, it was found that male players found female-to-male gender-bending significantly less troubling than the other 3 combinations.

Yee (2005) also briefly discusses the perceptions of the EQ community of male and female players. Largely, it seems that the genders perceive themselves the way the larger community does. And when gender bending, males and females discover that they need to adhere to those stereotypes in order to pass for that gender. For instance, male players found that emotions were more acceptable as a female and female players that were perceived to be male enjoyed more direct conversation. Male players also found that they bonded more with female counterparts if they presented themselves as female. One male in his thirties said that he formed "closer bonds to other female characters than any male/male character bonds. Also some male characters roleplay the 'helping the lady’ bit. I think I realized that women are much closer to each other than man are” (Yee, 2005). This idea of femininity somehow being linked to greater socialization if definitely not new and a view that both genders seem to share. 


\section{PARTICIPANT OBSERVATION}

While feverishly working out a problem with my colleague and dear friend at my coffee table, my significant other moves his Human Paladin through the streets of Stormwind looking for the Auction House. He is sitting less than ten feet away from us, almost utterly stationary and staring at a large 42 inch display of his Human Paladin, aptly named Link for the popular video game character. He is completely immersed in his dealings with the Auction House and watching Trade chat scroll by when he suddenly turns to us.

"Uh, hey, I think Michael Jackson is dead."

My friend and I stop, look up from our paperwork, look at each other and then turn to him.

"What," I ask.

He repeats it and I am already accessing The New York Times on my iPhone, while my friend starts to check the Internet on her laptop.

"I’m getting nothing from the Times, are you," I ask her.

She shakes her head and he replies, “That's what they're saying on WoW.”

I laugh it off and say, “It can’t be,” but something tells me the WoW community is eerily reliable when it comes to breaking news like this.

Meanwhile, in our search of all the major news sources, we continue to come up empty.

Finally, after a desperate Google search, I find something on TMZ. Not exactly a 
noteworthy source, but they are reporting that the King of Pop is sick. Sick, not dead. I remain skeptical, since I am sure that there is something to the rumors as Trade chat continues to scroll insensitive commentary such as "MJ FAILS AT LIFE” and “No rez for the King of Pop”.

“CNN’s got it,” my friend exclaims, triumphantly. "Still saying he’s sick!”

I refresh the Times again, go back to MSNBC, back to TMZ, back to the Times.

I refresh once more.

And there it is!

“Michael Jackson, 50, Is Dead” read the New York Times headline.

The three of us just look at each other, mouths gaping, taking in the significance of what just happened.

Not only did a legendary musical icon just die, but we found out (seemingly before mainstream media) through a video game, an MMO. The self-deprecating, darkly sarcastic, ever antagonistic WoW community had alerted us to the death of Michael Jackson, an international music icon and one of the most recognizable faces in pop culture.

Why that anecdote? I find it powerfully indicative of the sleeping dragon of information that is social media. Finding out about the death of an international pop star several minutes before the rest of the world is sobering to some degree. If the Internet had been available when JFK had been shot, the world might have known seconds after 
the event. Would this have changed the course of human history? Would we conclusively know who pulled the trigger(s) that ended the life of the $35^{\text {th }}$ President of the United States? I think that social science and the world need to realize that the Internet is a force to be reckoned with and that gamers, those people that are nearly constant citizens, denizens, and natives of the Internet are powerful people. With their fingertips they are purveyors of the world's most pressing news, the keepers of the truth, simultaneously the messengers of justice and sources of misinformation. How can we continue to write these people off as wasting their time, their lives, and their very existence in virtual worlds when the virtual is so much a part of our physical, tangible lives?

It is here that I begin the account of my participant observation in WoW. Taking place over six months, I created various characters on three different types of servers or realms. The realms were Player versus Player (PvP), Player versus Environment (PvE) and Role Playing (RP). Characters were created on both Horde and Alliance factions. As I played, I felt my involvement in a guild was going to be an integral part of this investigation. Because of that, the PvE or Normal realm investigation is much more indepth. On these realms, I primarily focused on playing an Alliance character.

Player versus Player Servers: Guilds are Serious Business

Over the course of six months, my husband (at the time) and I played together, trying out several different races and classes of character. We became very involved with three different types of guilds. All of them experienced some sort of break down in leadership or “drama” that caused members to leave and fractures between player 
relationships. I will describe the types of guilds I joined for the purposes of the discussion, although I will not mention the specific realms in order to protect the anonymity of the players.

The first guild we were a part of was named Cataclysm. I became part of this guild simply by virtue of my ex-husband's playing prowess. He joined after completing several harder level dungeons with members of the guild. They were impressed with the way he played and, thus, invited him into the guild. From discussions with them, he deduced that it was a rather difficult guild to become part of, complete with an interview process and a test-run through a dungeon to judge player skill. When my ex-husband suggested they invite my character as well, the guild leader had to be convinced that I could be "taught” to be a better player, since my ex-husband admitted I had never done higher level dungeons - or raids. I was told by the guild leader, Kaemon, that he would run with my character through a dungeon before officially inviting me. I cannot make the claim that it was because I was female that this guild believed I had to be "taught" anything, but they did let me join with obvious reluctance. I realized that I was the only female in this "hardcore raiding" guild. Usually, guilds like this are only concerned with end game content, besting the highest level dungeons in the game, and obtaining the best gear available for their avatars. Gear refers to pieces of clothing a player can wear that will boost statistics, causing a player to do more damage to monsters or other players. I should also note that this was a PvP server. PvP servers are often considered "hard core" by the general populace of the game and are usually homes to raiding guilds that take the game very seriously. Many raiding guilds set apart designated days and times for raids, 
sometimes lasting as much as 4 or 5 hours a night and taking nearly a week of continuous game-play to complete. There is research available (Yee, 2015) that discusses how some see their involvement in MMOs as a second job, and it is within gatherings of this type that one might find players like that.

My first raiding experience with this guild was on a night when they required a shaman. It was apparent that I was the only choice, as I was the only high level shaman on-line with passable gear. My ex-husband was at work and I was a little nervous to be raiding for the first time without someone there to guide me. We were going through Naxxramas (Naxx), the highest level dungeon at the time. Naxx contained several wings with "boss" monsters in each wing that all required very different strategies to beat. The boss requiring a shaman was in the Construct Quarter of the dungeon and the totems a shaman uses to boost player statistics and damage are very important for this part of the raid. Kaemon asked me to join Vent once I was invited to the raid group. Again, I felt nervous speaking over Vent, but some of the initial reservations were assuaged by the fact that they already knew I was female. When I first spoke, it was clear my microphone was too loud. All the other raid members in the chat expressed annoyance that I had not thought to check my settings before entering Vent. After exclamations of “Woah!” or “Geez, that’s loud,” I asked if I should turn my mic down.

"Yeah, turn it down please," Kaemon said in a diplomatic tone.

I could tell he was also annoyed, but trying hard to be the level-headed leader. I was brought into the fray and led to the room where we waited to "pull" the boss - that is to say that Kaemon would explain the fight and our individual roles in detail before he 
engaged the boss in battle. He was a tank, a player designated to keep the boss from attacking other players. Tanks usually have the hardest job in a raid because it is their responsibility to keep the boss from attacking other integral members of the raid, particularly the healers. Kaemon's explanation was general, but he did explain to me exactly where he wanted my character to set her totems and which totems I should use. I was playing a female Draenei shaman at the time. I was melee character, meaning I would need to fight close to the boss. However, because I was managing totems, I also had to be mindful of their placement. This boss needed to be fought in a circle around the room, meaning my totems would need to be placed in the center so that all the players could benefit from the boost in stats.

Kaemon pulled the boss down an incline as we all waited patiently. The Vent channel was quiet and I watched with a pounding heart as a giant abomination hulked its way down into the circular room. A massive construct built from putrid body parts that were crudely stitched together, certainly fitting of the name Patchwerk, made the ground shake under us as he came closer. We were surrounded on all sides by poison slime, leaving us no choice but to fight. Immediately, I felt my adrenaline spike as I heard "Go! Go! Go!,” over Vent. I could not be sure who had shouted the order, but that instant I could hear the players around me shooting off spells and the group I was meant to go with was already running towards the boss before I even realized what I had to do. My totems were already on the ground, but we soon discovered they are not affective since Patchwerk had to be continually moved because of the poison slime he leaked on the ground. He would also randomly shoot poison slime at one of the players in the group. 
Once this happened, a skull would appear over your head and you had to run or risk infecting the others around you. This happened to me several times and I was treated to shouts of "Run!" as I nervously made my way to the other side of the room. Inevitably, the first attempt was a failure and our group very quickly "wiped”, a term used to signify that the boss had been successful in killing off every last member of your raid. As we regrouped and "rezzed" (i.e. came back to life by finding our dead bodies), I felt my heart racing and my palms sweating. Because I had not been invited to this guild by my own virtue, I already felt like an outsider. I did not want to prove that they were justified in their reluctance to accept me into their guild by turning out a bad performance. It was a tremendous amount of pressure and it made me question the term "game". A game cannot possibly be this nerve-wracking!

In fact, the first few attempts to kill the boss were colossal failures. Many people were making mistakes and I had made many. I benefited from a few shouts to "get back" or "move" in one direction or another. In the back of my mind, because this group was comprised exclusively of male players, I felt that the blame would be placed on me. I was the girl, I was the weak link. I started to understand the insurmountable pressure felt by a female player that is in a group of males, males aggressively attempting to kill something. Virtual or not, it is a heady experience. With each failed attempt, Kaemon's diplomacy began to fade. He was sighing a great deal and coming up with new strategies. By the fourth attempt, he had resorted to visual demonstrations in the waiting area. He would use four players who knew the fight and position them accordingly, marking one as the "boss", and then proceed to act out the fight while the rest watched. 
My nerves were as shaky as Kaemon's tact and I began to wonder why I felt this way. Why was I letting my assumptions about how they viewed my femininity dictate how I felt about my own expertise? It was a surreal experience and when I was finally able to step back from it, I found that I was judging every exchange, every sigh, every frustrated grunt or corrective shout under a discourse that existed in my mind. I was my own worst enemy and because of it, I was judging myself just as harshly, if not more so than those with whom I was playing. I wanted to prove so badly that I was not a failure just because I was a girl, that I was failing because of shaky hands and frazzled nerves. I started to wonder if other female players experienced this and if it got better over time.

Finally, we managed to slay the boss, with much of the group dying in the process. It was not a glorified victory. The comments on Vent expressed relief and annoyance that it had taken this long and been this difficult. Kaemon then sent me a private whisper. "Thanks for your help on this, but I think we're going to bring in someone else for the other fights. We might need you for Saph, I'll let you know.” I left the group immediately after that, half relieved and half insulted. I felt used for my totems. How ridiculous is that, I thought to myself. "Saph" referred to a dragon boss, Sapphiron. "They probably just want me for my totems again,” I lamented to my exhusband later that night.

Findings

As a social scientist, I tried to separate myself emotionally from the event. I tried to analyze what had happened based on the points I have set out to examine through this study. From my own behavior, I could tell that this was indeed evidence of a perceived 
bias from other players based on my gender and that it was affecting how I played and how I interacted. Being someone with a naturally open and friendly personality, my initial comment in Vent was a cheerful "hello". The reception I got quickly stunted my cautious cheer. After that, I did not speak on Vent again to this group. I noted that all the responses that followed from me were typed in the raid chat. I was afraid to ask questions and afraid to interact with the others in general because, as I said, I felt judged, I felt like I did not belong. Personally, the bias I perceived based on my skill and my gender was a definite factor in the way I communicated during the rest of that fight. And even as I was emotionally hurt, I wanted them to call me back so that I could prove I could do better. I was sure that I could be a better player. I was determined to change whatever opinion of me I imagined they had formulated based on my debilitating performance. I wanted to do better and I had cut off all verbal communication in the effort to downplay my femininity, as if they would forget my gender.

Gendered Interactions Online and at Home: My Husband Plays Better Inevitably, I was called back for the Saph encounter. My ex-husband was available for this fight, much to the apparent delight of Kaemon and the other players. He had been through several fights with them before the group collectively decided they needed my shaman for her totems. Again, I was instructed as to their proper placement. The fight was explained in general and it went rather well. It wasn't a particularly difficult fight and I felt as if I'd done a good job. While I did die during one encounter, my ex-husband quickly soothed, “Don’t worry, that was the healer's fault.” He always seemed to be watching everyone else, while I was so busy worrying about myself. The 
same goes for the raid leaders and others in the group. They seemed to be on top of who committed what error. It amazed me how aware of everything they were, while I was struggling to catch up and not die. One of my female respondents was elaborating upon a situation similar to this. She explained to me her decision to quit being a tank, arguably one of the most important positions on a dungeon or raid team. A tank is responsible for keeping the monster in its proper place while the others must work on actually slaying whatever monster is being fought. She explained, "It was due to the fact that I sucked. I enjoyed being a very important part of the team but my husband was constantly trying to tell me I was doing something wrong or telling me to do something different or trying to rearrange my abilities, it is why it wasn't fun anymore.”

My respondent, a 28 year old mother of four, had been playing video games since she was 7 years old, yet she still felt as if her husband's video game prowess was superior to her own. By her own admission, his ridicule made her feel as if she "sucked". I could certainly relate to her explanation, as I found myself feeling much the same way. It was not until I began playing this MMO in the same room as my then-husband, that I realized how much more effort he put into the game-play. And, honestly, I felt as if the skills he taught me made me a better player as well. After informal talks with several heterosexual couples that play video games together, this seemed to be a pattern. The male tended to try to exert some kind of expertise over the female, regardless of her own video game experience. 


\section{Findings}

The above discussions are eerily reminiscent of some of the childhood gaming studies referred to previously in my investigation, where boys were reportedly more intrigued by intricacies and problem solving in video games than girls. However, I would argue that neither my respondent nor I are put off by the intricacies of the game. In fact, we both seem to strive to find ways we can play better. It is simply that our male counterparts do not feel we are good enough, and not on their level. And I would further argue that this is a consequence of the socially accepted idea that these video games cater to men and are largely an arena built by and for men. The manufacturers perpetuate this stereotype and we as researchers repeat it and it becomes, in the words of others before me, "a self-fulfilling prophecy" (Yee, 2015). It is this idea that makes its way into our performances. Without realizing the cause, female players will find themselves feeling inadequate to their male counterparts. In the above scenario, not only was perceived bias of male playing partners affecting behavior, for my respondent, it also affected her avatar choice. While my hypothesis catered more towards the aesthetics of avatar choice, it can certainly be counted as choice if one changes the purpose $\mathrm{f}$ the avatar one has created.

Player versus Environment: Not so Serious Business

Eventually, the PvP guild became a little more intense as far as raiding schedules and both my ex-husband's and my work schedules conflicted. As part of my plan, we began playing on a PvE server. PvE servers center on defeating monsters and completing quests rather than killing players of the opposing faction. Guilds in servers like this cater to many different types of players. In this new server, we joined a guild named Knights 
of Valhalla through much the same means we had stumbled into the other guild. Through running dungeons with random groups of people in the game, we met a group we enjoyed playing with. Witty comments through the in-game chat allowed us to make connections with these people and we were invited to their guild.

Immediately, I noticed that the personalities of those players we had initially met (Igor, an 18 year old male about to enlist in the army, and Aldis, a 14 year old male) were the ones who set the tone of the guild chat. Another personality later made itself known, Browning, a middle-aged mother whose adolescent son was also a player and guild member. It became apparent that Browning had some tensions with both Igor and another guild member, Masterofbeast. The guild leader, Gwrol, was consistently trying to mediate tensions between Browning and Masterofbeast. One or the other of these two would initiate a fight or leave the guild after a fight. Browning was usually the one to leave the guild, ask to come back, and then leave again at the next perceived slight.

In this guild, we would often talk over Vent, so I got to know these people pretty well. In fact, they were aware of my status as a researcher and had all given their consent to be part of my participant observation, giving me vital access to some of their thoughts and emotions as they played the game. I was also able to record several conversations for later transcription and use.. At first, Igor and Aldis were very curious. They seemed intrigued by the idea that someone could focus a dissertation on a video game. It was their excitement that allowed for this unique experience.

Each night when I logged into WoW, I would also log into Vent. The arguments over Browning and her expressed concerns were often over Vent, so I was able to hear 
the tension in people's voices, and able to pick up on some emotions as well. Browning seemed to take changes in the guild very personally. She felt she was a part of the original members and, thus, should have a say in decisions made by the guild leader. As far as classification in the guild, she was an "officer", meaning she had a say in rules and loot/item distribution after large battles with monsters in-game. Browning played a Night Elf Druid and was the main healer for the group. She also had a penchant for selfdeprecating behavior, calling herself a "bad healer" and thanking everyone for "putting up with her heals”. During a routine dungeon run, Browning was not able to heal through the larger fights. After the run was over, Igor said that he would make a healer and the Guild Leader asked that he and Masterofbeast join him in a private Vent channel. Private channels can only be accessed by the Vent server owner and whomever he or she allows into the channel. Browning immediately began to feel uncomfortable, voicing that discomfort over Vent to myself, my then-husband, and Aldis. Aldis was also an officer and Browning felt that if there was an officer's meeting, then she and Aldis should have been invited.

“Aldis, do you know what they're talking about,” she asked, audibly agitated.

"Uh, no," said Aldis, as if he was completely unconcerned that he was not involved.

“I don’t know,” she replied, “Don’t you think... I mean, we’re both officers. This isn’t fair, we should be involved in this. Does anyone else see my point here?”

Aldis’ only reply was, "I guess.” 
Browning often asked for direct input from others on her feelings. In fact, as the meeting wore on between Gwrol, Masterofbeast and Igor, Browning became even more agitated. She turned to me, as she often did because of what she decided was a camaraderie based on the fact that we were both women.

"You can see my point here, right Caskar," she asked. Caskar was the name of my avatar on that server.

“I'm really not a part of this,” I said tentatively, trying not to throw my hat into what I felt was brewing tension. "I mean, they might be discussing something else, not guild related.”

I was trying to mediate in my own way, to assuage Browning's fears. However, at the same time, I felt her agitation was unnecessary and causing a great deal of needless strife amongst those of us in the chat simply trying to enjoy light banter while we played. It is here that one can find another assumption made about the "real girl": the tendency towards drama. Drama, dramatics, the need to make everything an emotionally draining experience, rabble-rouse, start pointless arguments, and generally ruin everyone’s good time. This is a sentiment expressed in reference to female players so often, that I was almost saddened to see Browning perpetuating such a hideous stereotype. Indeed, even I became irritated by her consistent changes in emotion.

"She just brings the drama," Masterofbeast later confided to me when the situation had dissipated. Eventually, Browning spoke to Gwrol privately and he assured her that the meeting was to discuss something that was not directly related to the guild. 
This was not the last of the "drama". Although the other guild members felt comfortable enough to confide in me, I often wondered if they were careful not to designate the "drama” brought on by Browning as specifically "female drama”. Instead, they would simply explain to me that before I joined the guild, she was constantly causing issues and starting arguments. It appeared to me that these male players that I had come to consider friends were trying to imply that I might have some sort of mollifying effect on Browning simply by virtue of my gender. "You're not really like other girls," Masterofbeast said, his tone suggesting it was meant as a compliment. I had encountered this kind of thing before, when reading Kendall’s (2002) auto-biographic expositions on her experiences in the technological chatrooms.

Events culminated one night when the guild decided to take Igor's new Night Elf Druid healer on a raid. After having Igor heal the group through several dungeons, it was determined that he was indeed a superior healer. In what sounded like good will, Browning commented over Vent, "Igor will heal a lot better. He’s so much better than me.” She even laughed and seemed to take the decision well. Indeed, Browning spent much of her time praising other players and devaluing her own skills in the process. Although she seemed to seek comfort for her perceived failings, the other players often did not respond when she said something of a self-deprecating nature. As this raid continued, Browning suddenly left the guild. We were made aware because the in-game chat scrolled the yellow text, "Browning has left the guild."

“Oh, wow, not again,” said Aldis while we were waiting to kill a difficult monster.

"What the hell is that about," he went on. 
“Who knows, who ever knows what's up with her,” replied Igor and I could almost hear the roll of his eyes.

“I’ll deal with it,” replied Gwrol.

Gwrol later informed us that Browning felt like the guild no longer needed her and would be better off without her. Again, this felt to the other guild members like a cry for attention, because players often join guilds for social reasons rather than to solely contribute to raids or dungeon runs. Browning did not downplay her femininity to fit in, nor did she over-exert it to gain any advantages. Instead, she played upon the emotions of the other players to gain sympathy. It is unclear to me why Browning persisted in both ridiculing herself and encouraging arguments between the other players. She did confide in me during several of these instances and, at one point, said, "We're the only two girls, we need to stick together, you know?”

\section{Findings}

I did not "stick together” with Browning and it was largely because I had formed such close relationships with the other guild members, I felt uncomfortable at her pressure to take a side, particularly based on gender. Instead, I chose to stay outside of the arguments. Also, as a researcher, I did not want to damage my relationships and cause myself to be alienated from group discussions or events. However, even though I did not take any sides outwardly, I found that I could sympathize with their sentiments when it came to Browning causing “drama”. Indeed, it felt as if she was just trying to make a scene so often that it became a hindrance to game play. And even though her gender was never explicitly called into question as a possible cause for her behavior, 
Browning used her gender to try and establish an allegiance with me, as if the problem was males versus females, when there was never any such implication in these arguments. Underlying the arguments was her own sense of inferiority and it was implied that she believed this was some issue relating to her gender because she tried so hard so often to involve me in her defense. And this was when I realized that this perceived bias from other players, though it might not have been specifically related to Browning's gender, quickly became gendered. She was cast in the light of a girl who causes “drama” and even I was avoiding her or removing myself from situations that involved her, forming my own judgements. And her behavior was greatly altered based on the idea that she was not welcomed.

Gender and the Avatar: Speak Softly but Carry a Very Manly Staff

Of all my experiences playing, it was with Igor, Aldis, and Gwrol that I had the most fun playing. I felt closest to these players, although I cannot quite point to why. Perhaps our senses of humor were similar or perhaps we just got along really well, but it was with some sadness that we left this server. The guild broke apart when Gwrol switched servers to play with a real-life friend. Later, Igor enlisted in the Army and Aldis stopped playing as often. Masterofbeast sold his account and Browning left a final time and never returned. There were more members in the guild, but they were never as involved in this core group.

The next guild we became a part of was also on a PvE server. This guild, Punishment, seemed a far more casual guild, although they were beginning to raid when we joined. We joined through a recruitment advertisement in Trade chat. It was 
originally headed by Pammy, a middle-aged married woman who ran a residential park for recreational vehicles. She was constantly on Vent and enjoyed chatting while playing. Her partner in running the guild, Aeres, was much quieter in Vent, although he was usually the one to head the guild meeting discussions. He ran these discussions in a very professional manner, as the guild was trying to become more serious in terms of raiding upper level dungeons.

Shortly after my then-husband and I joined this guild, Pammy decided that she no longer wanted to run the guild. She never revealed her motivation, but she did express some feelings of "stress" - as she called it - with guild management. She gave up the reigns to Aeres and there was no further discussion from anyone else on the subject. At least, not in the general guild chat. The rest of the guild seemed to accept Aeres because he had already been in charge of upper level dungeon management and all the end-game content, which is arguably considered most important to a large majority of players in PvE and PvP servers. We became very active in this guild and several events took place that I feel were of great significance.

Our group had just defeated Emberscar the Devourer and the Crucible of Carnage arena was beaten. This is a high end quest in the then-new content of the game. At the time of this investigation, the new expansion to the game had just been released and all players were struggling to reach the highest level and explore the new areas the game had to offer. In a celebratory mood, we flew upon our mounts to collect our rewards. We had been coordinating through Vent and Pammy boomed through the speakers, “Oh yeah! Very Manly Staff!” Her reward was a staff perfect for her Mage. It 
was called the "Very Manly Staff”. She was clearly excited and immediately began to tease Mago, one of our group mates. “Hey! Mago! You want to touch my Very Manly Staff?” Mago just laughed.

What struck me about this was not the comedic irony of a female boasting an item with a clearly phallic reference. It was mostly that Pammy immediately sought out the first male she could find, Mago, and try to make him submit ( if only in jest). In fact, Pammy continued to make light of her new staff by inviting other males in our guild to touch her "very manly staff." Never did she invite me to do so, knowing full well I was female - one of only four known females in the guild.

If we tie this back to our attempts to spot a "real girl", we would see this as a veteran female player using crude sexual humor and flaunting the very symbol of masculinity, making it a part of herself, inviting other males to "touch it". Pammy was showing off something she felt made her more powerful and the irony was that it was a euphemism meant to bolster masculinity. Even as a joke, the staff was a powerful upgrade for her character and that fact was very much a part of her joking. In subsequent dungeon raids, she continued to boast about the new skill boosts her staff was granting to her character. I argue that this self-validation was just another way for Pammy to make herself "one of the boys”. As a dedicated female player, Pammy spent a great deal of time leveling her characters and continuing to help run the guild. However, even with all her efforts in game and her considerable achievements, she still found ways to try and validate herself as a valuable player to the rest of the guild. Particularly with her recent 
decision to relinquish power, she had to find a way to still be a prominent guild figure with adequate authority.

\section{Findings}

One could make the argument that Pammy's actions were being guided by her own perception that she'd "lost face" with the other guild members, mostly male. Even if her "very manly staff" jokes came off as humorous banter, there was something far deeper. And, in essence, we can go back to the power of rhetoric and the powers that be in a virtual environment such as this. Who named this staff in the first place? The staff itself was satire about masculinity tied to penis size. It is the programmers that allowed for an exchange of this type to take place by introducing this object into the game. Our preconceived notions and gender-based insecurities (ones arguably shared with the game designers) did the rest. It is a vicious cycle tied to language, to rhetoric, to an amorphous and indefinable power structure that underlies our society. This relates to not only perceived gender bias from other players affecting behavior, but it also relates avatar choice. Although the staff was a significant upgrade, Pammy chose to flaunt the addition.

Gender and the Voice: You Sound Hot!

In another incident, our group again found themselves in a dungeon, making our way through and trying to learn the new fights. Pammy had never done the dungeon before, so she was asking me to explain over Vent. After she was done speaking, one of the males in our group (Rip) said, “Hey Pam, my roommate thinks you sound hot. He wants to know if you're single.” As mentioned above, Pammy was married. Her 
husband sometimes joined in our group quests and raids. He was not present for this exchange. "Yeah well, tell him he can’t handle me. Bill can barely handle me.” (Bill was her husband.) Before this exchange, I have to admit, I had felt a sense of curious pride that I'd been asked to do the explaining. For once, I thought, I understood things enough to explain it to a group. After Rip's comment, I felt scrutinized and indignant, even if the comment wasn't made about me. Again, sexuality had come into the equation in some form, threatening to undermine my authority. It felt uncomfortable to think that my voice might be sexualized while attempting to explain something non-sexual. This would not have been an issue if either Pammy or I were male.

However, Pammy did not allow herself to be sexualized, even if the attempt was made. In fact, her tone was very much a warning to Rip and his roommate that she was not to be taken lightly. Rip was a relatively new addition to the guild and this incident was a clear indication of that inexperience, as the rest of the guild members almost never tried to use Pammy's gender to sexualize her unless she herself steered the conversation towards joking flirtations. This was a rare thing, and the flirtations were usually based around Pammy being the one in control. Pammy's seemingly hard-earned place as "one of the boys" had to consistently be defended from challenges. The burden of proof was again on the female and this time it was not to prove her femininity, but to prove her pseudo-masculinity. Indeed, it had to be continually defended.

\section{Findings}

When faced with what most female players have encountered at one time or another in Vent, Pammy responded with a resolute affirmation that no such advances 
would be tolerated. Thereby, she imparted to Rip that she was the one in charge and her gender was not to be taken as an automatic invitation to be ridiculed or hit on. However, as mentioned above, her gender seemed to necessitate that she continue to assert that pseudo-masculinity in order to be taken seriously. Rip’s comment had effectively halted our game play until the issue was resolved. It was only after Pammy established her dominance that he continued with the instance under her direction. After my explanation, I naturally defaulted to Pammy to guide the rest of the run. After all, she was in charge. While this particular case did not result in any observable change in behavior where Pammy was concerned, my behavior was affected by my perception that my voice may have been used to sexualize me in some way, thereby undermining my ability to play.

Gender and Power: The White Knight Syndrome

As I said, there were a couple of other females in this guild. One was Rain and she often played with us in group dungeon situations. Rain was typically quiet, but had a seemingly close relationship with one of the guild members in charge of raiding and the more important guild decisions. Exorcïst often acted as Rain's defender when he felt like she was the subject of ridicule. This is another paragon of male reactions to femininity, the "White Knight" syndrome. The brief chat excerpt below is an example of one of these situations. Exorcïst asks in the guild chat if anyone has "made a comment" about her dps. DPS or Damage Per Second, is very important to WoW players who play melee or ranged characters. The higher the DPS in a fight, the more prestige the player garners. Certain benchmarks exist in the game that change with every update as to what is "good DPS". After Exorcïst asks his question, a guild member named Alorex mentions that he 
was trying to find out what her "ilvl" was. This means her "item level"; essentially he wanted to know how good her avatar's gear was to figure out how this might be affecting her DPS. Alorex's inquiry might have been an innocent attempt to help Rain. Alorex is, by his own admission, a male member of the guild. Here, he displays a passive knowledge of item level in relation to player skill. Soricoder, a male guild member that often turned to comic relief in tense situations, immediately classifies this exchange as "drama", and Exorcïst responds by implying he has blocked Alorex and announcing that Rain does not play as often because she's been ridiculed about her DPS and her "abilities" before.

8/28 22:30:12.411 [Guild] Exorcïst: ok i got a question

8/28 22:30:24.372 [Guild] Exorcïst: who made a comment about Rain'd dps?

8/28 22:30:32.328 [Guild] Exorcïst: rain's

8/28 22:31:01.809 [Guild] Alorex: i was inquring as to her ilvl

8/28 22:34:27.466 [Guild] Exorcïst: she's upset.

8/28 22:34:48.917 [Guild] Soricoder:

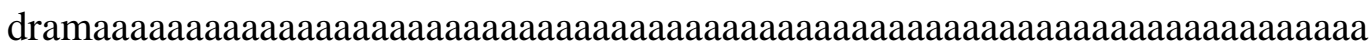
aaaaaaaaaaaaaaaaaaaaaaaaaaaaaaaaaaaaaaaaaaaaaaaaaaaaaaaaaaaaaaaaaaaaaaaa

8/28 22:35:02.765 [Guild] Exorcïst: man...

8/28 22:35:15.771 [Guild] Exorcïst: another one made it to the ignore list

8/28 22:35:20.214 [Guild] Exorcïst: anyhow. 
8/28 22:35:42.793 [Guild] Soricoder: wait do you mean me?

8/28 22:35:57.175 [Guild] Alorex: im sorry i was just wondering how big of jump her upgrading weapon affected her ilvl

8/28 22:36:12.498 [Guild] Exorcïst: not saying it was you

8/28 22:36:22.172 [Guild] Soricoder: oh, ok sorry lol

8/28 22:36:30.151 [Guild] Exorcïst: she has had comments made about her dps/ ablities.

8/28 22:36:38.516 [Guild] Exorcïst: kinda took the fun out of the game for her

Several things are going on here in reference to this particular investigation. First, we have the "White Knight”, Exorcïst, defending the presumably weaker female, Rain. What is strange about his defense is that he is not saying Rain's DPS is fine or comparable to that of any other member's. He is simply implying that no one make any comments about it and that it is hurting her feelings in some way, so much so she no longer finds the game enjoyable. Alorex is exerting authority in a passive way, having admitted to asking Rain about her item level in what can only be assumed was an attempt to tie her DPS to her gear. Was this attempt a way to explain her skill, markedly separate from her femininity and from the presumption that gender somehow affects skill?

Findings

It seemed from Exorcïst's comments that Rain took it as a personal attack. Rain never did come back to play. On one occasion when she did sign on, I made the attempt 
to speak to her and ask her how she'd been. She mentioned she had "more important real life stuff" to attend to, undermining the reality of this virtual world and making the assertion that her experiences in WoW were not very important to her in the grand scheme of things. This may be true, but as Exorcïst said, "she [was] upset". Clearly, her player skill coming into question was not something she was able to handle and so, she quit the game rather than adopt any kind of pseudo-masculinity. Regardless, the perception that she was somehow seen as a lesser player seemingly resulted in her decision to leave.

\section{Role Play Servers: Less Than Serious Business}

Moving on to role play (RP) servers, I must report that my experiences in roleplay servers were limited. I did not foresee the difficulty I would have with RP servers in general. To become part of a serious role-playing guild, one had to fill out applications and, often, pass extensive interviews where role-play skill would be assessed. In one of my RP server investigations, I joined a general role-play guild that did not require an application. As a result, the degrees of role-play experience and role-play styles were varied.

In general, I would sit my avatars in areas with large amounts of people, most engaging in role play with one another. The most popular places on both Horde and Alliance servers were Inns, where most players congregate anyway to gain experience rewards from “resting”. Avatars gain extra experience when killing monsters or completing quests if they have spent a certain amount of time in an Inn. Inns also usually contain bar areas with bartenders that serve drinks that can intoxicate your character in 
the game. When a character drinks enough of an alcoholic beverage, messages will scroll in the local chat reading statements such as: “[Avatar name] becomes tipsy from [beverage name]”. All other avatars in the vicinity will see the message. In role play situations, bars or pubs are a good place to meet and start role-play scenes, many times with total strangers.

The most attention I received in these situations was as a pink-haired, pigtailed, female Gnome rogue. I "parked" my level 2 Gnome rogue, Amaryllis, in one of the most frequented areas for casual role-play in the Alliance server, Goldshire Inn, just outside of the largest city center, Stormwind. I visited Goldshire Inn on my Gnome for several nights. Most evenings there would be females of Night Elf, Human and Draenei races dancing on the tabletops on the first floor of the Inn. The floor plan includes a long table by a large hearth and scattered tables on the other side of the room, as well as a bar area. The females would sometimes shed their clothing and be left in the default bra and panties the game provides once a female character has shed all her clothing. Male avatars would take the seats around the dancing females and often make lewd comments in the local area chat.

Interestingly, there are modifications one can download (aptly named “mods”) to change the interface of the game. Mods often work to help guilds with raids or to help in "farming" - gathering materials to create items, spells, or potions in the game. There are even mods to make the avatars completely naked, thus stripping the default underwear presumably meant to preserve the modesty of the avatars and the game's "T for Teen" rating. Mods of this nature have been part of good-natured joking amongst male players, 
at least insofar as I have been made aware of their existence. Although, I have never encountered anyone directly admitting that they had such a mod. One could assume the implications of it in role-play were to enhance realism.

I first tried setting myself apart from the main area role-play to get a wider view of what was going on around me. However, that proved a little difficult, since I would get private whispers from other players wanting to role-play. Finally, I relented to casual play with a male Human warlock, Flintlock. I was surprised that he was so interested in my little level 2, as he was a level 65 and clearly had invested a great deal in his character. He spent much of the role-play showing my character all the different things he could turn into. It was clear he had spent time collecting trinkets to transform his character into other things and had incorporated as part of his character's class - warlock. In response, I played my character as appropriately impressed and a little frightened at the displays of power.

The pink-haired female Gnome was one of the most popular choices for female players in WoW for a very long time. It is an interesting archetype because Gnomes are often ridiculed in the game for their small size, as if choosing to play a Gnome is an admittance of being somehow less capable. As has been previously mentioned, female WoW players are generally assumed to be less capable than male players. With that intent, I chose my avatar purposely and role-players responded with immediate interest. Some of that interest was lewd in nature, others like Flintlock initiated casual role-plays.

In role-play, one can immediately tell a lewd encounter by the question "a/s/l?” From its inception, the Internet has primarily been used as a way to meet and connect to 
other people. If one could boil down all they needed to know about a person into three characteristics, the three most arguably important over the amorphous ether that is the Internet are "age”, “sex”, and “location”. Armed with these three key pieces of information, a potential partner in gameplay, role-play, or otherwise has enough knowledge to spark an interest. Post-modernism and social science would argue that these three characteristics can tell you next to nothing about who a person really is and are very fluid in and of themselves, subject to the definition of the informer and that person's individual society.

Nevertheless, when little Amaryllis received an in-game “whisper” - similar to an Instant Message, a form of private communication between two players within WoW and it was those three letters in some form, I knew that it meant my potential role-play partner wanted to find out if I was actually female, within an acceptable age group, and perhaps close enough to him/her to progress our prospective in-game romance. Alas, since I was far more interested in identity and less so in sexuality, I did not pursue these encounters to fruition. Not wanting to make assumptions, I would always answer the question truthfully. However, the inevitable follow up was some suggestive comment like “do you want private play” or the admirably direct “want sex?”

And so it was that Amaryllis was charmed by Flintlock and his repertoire of shape-shifting spells. He began by role-playing a quick hello. In role-play, those that actually want to engage in involved story lines between two or more characters will write out lengthy "posts" - one or more paragraphs of story-telling that informs other players of what the character is thinking, feeling, doing, and saying. These role-players 
(sometimes called "para-posters" because they engage in paragraph-based descriptive role-play) are typically seen as taking the role-play aspects of the game more seriously than anything else. On a RP server, one is far more likely to encounter this type of player than on any other kind of server and, indeed, it is for this reason that RP servers were set up. The "asl?" role-players (RPers) are typically what are known in the RP world as "one-liners" where role play reads less like a story and more like stage directions. RPers will type out minimal amounts of description for actions and mostly type out what the character might be saying while letting the actions of the avatar reflect what is happening in the scene.

However, Amaryllis and Flintlock's meeting was far more detailed. Amaryllis, being a short Gnome (no more than 2 and a half feet, really), and tired from a day of sneaking around as a stealthy rogue, decided to take a break and so she made her way towards one of the smaller tables near the kitchen at the Goldshire Inn. She sat on the table top rather than on an actual chair. Clearly, nobody had taught the little Gnome basic table manners. Either that, or she did not care. In truth, for Amaryllis' writer (i.e. me) it felt like a natural thing to want to do in a crowded inn when sitting in a chair really just meant that you were nose-level with the side of a table. What a cruel world for Gnomes.

Flintlock walked into the Goldshire Inn shortly thereafter. Clearly a warlock by his garb, Flintlock wore a crimson robe with purple trim, with shoulder pieces that were broad and pointed at the ends. He held a large staff with a spinning jewel at the end. A human male, light-skinned, and with shoulder length blond hair, he had rough features, 
but was fairly attractive. Skipping along beside him was an olive skinned gremlin-like creature, an imp. Every warlock, when first learning to summon a familiar to aid them in battle, was graced with an imp. Trailing behind the imp were footsteps of yellow fire that vanished quickly as he walked forward, or skipped and tumbled forward. Indeed, the little guy's entire body seemed to be burning with greenish-yellow flames.

Back in the physical world, across my screen flashed the following message in pink, indicating it was a "whisper" or a private message just for me.

Flintlock whispers: Hi there, I hope you don't mind if I start a scene?

Intrigued and far from the typical three-letter greeting Amaryllis was getting in her little corner of the Inn, I replied, "Not at all! By all means." I had to stop myself from adding the emoticon smile at the end. I am not sure what force or subconscious thought precisely stopped me, but I made the effort and, of course, overanalyzed the "why" of it for far longer than it took to make the decision. Perhaps, in this environment of role-play where the actual player's gender seemed to be much more in question and where deception was so vastly important, I felt that an emoticon might be a "red flag" so to speak. Perhaps what I had been told prior to starting this journey about how to "spot a real girl" came to the forefront of my mind and I made the effort not to look like I was trying too hard to be a girl... even if I am actually a female. One could get lost in these kinds of circular thoughts, so instead I turn to Flintlocks resultant post, which flashed across my screen in an orange color, the color reserved for stage directions and which appears when either the player has typed a command such as "/dance" or has typed "/me" (as Flintlock did) and then proceeded to write out a paragraph which read: 
Flintlock steps into the pub with Jubjub jabbering and somersaulting beside him. Across the way he sees a little gnome with pink hair done up in pig tails and he walks over to her with a large smile. "Hello miss" he says and waves a large hand while his imp sniffs the leg of the table.

It would be a good time to interject that I personally have a great deal of role play experience in MUD type or text-based chat situations. In recent years, my role play has moved to SL where the visual experience almost completely takes over. Avatars are highly customizable and both they and the environment are limited by the imagination of the players (residents). Therefore, I was pleasantly surprised to find that the WoW role play etiquette seemed to follow the same rules of paragraph, turn-based posting.

Now, back to Amaryllis’ meeting with Flintlock. In response to his very standard greeting, Amaryllis was mildly curious as to what the human warlock could want to discuss. And so I emoted:

Amaryllis looks up with wide wondering eyes at the human before she catches the movement of the imp in her periphery and her gaze is drawn upon the little creature. "H-hello," she said uncertainly and looked back up at what she guessed was a warlock. After a moment she remembered polite smile and inclined her head so the pig-tails bobbed.

Although I was not doing it consciously, I noticed that I was accentuating the features of my character that made her feminine. This was something I realized only after I had analyzed the exchange. After the initial introduction, Flintlock asked 
Amaryllis what she was doing so far from her ice-capped mountain home near that massive structure, Ironforge, a veritable metropolis carved into the side of a mountain. Amaryllis replied that she had needed a change of scenery and was told the Goldshire Inn was a nice place to unwind with a good drink. It was then that Flintlock decided he wished to impress Amaryllis with his ability to shape shift. He turned into all kinds of things, including a dancing Snowman and a Blood Elf, the latter of which he was particularly proud to show off. Amaryllis was appropriately impressed and their encounter ended with Flintlock asking that the little Gnome come back to Goldshire the next night and see him. He claimed he would be looking out for her. While Flintlock seemed to want to continue his new friendship with little Amaryllis, the Gnome and her typist (i.e. me) would have to move on to other venues. Indeed, the next night I visited the Horde side inn at the Blood Elf main city, Silvermoon City. It was here where I encountered the kind of role play exchange that Flintlock and Amaryllis had had only the night before, but in the local chat rather than whispers and with greater frequency.

\section{Findings}

It seemed to me that these role players were far more sophisticated than the single line of text or speech that I had witnessed in the local chat when I was in the Alliance inn. I wondered if this stark difference in role play professionalism, if you will, was related to the stereotypical view that only new, young, and inexperienced players chose to play Alliance side characters. In addition to the Alliance being seen as a place for women, it is also seen as the faction of children and bad players. Through the role play servers, I started to see that being a part of the Alliance carried its own stigma. 
In fact, even players within the Alliance would often engage in self-deprecating humor. For instance, in PvP challenges, Alliance players would belittle their fellow players. It is not uncommon to see statements like "Come on Alliance, let's win for once!” or “Of course he sucks, he’s Alliance.” Again, these statements are made by Alliance members against their own brethren. If there is already such a harsh stigma simply for choosing the "good" faction, imagine the stereotypes that start to pile up for female players that choose to be Alliance. This digression will be explored later. The point was, I now found myself seeing the stereotype come to life even when it came to role play. Again, that notion of the self-fulfilling prophecy was apparent even when it came to judging players' skills collectively. If it was more beneficial to be part of the Horde in terms of social status within the game, it would be only natural for those who had been playing for a long time to be more inclined to choose Horde side avatars. For veteran female players that are also aware of the stereotype, again, they would recognize the advantage in choosing a Horde character. My observations seemed to be lending a great deal of support to those initial discussions with female players.

Trade Chat: The Foremost Authority in World News

Turning again from RP, it is important to explore Trade Chat. This is the specified chat channel within WoW where players will hold general discussions (since the chat reaches all major player cities) and barter for items. Trade Chat acts as a catchall. Not only do players use it to trade for goods, they also use it to find other players for group dungeons, difficult quests, and to chat across different cities. The Trade Chat reaches all major cities in the faction you are part of, thus making it a wide-spread 
communication tool. It is through Trade Chat that Michael Jackson’s death was announced to the WoW community and through Trade that many other major world events have been announced while I have been playing. In more recent memory, and after my participant observations ended, I remembered the death of Osama bin Laden sparking quite the heated debate.

The following Trade Chat excerpts will serve to shed a little light on the other discussions that often take place in Trade Chat. Trade Chat itself is a running joke amongst WoW players as the place where one can, at any given time, find degrading, insulting, sexist, racist, or downright silly discussions. Take this instance where Fullmetalfox is discussing some of the accents he hears on his guild Vent.

[2. Trade] Fullmetalfox: hell yea omfg you and a few others in eoi have some sexy ass accents that make me hot and bothered

[2. Trade] Redryder: I should put that on my recruiting spam then

[2. Trade] Fullmetalfox: lol

Fullmetalfox, implying he is male and later confirming the implication in further discussion, claims that he thoroughly enjoys listening to the female players in the guild (noted by the acronym "eoi" in the excerpt) talk over the voice-chat system. In particular, he felt that Redryder had an alluring accent. Redryder responded not by being insulted that he was sexualizing her voice or objectifying her. Instead, she joked that she should include his comment in her "recruiting spam" - meaning that when she advertises for new guild recruits in Trade Chat (which often takes place) that she can include the 
endorsement that the females in the guild have "sexy ass accents". In this instance, the desire for membership in the guild is not based on player skill, arguably what should be considered most important in a game like WoW, but rather on how "sexy” the female members of the guild sound. Sexual gratification becomes the focus and it was met with no resistance. Redryder's skill or the skill of her guild mates never comes into question and she does not seem to mind the public advertisement of her presumably agreeable voice as incentive for joining her guild. In fact, she embraces it, complicating the role of the female player. Sexual desirability, if it can be proven in some way as through voice chatting, excuses or nullifies player skill in some form. Suddenly, it's okay if you're a girl and you're not that good, because you have value as a sexual object. It is almost as if you need to bring something to the table and if that thing is not the ability to beat a difficult monster, then it's still okay if you can turn on your male counterparts.

The idea of the "real girl” is not just something one encounters once when watching the Trade Chat scroll by during idle times. In the following excerpt, a player named Bloodlúst finds his masculinity both confirmed and questioned within the space of a couple of minutes.

[2. Trade] Slammered: Whisper if uve ever played runescape

[2. Trade] Bloodlúst: Whisper if you think David Hasslehoff is sexy

[2. Trade] Rawnblade: Whisper Bloodlust and she'll tell you if she is really a girl or not!

[2. Trade] Bloodlúst: And I mean the David Hasselhoff drunk eating wendys 
[2. Trade] Oneshotko: ^ lol

[2. Trade] Bloodlúst: No need to whisper Im a guy

[2. Trade] Rawnblade: Or are you?

[2. Trade] Paltor: O.o

[2. Trade] Bloodlúst: I am thnx

\section{Findings}

By making a joke about a male celebrity, Rawnblade was able to bring his masculinity into question, by first assuming he was male and then using the implication that he might be female as an insult. And just like that, the conversation turns to Bloodlúst proving he is male. This is an interesting oversight in nearly all literature pertaining to gender and identity in the virtual community. When male gender is complicated or comes into question, then it can sometimes be just as difficult proving you are male... a "real man"! Proof of gender seems a slippery slope in the virtual world, mirroring the real world where gender deception is considered a grave social offense. Taught in gender classes all over the country, the story of John Money and his gender experiment with the Reimer twins (O,Connell, Sanjida, 2004) or the story of Brandon Teena (Muska and Olafdottir, 1998) where a transgendered man later poignantly remarks in footage from the trial of Brandon’s accused murderers, "you don’t fuck with gender." And while this analysis does not entirely relate to the hypothesis of male players choosing female avatars, it does present a new finding that male players may sometimes be subject to gendered biases as well. 


\section{Trade Chat: Lessons on Spotting a Real Girl}

One cold November, I was watching the chat messages scroll by in Trade Chat. General discussions can go from insignificant or random to full-scale debates and heated arguments. On this day, the topic of "spotting a real girl" became the central focus. A player by the name of Reavenge claimed that he could always tell when someone was "not a real girl". When asked for elaboration upon his techniques (he claimed he was male), Reveange came up with a small checklist to guide other players. The first was over use of emoticons. (e.g. :) ;) : ( ). Reveange suggested that males posing as females often overcompensated by using emoticons too often, the underlying assumption being that females use emoticons more than males. Player Thromm, offered the obligatory "pics or it didn't happen", which is the go-to response for proving femininity, implying that there are "no girls on the Internet" (the Internet-famous axiom discussed earlier) and, therefore, pictures are necessary to prove any claims to the contrary. Reveange shrugs the suggestion off and moves on with his list. The second is "asking for money". He goes on to explain that males that gender bend "know" that female players often get special favors. Thus, when they are adamant about monetary compensation, they are very likely an incognito male. Reveange's last point was "asking for help too much". Here he seems to side with Janx's ideal of the long-time "respectable" female player. A female player wishing to be "one of the guys" would never ask for help all the time. For Reveange, this is another male assumption taken to extremes when gender bending. 
Findings

Gender bending in male players is so wide-spread that the reasons for doing so largely cited as "special favors" - has become a popular ideal, so much that the above conversations seems to suggest that there might be "rules” for finding out about deception. It also demonstrates that male players choose female avatars based on what they expect will be favorable reactions from other male players. Additionally, this is evidence of players using the physical attributes of their avatars to their advantage.

Guild Chat: How to be Offensive in 10 Chat Lines

Trade Chat is not the only place privy to gender driven content or stereotypes. Guild Chats will very often suffer from the same kinds of discriminatory remarks, oftentimes more offensive. Take this excerpt from one of the guilds previously mentioned in this discussion. Freerunner decides to open up the conversation about weight. It is fairly well recognized that the stereotypical gamer is overweight, under- or un-employed and living with his parents. Additionally, the nature of Western culture and the standard of beauty in our society equates being overweight with not being desirable. Jean Kilbourne (1999) has done extensive research on the role of advertising and negative body image, and her pioneering work has launched studies the world over that investigate the damage this does to our society’s culture. As before, it is not simply proving you are female that is an issue, but to excuse the fact that you are female you must also be beautiful and desirable. The standard can sometimes affect male players as well. 
9/22 20:20:30.176 |Hchannel:GUILD|h[Guild]|h Freerunner: just weighed myself lol

9/22 20:20:40.474 |Hchannel:GUILD|h[Guild]|h Kaldris: I don't bother weighing myself.

9/22 20:20:43.889 |Hchannel:GUILD|h[Guild]|h Dryver: haha

9/22 20:20:48.415 |Hchannel:GUILD|h[Guild]|h Dryver: im like 130-140

9/22 20:20:48.946 |Hchannel:GUILD|h[Guild]|h Kaldris: I'll probably die in 10 years or so anyway.

9/22 20:20:54.676 |Hchannel:GUILD|h[Guild]|h Dryver: and im skinny as crap haha

9/22 20:21:05.339 |Hchannel:GUILD|h[Guild]|h Freerunner: lol i am chubby

9/22 20:21:11.351 |Hchannel:GUILD|h[Guild]|h Dryver: lol who cares haha

9/22 20:21:20.279 |Hchannel:GUILD|h[Guild]|h Kaldris: I'm fat.

9/22 20:21:29.697 |Hchannel:GUILD|h[Guild]|h Kaldris: I like to eat. I like to eat good food.

9/22 20:21:37.252 |Hchannel:GUILD|h[Guild]|h Freerunner: lol

9/22 20:21:43.230 |Hchannel:GUILD|h[Guild]|h Kaldris: Corndogs especially.

9/22 20:21:45.173 |Hchannel:GUILD|h[Guild]|h Dryver: well 
9/22 20:21:45.422 |Hchannel:GUILD|h[Guild]|h Kaldris: Right Rain?

9/22 20:21:52.134 |Hchannel:GUILD|h[Guild]|h Dryver: no offence but i like to fuck.

9/22 20:21:54.094 |Hchannel:GUILD|h[Guild]|h Freerunner: what you mean

9/22 20:21:55.026 |Hchannel:GUILD|h[Guild]|h Raïn: omg don't start

9/22 20:21:57.398 |Hchannel:GUILD|h[Guild]|h Dryver: lol

9/22 20:21:59.325 |Hchannel:GUILD|h[Guild]|h Kaldris: lol

9/22 20:22:11.367 |Hchannel:GUILD|h[Guild]|h Raïn: well

9/22 20:22:12.747 |Hchannel:GUILD|h[Guild]|h Dryver: thats how i stay skinny

9/22 20:22:13.013 |Hchannel:GUILD|h[Guild]|h Freerunner: lol 16 yr old sex addict

9/22 20:22:13.744 |Hchannel:GUILD|h[Guild]|h Kaldris: She gives me a hard time because I ate corn dogs for dinner one day.

9/22 20:22:26.317 |Hchannel:GUILD|h[Guild]|h Dryver: hey its not me its all of these girls

9/22 20:22:28.518 |Hchannel:GUILD|h[Guild]|h Kaldris: Something about they are unhealthy. 
9/22 20:22:37.034 |Hchannel:GUILD|h[Guild]|h Raïn: Well your eating habits are terrible

9/22 20:22:46.018 |Hchannel:GUILD|h[Guild]|h Kaldris: I know.

9/22 20:24:37.316 |Hchannel:GUILD|h[Guild]|h Dryver: lol yeah i should cool it with the sex, im getting too skinny for a 16 year old

\section{9/22 20:24:54.852 |Hchannel:GUILD|h[Guild]|h Dryver: ./flex}

In this brief snapshot, Dryver feels the need the exert his masculinity by not only confirming that he is slim, but also that it is a result of engaging in intercourse, at the tender age of 16 . Kaldris attempts to excuse his admittance of being fat by bring Raïn into the conversation. She is his real life partner and so she acts as a buffer for any ridicule Kaldris might encounter for being overweight. Again, the female in the situation is brought in as a sexual object, only this time to somehow excuse a perceived undesirability in her male counterpart. This is, indeed, the same Raïn mentioned above that is later "chased" out of the guild because she feels attacked in some way in regards to her skill.

Findings

The preceding discussion is an indication that sexuality is also important when it relates to masculinity. While the female is sexually exploited in some way, the point is not so much to objectify her as it is to prove the heterosexuality and sexual prowess of her partner. This is largely in keeping with what one would hold as traditional gender roles in physical society. 


\section{SURVEY RESULTS}

An on-line survey was prepared using Surveymonkey.com complete with a secure server and IP protection to prevent the same respondent responding more than once to the survey. The questionnaire included matrices, short-answer and multiple choice responses. The link was advertised on the official Worldofwarcraft.com gaming forum, MMO-Champion.com forums, a specialized forum for WoW players and raiders, and SomethingAwful.com forums. The link was also distributed to specialized Livejournal.com communities, particularly those communities devoted to WoW players and female WoW players. The goal was to catch primarily gamers who had been playing for a long time, in order to tap into the identity struggles of veteran female gamers in particular. The MMO-Champion forum was ideal in this respect because it catered to "serious" WoW players, those that play consistently, and enjoy the difficult end-game content, which requires dedication to game play. This forum was also the most enthusiastic in response to the survey. Several members asked to know more about the research and contacted me to be interviewed further should it be required.

It is important to highlight another limitation suffered by this survey, and perhaps shared by other surveys similar to this one. One respondent from Livejournal.com messaged me privately and asked why I did not include "transgender" as one of the gender options. This respondent seemed put-off by the fact that there was no third sex, just male and female, and added that such a choice would certainly yield some interesting results. I had to agree, but at the time I felt that the addition of a third sex when one is analyzing dichotomies would complicate an already complex study. Within the breadth 
of this dissertation, I was not prepared to handle the addition of "transgender", "transexual", or "third sex" to the survey results. However, that does not diminish the fact that I feel it is of high importance to take into account those that do not fit within the two-gendered model of Western society. In fact, the experiences of these players must be unique within a heteronormative virtual community like that of WoW players. When taking into account the implication for further studies, this observation certainly falls into that category. By way of a compromise I did add "other” to the gender listing. However, the few respondents that marked this category either did not finish the survey or gave responses that strongly suggested the individual was disingenuous. Thus, these issues will need to be explored by other scholars.

The survey's intended goal of attracting veteran WoW gamers seems to have been reached, as only $2 \%$ had played WoW for under 6 months and 3\% of respondents had played from 6 months to a year. The majority, $49 \%$ played from $1-4$ years and $46 \%$ had played WoW over 4 years.

Survey results were analyzed using simple cross-tabs to determine some general statistics and gaming demographics. However, there are many limitations to this survey, including the mode of distribution. Nick Yee's (2005) survey is far more complete in terms of player demographics for MMOs in general. This will be more relevant for an accurate analysis. That will be provided later in this investigation.

First, the preliminary results of my survey. There were more male respondents than female respondents 872:243. This is consistent with the percentages of female MMO players, which is about $16 \%$ (Yee, 2005). 
Female respondents seemed to prefer $\mathrm{PvE}$ (53.1\%) while male respondents seemed to prefer PVP (51.7\%) (See Tables 1 \& 2). This is consistent with player stereotypes about female players wishing to avoid conflicts. PvP is highly competitive and even while casually gaming, killing monsters, or simply walking around the different areas in the game, one could encounter a player from the opposing faction and be embroiled in a battle without having really sought one out. Male players will often comment on the inability of female players to PvP adequately. And, additionally, skill in player versus player battles lends a great deal of prestige to a player. A successful PvPer will sometimes gain as much notoriety within the community as a hardcore end-game raider. Both male and female respondents saw PvE as more important than PvP and both discounted RP as "not important” (See Tables 1, 2, \& 3). Again, this result may be because the forum that seemed to garner the most responses was catered towards endgame raiders. This obvious bias does not discredit the responses, but these results serve as support for the ethnographic portion of this investigation rather than as a stand-alone quantitative analysis. Further, it is the opinion of this researcher that it would be difficult to obtain a survey that adequately reflects all types of WoW players. These are sentiments echoed by Yee (2005) in his analysis of his own survey results. 
Please tell me what features of MMOs you consider most important. (by Gender)

Count

\begin{tabular}{|c|c|c|c|c|c|c|c|}
\hline & \multicolumn{5}{|c|}{$\mathrm{PVP}$} & \multirow[b]{2}{*}{ Total } \\
\hline & & Not Important & $\begin{array}{l}\text { Somewhat } \\
\text { Important }\end{array}$ & Important & Very Important & 4 & \\
\hline \multirow[t]{3}{*}{ Gender } & Female & 80 & 71 & 45 & 32 & 15 & 243 \\
\hline & Male & 125 & 247 & 232 & 236 & 14 & 854 \\
\hline & Other & 5 & 2 & 3 & 4 & 0 & 14 \\
\hline Total & & 210 & 320 & 280 & 272 & 29 & 1111 \\
\hline
\end{tabular}

Table 1 Features of MMOs - PvP

Please tell me what features of MMOs you consider most important. (by Gender)

Count

\begin{tabular}{|c|c|c|c|c|c|c|c|}
\hline & \multicolumn{5}{|c|}{ PvE } & \multirow[b]{2}{*}{ Total } \\
\hline & & Not Important & $\begin{array}{l}\text { Somewhat } \\
\text { Important }\end{array}$ & Important & Very Important & 4 & \\
\hline \multirow[t]{3}{*}{ Gender } & Female & 4 & 11 & 104 & 123 & 1 & 243 \\
\hline & Male & 5 & 53 & 311 & 481 & 3 & 853 \\
\hline & Other & 2 & 3 & 2 & 7 & 0 & 14 \\
\hline Total & & 11 & 67 & 417 & 611 & 4 & 1110 \\
\hline
\end{tabular}

Table 2 Features of MMOs - PvE 
Please tell me what features of MMOs you consider most important. (by Gender)

Count

\begin{tabular}{|c|c|c|c|c|c|c|c|}
\hline & \multicolumn{5}{|c|}{$\mathrm{RP}$} & \multirow[b]{2}{*}{ Total } \\
\hline & & Not Important & $\begin{array}{l}\text { Somewhat } \\
\text { Important }\end{array}$ & Important & Very Important & 4 & \\
\hline \multirow[t]{3}{*}{ Gender } & Female & 113 & 62 & 32 & 13 & 23 & 243 \\
\hline & Male & 453 & 261 & 99 & 24 & 17 & 854 \\
\hline & Other & 3 & 2 & 4 & 4 & 1 & 14 \\
\hline Total & & 569 & 325 & 135 & 41 & 41 & 1111 \\
\hline
\end{tabular}

Table 3 Features of MMOs - RP

However, contrary to stereotypes from both gamers and gaming researchers, both male and female respondents seemed to favor customization of the avatar (See Table 4), userfriendly interfaces (See Table 5), co-operation (See Table 9), a friendly community (See Table 8), and advanced interaction with the gaming environment (See Tables 6 \& 7). Taken individually, these preferences have often been gendered in traditional virtual gaming research. However, this survey shows that both genders essentially value the same things. 
Please tell me what features of MMOs you consider most important. (by Gender)

Count

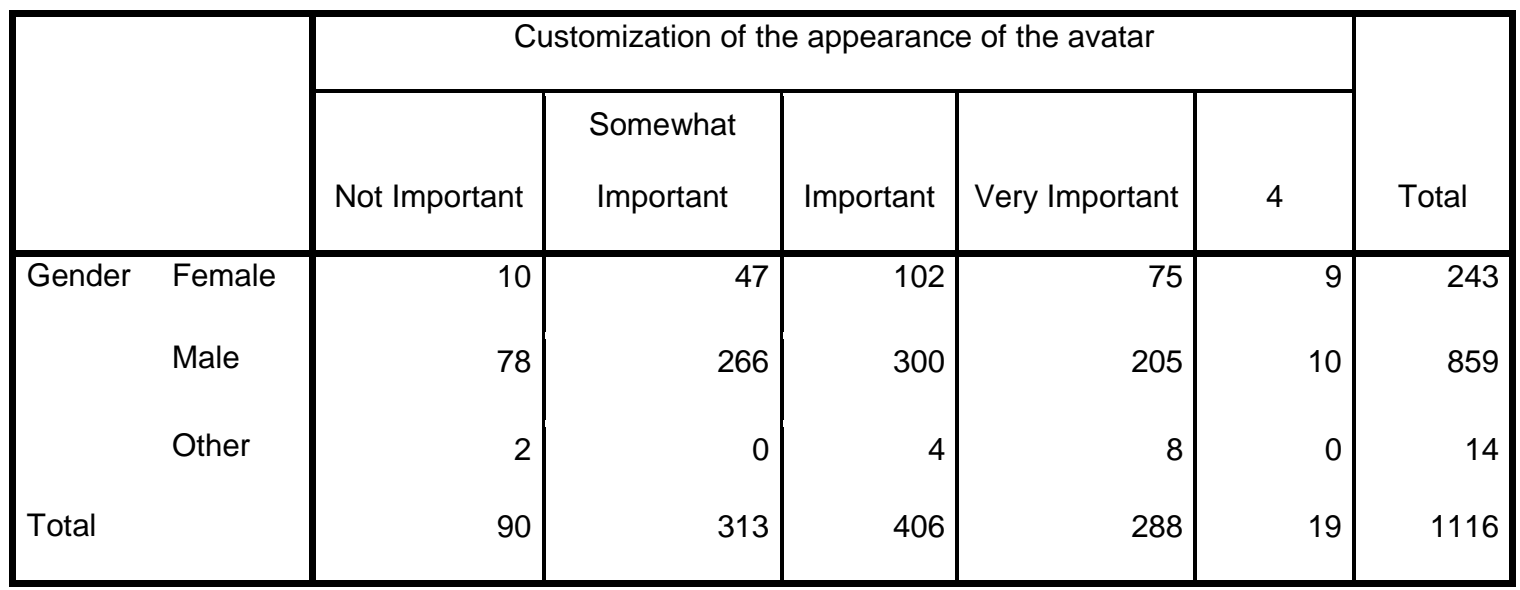

Table 4 Features of MMOs - Avatar Customization

Please tell me what features of MMOs you consider most important. (by Gender)

Count

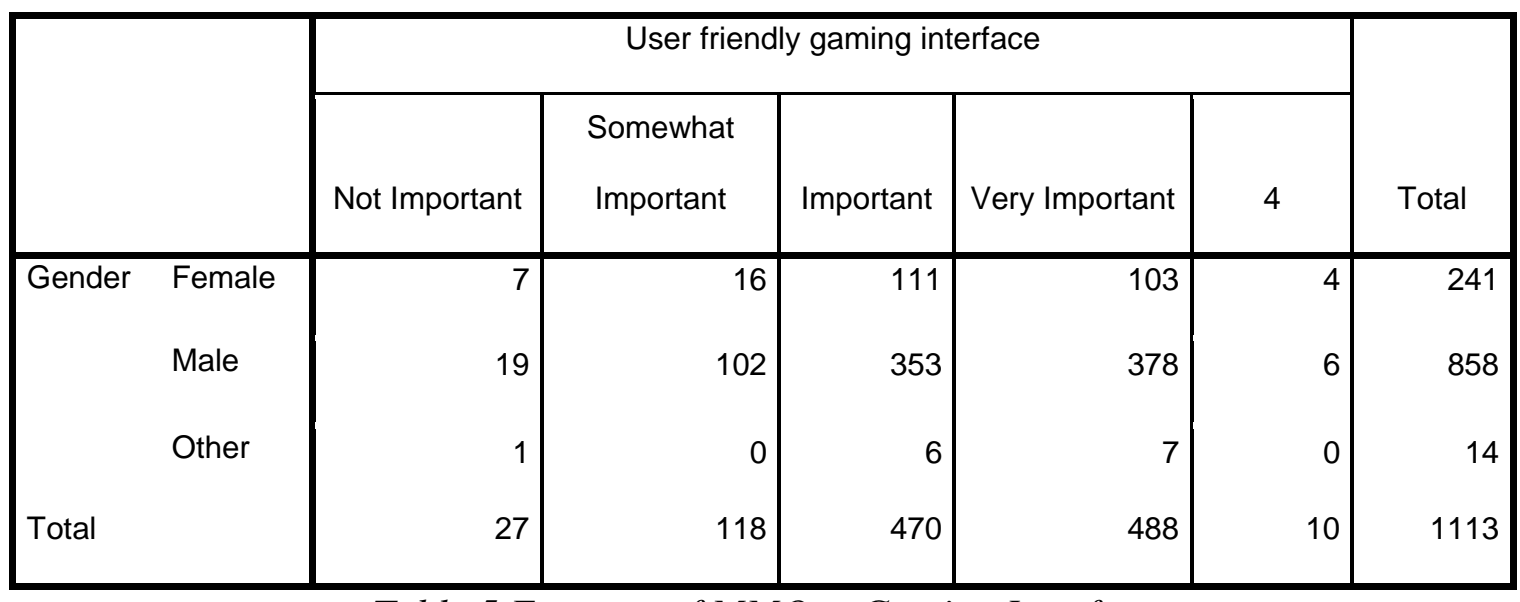

Table 5 Features of MMOs - Gaming Interface 
Please tell me what features of MMOs you consider most important. (by Gender)

Count

\begin{tabular}{|c|c|c|c|c|c|c|c|}
\hline & \multicolumn{5}{|c|}{ Advanced interaction with the game environment } & \multirow[b]{2}{*}{ Total } \\
\hline & & Not Important & $\begin{array}{l}\text { Somewhat } \\
\text { Important }\end{array}$ & Important & Very Important & 4 & \\
\hline Gender & Female & 3 & 24 & 122 & 87 & 7 & 243 \\
\hline & Male & 11 & 104 & 385 & 344 & 7 & 851 \\
\hline & Other & 1 & 0 & 8 & 5 & 0 & 14 \\
\hline Total & & 15 & 128 & 515 & 436 & 14 & 1108 \\
\hline
\end{tabular}

Table 6 Features of MMOs - Gaming Environment

Please tell me what features of MMOs you consider most important. (by Gender)

Count

\begin{tabular}{|c|c|c|c|c|c|c|c|}
\hline & \multicolumn{5}{|c|}{ Advancing stages of difficulty/challenge } & \multirow[b]{2}{*}{ Total } \\
\hline & & Not Important & $\begin{array}{l}\text { Somewhat } \\
\text { Important }\end{array}$ & Important & Very Important & 4 & \\
\hline \multirow[t]{3}{*}{ Gender } & Female & 5 & 12 & 106 & 112 & 8 & 243 \\
\hline & Male & 6 & 62 & 294 & 490 & 3 & 855 \\
\hline & Other & 3 & 0 & 5 & 5 & 1 & 14 \\
\hline Total & & 14 & 74 & 405 & 607 & 12 & 1112 \\
\hline
\end{tabular}

Table 7 Features of MMOs - Difficulty/Challenge of Game 
Please tell me what features of MMOs you consider most important. (by Gender)

Count

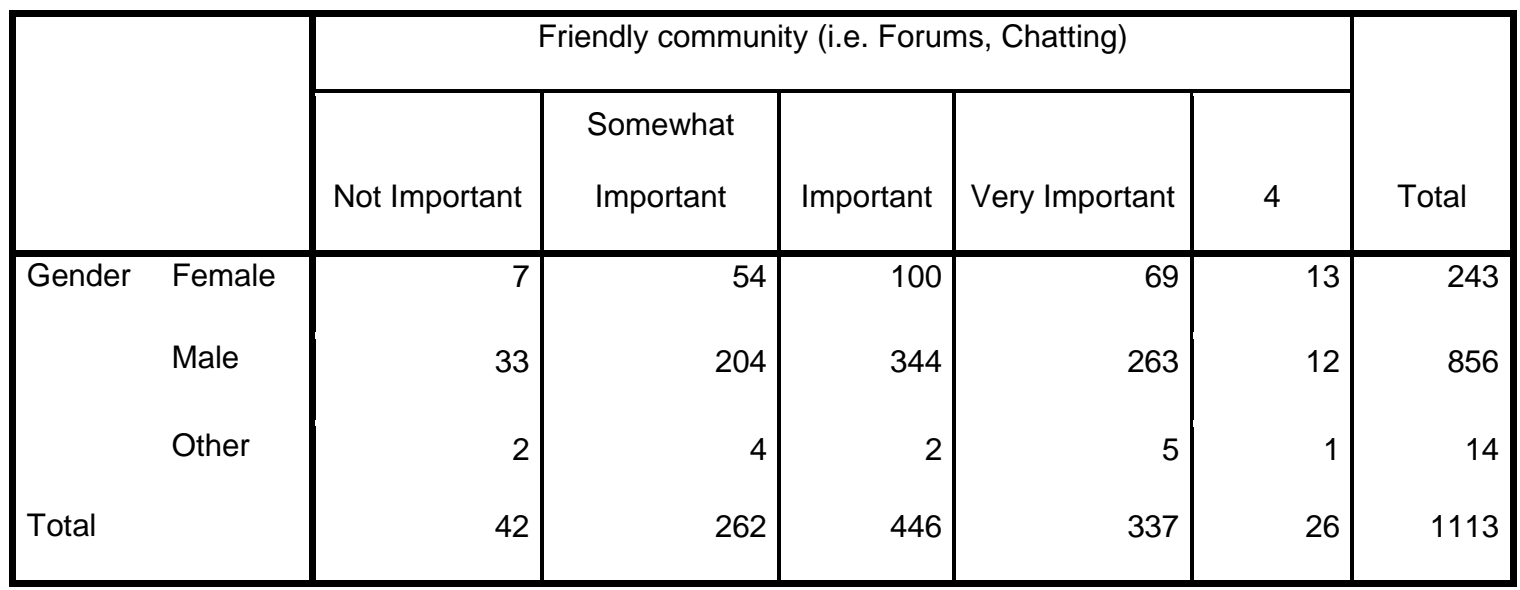

Table 8 Features of MMOs - Player Community

Please tell me what features of MMOs you consider most important. (by Gender)

Count

\begin{tabular}{|c|c|c|c|c|c|c|c|}
\hline & \multicolumn{5}{|c|}{ Co-op opportunities (i.e. Group Quests, Raids) } & \multirow[b]{2}{*}{ Total } \\
\hline & & Not Important & $\begin{array}{l}\text { Somewhat } \\
\text { Important }\end{array}$ & Important & Very Important & 4 & \\
\hline \multirow[t]{3}{*}{ Gender } & Female & 11 & 38 & 93 & 89 & 11 & 242 \\
\hline & Male & 24 & 94 & 313 & 418 & 5 & 854 \\
\hline & Other & 5 & 2 & 2 & 5 & 0 & 14 \\
\hline Total & & 40 & 134 & 408 & 512 & 16 & 1110 \\
\hline
\end{tabular}

Table 9 Features of MMOs - Player Co-operation

In keeping with the idea that veteran players preferred the Horde, both male and female respondents seemed to prefer Horde (See Table 10). However, the majority for female players is so slight, that it does not lend much credibility to the idea that veteran female gamers are compelled to stick to the Horde side given the community of respondents. In truth, the numbers were pretty evenly split, which does suggest that 
faction biases are part of the myths players perpetuate in their own understanding of their gamer culture.

Favorite Faction (by Gender)

\begin{tabular}{|c|c|c|c|c|c|}
\hline & & \multicolumn{3}{|c|}{ Favorite Faction } & \multirow[b]{2}{*}{ Total } \\
\hline & & Horde & Alliance & Both & \\
\hline \multirow[t]{3}{*}{ Gender } & Female & 57 & 49 & 17 & 123 \\
\hline & Male & 376 & 272 & 102 & 750 \\
\hline & Other & 5 & 3 & 0 & 8 \\
\hline Total & & 438 & 324 & 119 & 881 \\
\hline
\end{tabular}

Table 10 Favorite Player Faction

Both male and female respondents seemed to prefer ranged dps, although a close second for male respondents was melee dps and a close second for females was healer classes (See Table 11). The latter is in keeping with the stereotype of female gamers preferring healing classes, thus, may have some grain of truth. It may also be a part of this self-fulfilling prophecy that researchers like Yee (2005) keep referencing. However, the WoW-specific stereotype that ranged dps is "more fun" is also exhibited, and again harkens back to the suggestion that male and female gamers are not so dissimilar. 
Favorite Class (by Gender)

Count

\begin{tabular}{|c|c|c|c|c|c|c|}
\hline & \multicolumn{4}{|c|}{ Favorite Class } & \multirow[b]{2}{*}{ Total } \\
\hline & & healer & melee & tank & ranged dps & \\
\hline \multirow[t]{3}{*}{ Gender } & Female & 78 & 41 & 21 & 94 & 234 \\
\hline & Male & 175 & 233 & 140 & 268 & 816 \\
\hline & Other & 3 & 2 & 0 & 7 & 12 \\
\hline Total & & 256 & 276 & 161 & 369 & 1062 \\
\hline
\end{tabular}

Table 11 Favorite Player Class

Some of the questions I asked in the survey were an attempt to gauge perceptions based on the visible gender of the avatar. As far as class specific avatar choice, both responded that the best healer they knew was a female avatar (See Table 12) and the best melee they knew was a male avatar (See Table 13). For melee, the majority was quite large given the sample. While this may not seem important, it does speak to the stereotypes players hold. Whether or not the healer's player is female, the healer avatars are played as females. This is important when we look at the power of discourse and the value of language in our culture. If we perpetuate the stereotype by something as simple as avatar choice, it affects the way we view our world. 
Is the best healer you know a male or a female avatar?

(by Gender)

Count

\begin{tabular}{|c|c|c|c|c|}
\hline & \multicolumn{2}{|c|}{ Best Healer } & \multirow[b]{2}{*}{ Total } \\
\hline & & Female & male & \\
\hline \multirow[t]{3}{*}{ Gender } & Female & 145 & 87 & 232 \\
\hline & Male & 413 & 397 & 810 \\
\hline & Other & 8 & 5 & 13 \\
\hline Total & & 566 & 489 & 1055 \\
\hline
\end{tabular}

Table 12 Best In-Game Healer

Is the best melee you know a male or a female avatar?

Count

\begin{tabular}{|lc|r|r|r|}
\hline & & \multicolumn{2}{|c|}{ Best Melee } & \multirow{2}{*}{ Total } \\
\cline { 3 - 4 } & & \multicolumn{1}{|c|}{ Female } & \multicolumn{1}{c|}{ male } & \multirow{2}{*}{ Tom1 } \\
\hline Gender & Female & 59 & 172 & \\
& Male & 133 & 677 & 810 \\
& Other & 7 & 6 & 13 \\
Total & & 199 & 855 & 1054 \\
\hline
\end{tabular}

Table 13 Best In-Game Melee

It was a little surprising to note that both male and female respondents felt they grouped with female players often (See Table 14), particularly since they both felt like there were less female players (See Table 17) and that most of the players they encountered were male (See Table 16). Perhaps this is because most of the respondents had been playing for such a long time and were largely part of weekly raiding guilds, which very often include at least one or two females in the group. 
How often do you group with players who are female? (by Gender)

Count

\begin{tabular}{|c|c|c|c|c|c|c|}
\hline & \multicolumn{4}{|c|}{ How often? } & \multirow[b]{2}{*}{ Total } \\
\hline & & Never & Seldom & Often & always & \\
\hline \multirow[t]{3}{*}{ Gender } & Female & 2 & 67 & 138 & 23 & 230 \\
\hline & Male & 6 & 248 & 477 & 75 & 806 \\
\hline & Other & 2 & 3 & 4 & 3 & 12 \\
\hline Total & & 10 & 318 & 619 & 101 & 1048 \\
\hline
\end{tabular}

Table 14 Grouping with Female Players

Both male and female respondents seemed to raid weekly (See Table 15). This adds more credibility to the idea that this survey was skewed towards veteran WoW players that preferred raiding over any other activity in the game, thus this bias must be recognized when analyzing these results.

Do you raid? (by Gender)

Count

\begin{tabular}{|c|c|c|c|c|c|c|}
\hline & \multicolumn{4}{|c|}{ Raid } & \multirow[b]{2}{*}{ Total } \\
\hline & & Never & Sometimes & Monthly & weekly & \\
\hline \multirow[t]{3}{*}{ Gender } & Female & 15 & 53 & 6 & 118 & 192 \\
\hline & Male & 21 & 154 & 18 & 466 & 659 \\
\hline & Other & 2 & 1 & 0 & 5 & 8 \\
\hline Total & & 38 & 208 & 24 & 589 & 859 \\
\hline
\end{tabular}

Table 15 Raiding

As noted above, male and female respondents generally assumed players to be male. Female players "somewhat agreed” with the statement (See Table 16), though they still assumed most players were male (See Table 17). This is to be expected given that most players are indeed male. Additionally, this is a statistic that continues to 
pervade Internet and virtual community research. This survey result illustrates that players are aware of the environment within which they play. They are aware of their realities and the statistics specific to their virtual community.

I assume most players to be male, whether or not the avatar is female. (by Gender)

Count

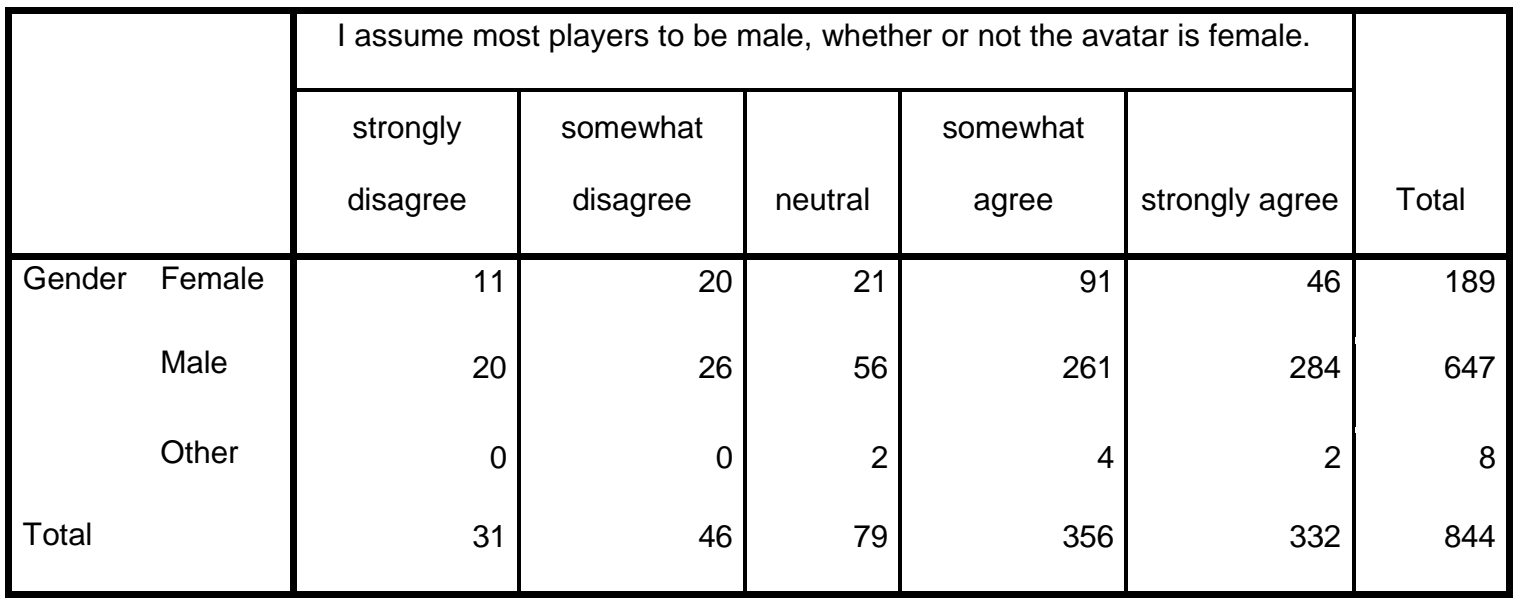

Table 16 Gender Assumptions - Avatar

I think there are more male WoW players than female WoW players. (by Gender)

Count

\begin{tabular}{|c|c|c|c|c|c|c|c|}
\hline & \multicolumn{5}{|c|}{ I think there are more male WoW players than female WoW players. } & \multirow[b]{2}{*}{ Total } \\
\hline & & $\begin{array}{l}\text { strongly } \\
\text { disagree }\end{array}$ & $\begin{array}{l}\text { somewhat } \\
\text { disagree }\end{array}$ & neutral & $\begin{array}{c}\text { somewhat } \\
\text { agree }\end{array}$ & strongly agree & \\
\hline Gender & Female & 1 & 7 & 8 & 49 & 124 & 189 \\
\hline & Male & 3 & 7 & 16 & 112 & 505 & 643 \\
\hline & Other & 1 & 0 & 0 & 0 & 7 & 8 \\
\hline Total & & 5 & 14 & 24 & 161 & 636 & 840 \\
\hline
\end{tabular}

Table 17 Gender Assumptions - Player

Male and female respondents agreed that other players had likely created avatars of the opposite sex (See Table 18). In terms of gender bending, if both felt this way, 
does this lend towards the assumption of rampant deception? And, to what degree is it deception? That is not something this survey covers, nor was it really a part of the initial train of thought that sparked this investigation. If one is permitted to lean towards the esoteric, how can avatar or character creation in a virtual world be subject to rules pertaining to how much the creation is comparable to the creator? If our judgments and perceptions of the vehicle - the avatar - are based only insofar as the vehicle resembles the driver, then is this really a virtual world or just a duplicate of the physical world? Again, these are not questions that can be easily answered, less so by a survey such as this, aimed at only figuring out player assumptions based on their preferences. In addition to agreeing that each other had created avatars of a different gender, both male and female respondents agreed that they had also created avatars of the opposite sex (See Table 19), although male players by an overwhelming amount (71.1\% to 46.8\%). This is in keeping with Yee's (2005) findings with respect to gender-bending in-game. It is interesting to note that during a face-to-face interview, when asked how she felt about gender-bending, one respondent replied that the term gender-bending was "going a little too far". She felt that creating an avatar of another sex did not count as gender-bending since it was not "like a real thing... it's pixels! Who cares?" Perhaps this is the ideal attitude to abolish our focus on dichotomies and on the true faces of the players behind the avatars. 
I think most players have created an avatar of the opposite sex. (by Gender)

Count

\begin{tabular}{|c|c|c|c|c|c|c|c|}
\hline & \multicolumn{5}{|c|}{ I think most players have created an avatar of the opposite sex. } & \multirow[b]{2}{*}{ Total } \\
\hline & & $\begin{array}{l}\text { strongly } \\
\text { disagree }\end{array}$ & $\begin{array}{l}\text { somewhat } \\
\text { disagree }\end{array}$ & neutral & $\begin{array}{c}\text { somewhat } \\
\text { agree }\end{array}$ & strongly agree & \\
\hline Gender & Female & 14 & 43 & 43 & 61 & 28 & 189 \\
\hline & Male & 49 & 115 & 115 & 194 & 172 & 645 \\
\hline & Other & 0 & 1 & 0 & 2 & 5 & 8 \\
\hline Total & & 63 & 159 & 158 & 257 & 205 & 842 \\
\hline
\end{tabular}

Table 18 Gender-Bending - Other Players

I have, at some point, created an avatar of the opposite sex. (by Gender)

Count

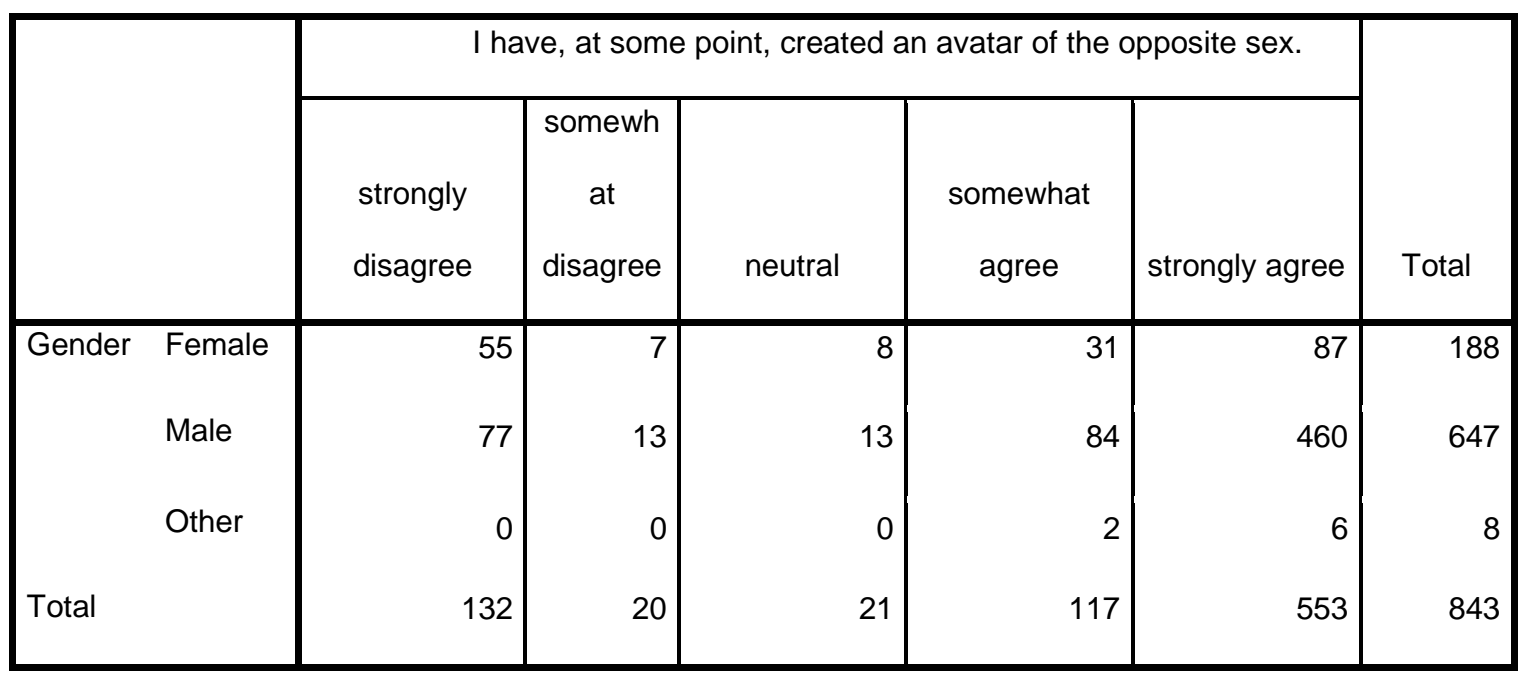

Table 19 Gender-Bending - Self

True to the stereotypes of aesthetics, both male and female players "somewhat agreed” that female players (See Table 20) and younger players (See Table 21) preferred more aesthetically pleasing avatars. Interestingly, both male and female respondents also "somewhat agreed" with creating aesthetically pleasing avatars for themselves (See

Table 22). This statistic might suggest that the aesthetics of the avatar make no 
difference in the perception of the player. Perhaps, it is only in the case of the Blood Elf that discriminatory ideas based on aesthetics are propagated because the Blood Elf (particularly the male Blood Elf) is a mockery of excessive vanity and the programmers have written the race as focusing on outer beauty.

I think female gamers prefer more aesthetically pleasing avatars. (by Gender) Count

\begin{tabular}{|c|c|c|c|c|c|c|c|}
\hline & \multicolumn{5}{|c|}{ I think female gamers prefer more aesthetically pleasing avatars. } & \multirow[b]{2}{*}{ Total } \\
\hline & & $\begin{array}{l}\text { strongly } \\
\text { disagree }\end{array}$ & $\begin{array}{l}\text { somewhat } \\
\text { disagree }\end{array}$ & neutral & $\begin{array}{c}\text { somewhat } \\
\text { agree }\end{array}$ & strongly agree & \\
\hline Gender & Female & 7 & 21 & 28 & 93 & 40 & 189 \\
\hline & Male & 10 & 41 & 181 & 272 & 137 & 641 \\
\hline & Other & 1 & 0 & 1 & 3 & 3 & 8 \\
\hline Total & & 18 & 62 & 210 & 368 & 180 & 838 \\
\hline
\end{tabular}

Table 20 Aesthetically Pleasing Avatars - Female Gamers

I think younger gamers prefer more aesthetically pleasing avatars. (by Gender)

Count

\begin{tabular}{|c|c|c|c|c|c|c|c|}
\hline & \multicolumn{5}{|c|}{ I think younger gamers prefer more aesthetically pleasing avatars. } & \multirow[b]{2}{*}{ Total } \\
\hline & & $\begin{array}{l}\text { strongly } \\
\text { disagree }\end{array}$ & $\begin{array}{l}\text { somewhat } \\
\text { disagree }\end{array}$ & neutral & $\begin{array}{c}\text { somewhat } \\
\text { agree }\end{array}$ & strongly agree & \\
\hline Gender & Female & 5 & 22 & 52 & 72 & 38 & 189 \\
\hline & Male & 17 & 70 & 174 & 240 & 143 & 644 \\
\hline & Other & 0 & 5 & 0 & 1 & 2 & 8 \\
\hline Total & & 22 & 97 & 226 & 313 & 183 & 841 \\
\hline
\end{tabular}

Table 21 Aesthetically Pleasing Avatars - Young Gamers 
I prefer creating more aesthetically pleasing avatars. (by Gender)

Count

\begin{tabular}{|c|c|c|c|c|c|c|c|}
\hline & \multicolumn{5}{|c|}{ I prefer creating more aesthetically pleasing avatars. } & \multirow[b]{2}{*}{ Total } \\
\hline & & $\begin{array}{l}\text { strongly } \\
\text { disagree }\end{array}$ & $\begin{array}{l}\text { somewhat } \\
\text { disagree }\end{array}$ & neutral & $\begin{array}{c}\text { somewhat } \\
\text { agree }\end{array}$ & strongly agree & \\
\hline Gender & Female & 5 & 12 & 27 & 69 & 74 & 187 \\
\hline & Male & 41 & 85 & 161 & 225 & 132 & 644 \\
\hline & Other & 0 & 2 & 0 & 3 & 3 & 8 \\
\hline Total & & 46 & 99 & 188 & 297 & 209 & 839 \\
\hline
\end{tabular}

Table 22 Aesthetically Pleasing Avatars - Self

Neither male nor female respondents judged the skill of the player based on avatar choice (See Table 23) nor the gender of the player based on avatar choice (See Table 24). Again, this might be typical of veteran players who are used to playing with several avatars on a regular basis. Judgments are not made based on avatar choice. Although judgments of avatar choice may come later as a result of interactions with players.

I judge the skill of other players based on their avatar choice. (by Gender)

Count

\begin{tabular}{|c|c|c|c|c|c|c|c|}
\hline & & \multicolumn{5}{|c|}{ I judge the skill of other players based on their avatar choice. } & \multirow[t]{2}{*}{ Total } \\
\hline & & $\begin{array}{l}\text { strongly } \\
\text { disagree }\end{array}$ & $\begin{array}{l}\text { somewhat } \\
\text { disagree }\end{array}$ & neutral & $\begin{array}{c}\text { somewhat } \\
\text { agree }\end{array}$ & strongly agree & \\
\hline Gender & Female & 127 & 38 & 11 & 8 & 3 & 187 \\
\hline & Male & 447 & 111 & 40 & 36 & 8 & 642 \\
\hline & Other & 3 & 0 & 0 & 2 & 2 & 7 \\
\hline Total & & 577 & 149 & 51 & 46 & 13 & 836 \\
\hline
\end{tabular}

Table 23 Judging Skill 
I judge the gender of other players based on their avatar choice. (by Gender)

Count

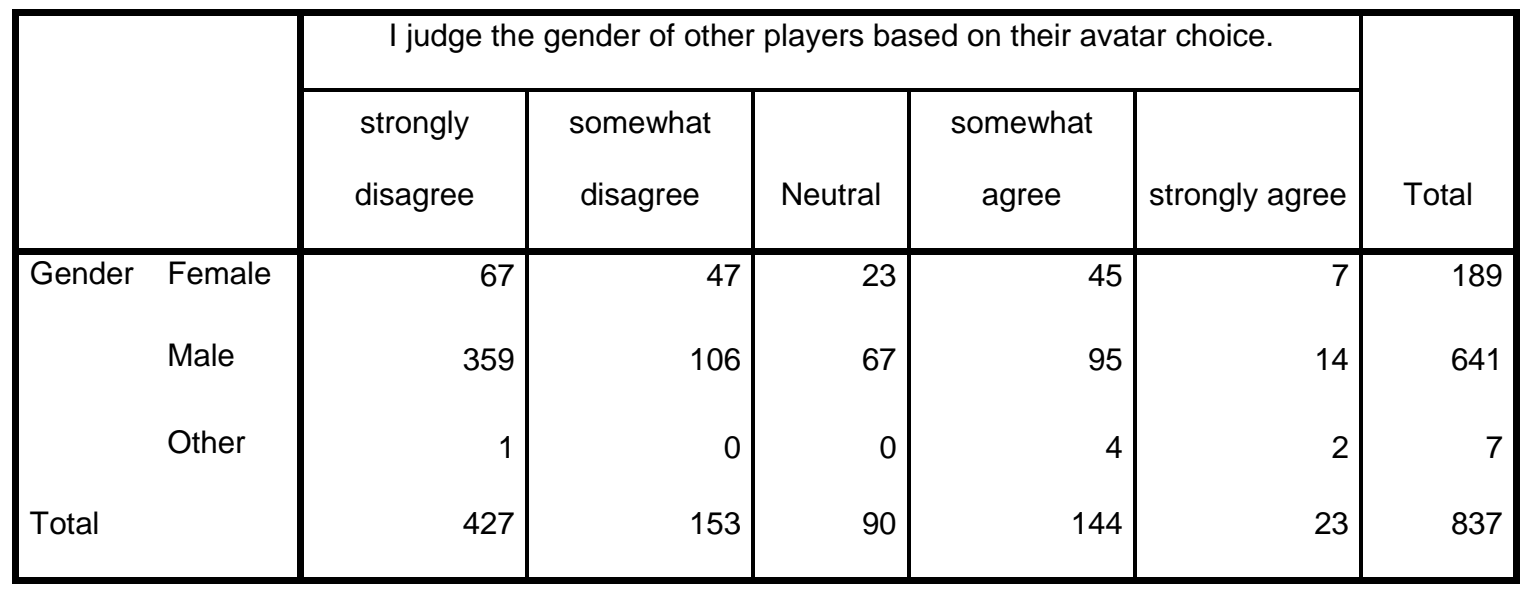

Table 24 Judging Gender

Male and female respondents "somewhat agreed" that female players tended to choose healing classes (See Table 25) and that female players tended to be more social (See Table 26). This finding is echoed in the literature, where even females perceive themselves to be more social than their male counterparts. Yee, Ducheaneaut and Nelson (2012) claim that female players were more prone to establishing friendships and longer lasting relationships in virtual communities. Although the statements in this survey may appear to be leading, they are important to discern both the perceptions of male players of female players and female players' self-perceptions. However, the responses were not overwhelming in terms of agreement, leading to no concrete conclusion. 
I think female players are more likely to choose healing classes. (by Gender)

Count

\begin{tabular}{|c|c|c|c|c|c|c|c|}
\hline & \multicolumn{5}{|c|}{ I think female players are more likely to choose healing classes. } & \multirow[b]{2}{*}{ Total } \\
\hline & & $\begin{array}{l}\text { strongly } \\
\text { disagree }\end{array}$ & $\begin{array}{l}\text { somewhat } \\
\text { disagree }\end{array}$ & neutral & $\begin{array}{c}\text { somewhat } \\
\text { agree }\end{array}$ & strongly agree & \\
\hline Gender & Female & 21 & 43 & 33 & 74 & 18 & 189 \\
\hline & Male & 34 & 76 & 123 & 311 & 98 & 642 \\
\hline & Other & 3 & 0 & 1 & 0 & 4 & 8 \\
\hline Total & & 58 & 119 & 157 & 385 & 120 & 839 \\
\hline
\end{tabular}

Table 25 Females Choosing Healing Classes

I think female players are more social. (by Gender)

Count

\begin{tabular}{|c|c|c|c|c|c|c|c|}
\hline & \multicolumn{5}{|c|}{ I think female players are more social. } & \multirow[b]{2}{*}{ Total } \\
\hline & & $\begin{array}{l}\text { strongly } \\
\text { disagree }\end{array}$ & $\begin{array}{l}\text { somewhat } \\
\text { disagree }\end{array}$ & neutral & $\begin{array}{c}\text { somewhat } \\
\text { agree }\end{array}$ & strongly agree & \\
\hline Gender & Female & 10 & 24 & 39 & 84 & 32 & 189 \\
\hline & Male & 22 & 59 & 143 & 288 & 130 & 642 \\
\hline & Other & 2 & 0 & 2 & 2 & 2 & 8 \\
\hline Total & & 34 & 83 & 184 & 374 & 164 & 839 \\
\hline
\end{tabular}

Table 26 Females and Socializing

Male respondents agreed that they were comfortable speaking in Vent and while female respondents also showed the majority in agreement, there was not a significant difference between "strongly agree" and "somewhat agree” (See Table 27). Again, these respondents mostly belong to guilds. Being active in a guild often requires a player to speak over Vent because of cooperative efforts at gameplay. Difficult raids, instances, or 
quests nearly always require coordination through chat, so those players with experience in a guild, would have to get used to speaking over Vent.

I am comfortable speaking on a voice chat system such as Ventrillo when participating in group activities in-game. (by Gender)

Count

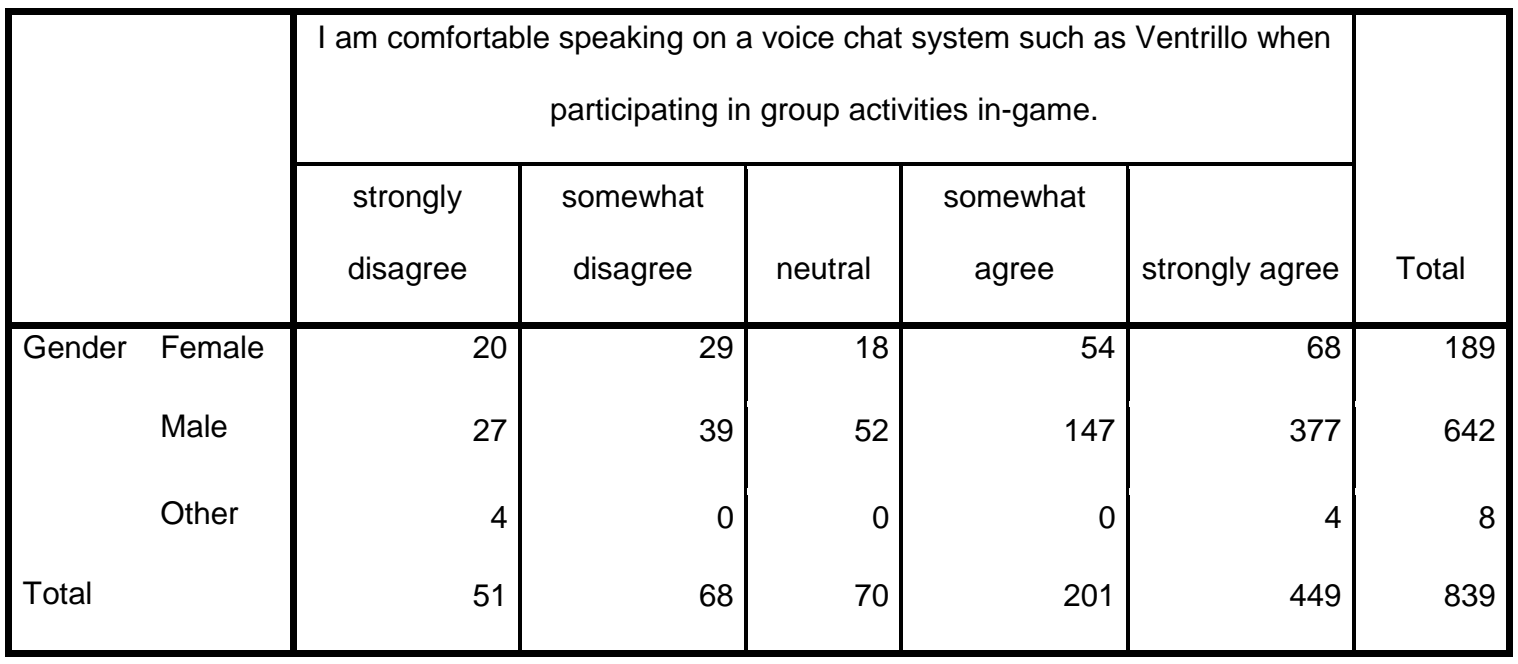

Table 27 Speaking in Ventrillo

Male respondents reported that they were not mistaken as being of the opposite sex. The numbers for the female respondents showed no significant response one way or the other (See Table 28). Again, this data might be affected by the fact that these players have been involved in the game for a long time and, thus, gotten to know the people they play with and their respective genders. The limitations of this survey are considerable, but still offer some valuable insight in that it seems to suggest that female players do often have a burden of proof placed upon them, whether or not they are willing to shoulder that burden. 
I am often mistaken by other players as being of the opposite sex. (by Gender)

Count

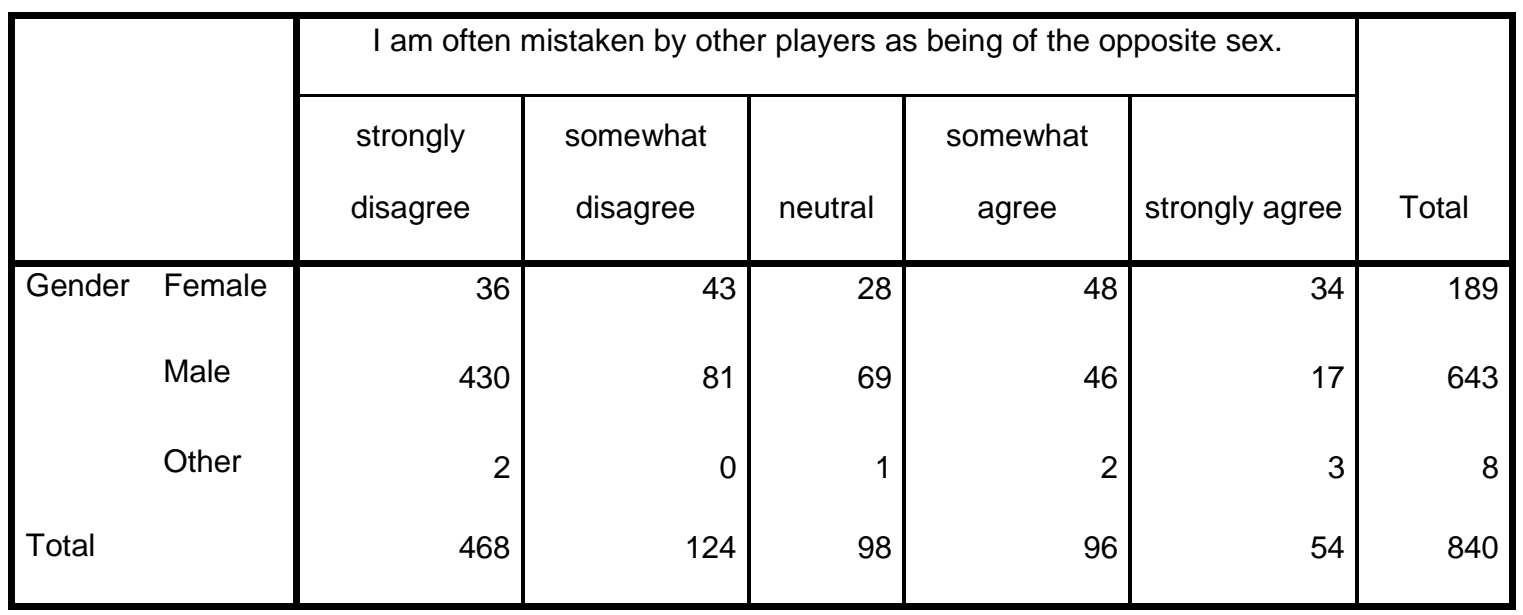

Table 28 Gender Identity

Some additional findings of interest include both male and female respondents

"somewhat agreed" that more popular MMOs tended to have more aggressive communities (See Table 29).

I think more popular MMOs have a more aggressive community. (by Gender)

Count

\begin{tabular}{|r|r|r|r|r|r|r|}
\hline \multirow{2}{*}{} & \multicolumn{6}{|c|}{ I think more popular MMOs have a more aggressive community. } \\
\cline { 2 - 7 } & strongly & somewhat & & somewhat & \\
& disagree & disagree & neutral & agree & strongly agree & Total \\
\hline Mender Female & 8 & 34 & 53 & 72 & 22 & 189 \\
Mole & 31 & 80 & 157 & 257 & 640 \\
\hline
\end{tabular}

Table 29 Aggressive MMO Communities

However, both male and female respondents also "somewhat agreed" that they were each comfortable asking questions on the WoW forums (See Table 30). 
I am comfortable asking questions in the WoW forums. (by Gender)

Count

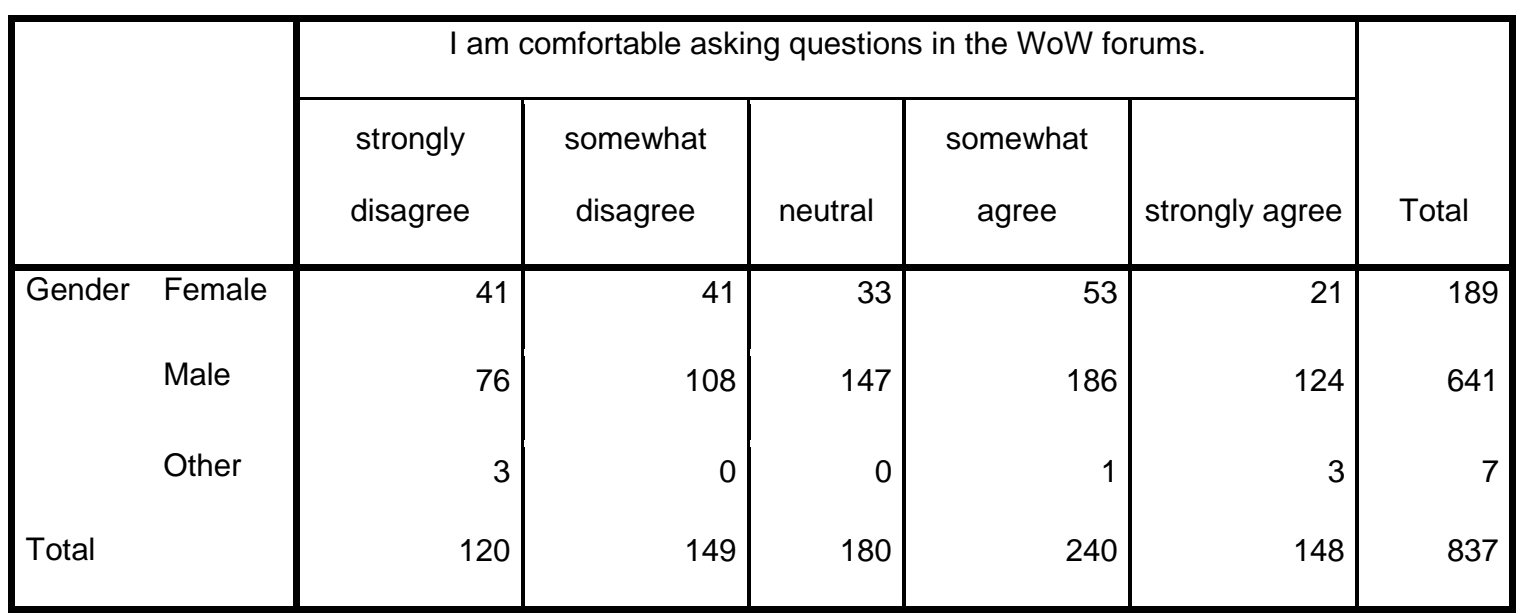

Table 30 The WoW Forums - Asking Questions

Another interesting side note is that male respondents "strongly agreed" they were comfortable revealing their genders on the WoW Forums, while female respondents' numbers seemed to suggest the majority were not comfortable (See Table 31). This may lend credibility to the initial idea that perceived bias may lead to a difference in communicative or behavioral habits of female players. 


\section{I am comfortable revealing my gender in the WoW forums. (by Gender)}

Count

\begin{tabular}{|c|c|c|c|c|c|c|c|}
\hline & \multicolumn{5}{|c|}{ I am comfortable revealing my gender in the WoW forums. } & \multirow[b]{2}{*}{ Total } \\
\hline & & $\begin{array}{l}\text { strongly } \\
\text { disagree }\end{array}$ & $\begin{array}{l}\text { somewhat } \\
\text { disagree }\end{array}$ & neutral & $\begin{array}{c}\text { somewhat } \\
\text { agree }\end{array}$ & strongly agree & \\
\hline Gender & Female & 52 & 35 & 37 & 37 & 28 & 189 \\
\hline & Male & 35 & 20 & 174 & 164 & 244 & 637 \\
\hline & Other & 4 & 0 & 0 & 3 & 1 & 8 \\
\hline Total & & 91 & 55 & 211 & 204 & 273 & 834 \\
\hline
\end{tabular}

Table 31 The WoW Forums - Revealing Gender

\section{Open-Ended Reponses}

The open ended responses from the main on-line survey for this dissertation research were very telling in terms of how respondents saw female and male players. They will be presented here with graphics and quotations. This survey reached over 800 respondents and the following are a few of their quotes when asked who they preferred to stay away from when gaming. Of note were many of the characteristics related to female players (See Figure 4). Even some female respondents were adamant about their reluctance to play with other females, emphasizing a marked hostility. 


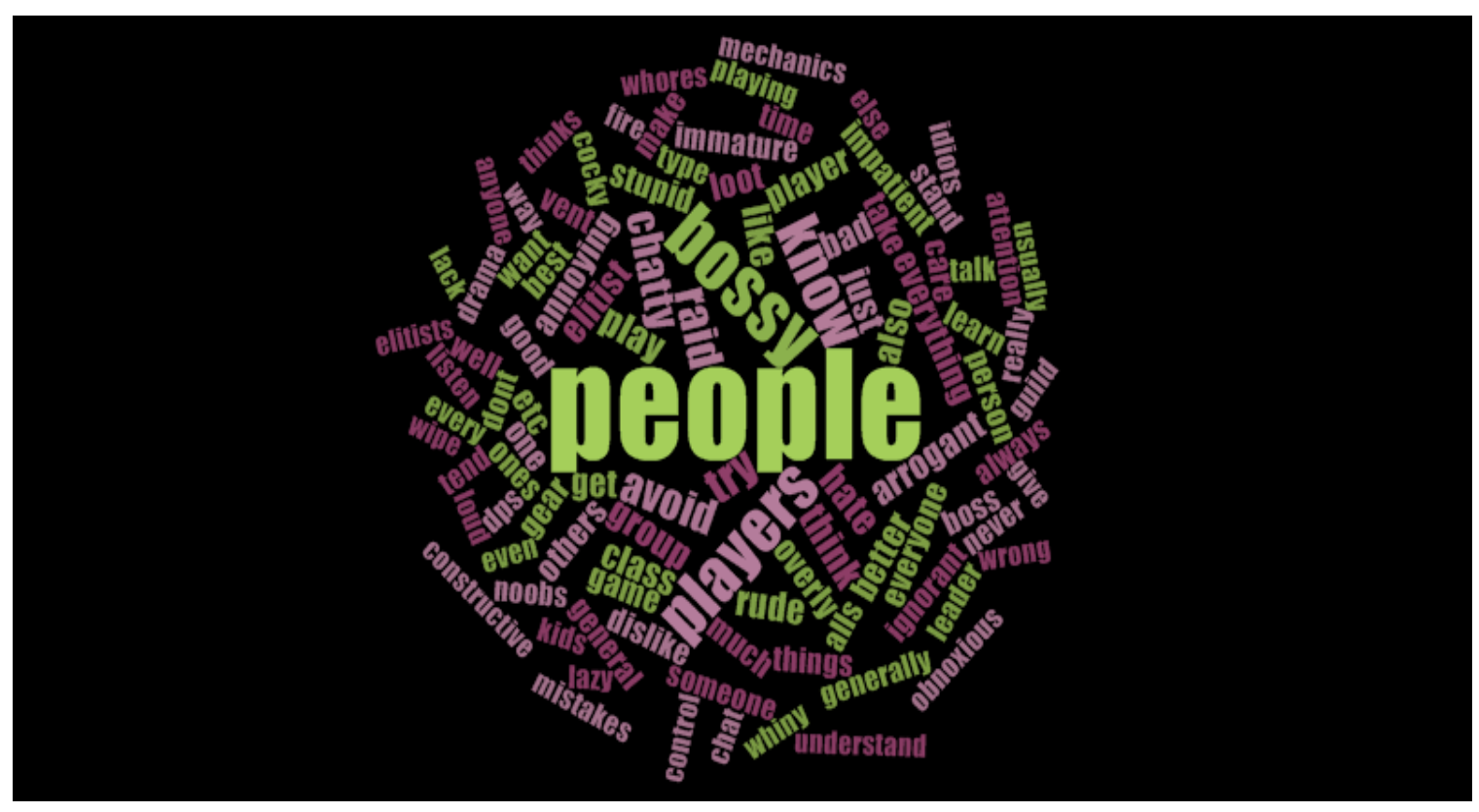

Figure 4 Characteristics associated with gamers that are negative. Image rendered by NVivo Software.

Some comments took issue with those who would use Vent or the game to exploit other players sexually:

“obnoxious, mean, people who hit on you and won't stop” [f, 35]

"12 year olds that hit on girls in vent are creepy and girls who flirt so much as to be slutty cause too much drama and tension” [m, 29]

“People who do not shut up on vent - I simply do not care about the random details of their lives. Also people looking to shift blame elsewhere constantly, or those who link meters to epeen - I see raiding as a full team effort.” [f, 30] 
The aggression towards the female player was palpable from both genders. Being a distraction, being a bitch, and being a bad player were all linked to femininity. Other female players made remarks that highlight the sentiment that any female player that does not make an effort to downplay femininity might have to deal with stereotypes such as these:

"shallow, whiney, people who are there to be carried through content, girls with a princess complex who think they need a big, strong man to save them and carry them and save them.” [f, 25]

“The bitch female [guild] officer who is a total bitch to everyone.” [m, 18]

"Bossy females who take advantage of being female and they usually suck too. Also hate people who are older (28+) who acts like dipshits and think they are better than everyone.” [m, 18]

“This may sound 'wrong', but I don't really enjoy playing with other women. In my opinion, most of them are bad at the game (facerollers who don't read up on encounters or their class). I find them to be whiny, often bossy and a lot of them think it matters that they're a woman that plays an MMO.” [f, 24]

“Girls who make sure you absolutely know they are girls. The ones that laugh or comment constantly so everyone can hear that they are girls, in order to get favorable 
treatment. It ruins it for those of us who succeed because we are good and work hard.” [f, 22]

"Females and teenagers. They're typically annoying in voice chat and bad. Especially the females.” [m, 25]

"Any female player who does nothing but flirt in vent and distract the raiders." [m, 20]

Male players were not exempt from their own judgements of character, as evidenced by these quotes:

"Young boys who feel the need to publicly comment about how much everyone sucks." [f, 27]

"I don't like 'princesses'. Males and females who think that they can get by on their flirtation skills instead of their gaming skills.” [f, ? ]

"I prefer not to play with younger males to be honest]. They always think they are the best, and that they know everything. They often become rude, and don't take into consideration that people play this game to have fun.” [m, 27]

The following are quotes that respondents associated with gamers that they liked to play with most often. Generally, people agreed on the characteristics they liked best, and the 
responses were essentially favorable, with some players detailing personal experienced with good player. However, words like "demand”, “command”, and "respect” were often mentioned, words that typically imply dominance (See Figure 5).

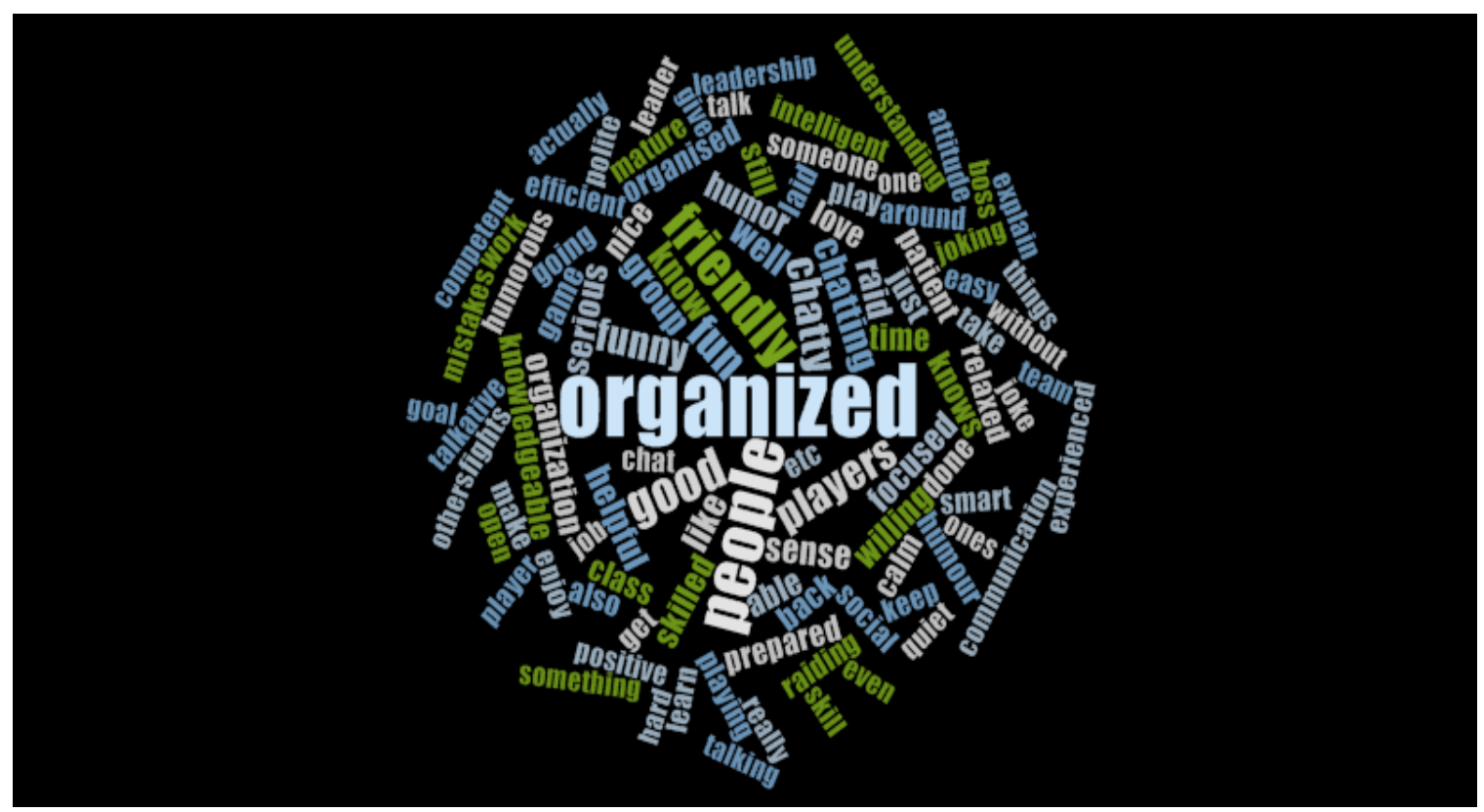

Figure 5 Characteristics associated with gamers that are positive. Image rendered by NVivo Software.

Players of both genders valued organization and cooperation as well as communication that was fun and fluid. There seemed to be no difference between the genders in terms of what they valued most.

“Cooperation and planning. Sexual innuendo going both ways.” [m, 27]

“The patient people who understands that everyone can make mistakes.” [m,18] 
"I love people who are nice. People that you can have a good conversation with.” [m,18]

“leadership, organization, humor” [f, 22]

"Chatting, I love the social aspect of the game, and since we do most content as a guild, the conversations do get very interesting since we know the boundaries of what we can and cannot say over Skype, and the cheeky ones often push the boundary and come up with quotes that can only be classified as legendary.” [m, 24]

"People who are supportive, have a good sense of humor, and are there to have a good time.” [m, 28]

Some male players did fall into the stereotypical view of the "professional player", where a player is concerned mostly with playing the game to succeed. These players typically interact with the game the way one might interact with software or co-workers at work. There are schedules and things must be done to precision. "Quiet, focused, willing to admit mistakes and wanting to improve themselves as a player, wanting to see the group succeed, willing to share loot drops, teamwork, being on time to a scheduled raid, encouraging to frustrated players, very skilled but never tells anyone but only shows it through their playing.” [m, 20]

"leading type that takes command" [m, 25] 
people that have a clue, they can be whatever they wanna be socially, I don't care, I'm here to play this game, if you're there for anything else, you're doing it wrong.” [m, 21]

This last quote was worth highlighting because I felt it really draws on what some of the female players have been expressing all along. They want to feel worthwhile and they want to feel like they belong. In the end, that is what it boiled down to, if one wanted to make this a simple as possible. The 'why' of belonging or, as it happened, not belonging, is the more complex principle to define.

"Diplomatic, considers any viewpoint, makes players feel worthwhile” [f, 28] 


\section{INTERVIEWS}

The research questions were explored in open-ended semi-structured interviews with six participants. I present them on a case-by-case basis to allow the reader to connect with the respondents that were part of this dissertation research. After presenting the relevant segments of the interviews, I will summarize their contribution to answering the research questions.

\section{From the Designer’s Perspective}

The first was a female lead designer for a popular game that I will not name in this dissertation in order to protect her identity. Her insight was important because, as a female player, many of the stereotypes associated with females are written into the code of the game. Revealing clothing, sexualized avatars, and objectification of the female form are common in all video games. She began by saying that, “[g]iving women positive role models through gaming is one of my biggest flags to wave, and I'm absolutely committed to it.”

This designer acknowledges that clothing for female avatars is sometimes revealing. It is a fine line to walk. The company wants to cater to male players that want revealing clothing on female avatars while not wanting their female fans to be offended by outfits they find - and this is her word - "skeezy”.

According to her, designers try to keep both men and women in mind, even taking into account what she called “female sensibilities” when designing game controls. The MMO designer goes on to describe why she thinks certain virtual worlds attract women more. 
Games like Second Life or Maple Story tend to attract more women than a combat-oriented game. I feel that has a lot to do with stereotyping and with ease of entry; nobody wants to play a game where they don't feel welcome.

At the beginning of her career she claimed she felt a little out of place at first. One of her male co-workers claimed it was like entering a "pirate’s clubhouse”. Many times at conventions, fans would express surprise that she was a female. This designer's name is androgynous, thus, she was often assumed to be male and she claimed to enjoy the look of shock on her male fan's faces when they discovered otherwise. This interview demonstrates that even those female designers that have made a name for themselves in the video gaming industry - largely dominated by men - also bring in biases and stereotypes that undermine the abilities of their female fan base.

\section{From the Gamer's Perspective}

“Trish” is a 28 year old Junior Systems Administrator and mother of four from Arizona. In Trish's interview, a feeling of self-consciousness emerged when she discussed playing with her husband. According to her, she cannot exert masculinity when in the same room with her playing partner. When asked why she stopped playing a tank - usually a role that requires a great deal of skill- she replied:

It was due to the fact I sucked. I enjoyed being a very important part of the team but my husband was constantly trying to tell me I was doing something wrong or telling me to do something different or trying to rearrange my abilities, it is why it wasn't fun anymore. 
She felt like she had to improve based on her husband's guidance and he felt like she was not good enough. This is an interesting dynamic. In this case, she gave up, but this adds to Yee's (2005) earlier discovery that females who play MMOs with their romantic partners sometimes find their abilities undermined. Trish was also asked about the types of avatars she chose to play and she replied,

Female. Always female. Usually humans. I found them more appealing and I enjoyed the starting levels the most... She was also a warrior tank for the longest time but ended up being a dps warrior.

The conversation progressed and I asked if there was any particular reason for choosing a tank or even a warrior.

Honestly? I saw warrior and I thought, 'Oh! Smash things in the face!' I had never played an MMO before so had no idea what I was getting myself into. I didn't even start using my abilities till I was level 10, to my husband's dismay. A tank? It just kinda snowballed into that and it's what the group of people needed. After tanking in raids I realized not only did I suck but I hated it and that's why I changed to fury.

It was when I asked why she hated it and why she believed she "sucked" that I got the response I started with in this narration, going on to say that her husband would continually suggest ways to improve her game-play, often by micro-managing the way she played. 
You have no idea how many times I have heard this stuff! Read this webpage. Do this. Change this spec. Don't click that button. Use this macro. Oh my God!

Trish seemed exasperated by her husband's attempts to guide her, though she masked it in amusement, laughing continually. During the interview, I could empathize because I heard the same kinds of comments from my partner at the time. It was almost as if he assumed some type of authority over how the game was "supposed" to be played which stood in stark contrast to the way I was playing. When I began playing in the same room with him, I remember distinctly his shocked horror when he found out that I was clicking the mouse button over my desired spell or attack rather than using the number keys - a markedly faster way to accomplish in-game attack sequences. Following his advice made me a faster and better player. However, I always harbored a resentment over the way he had ridiculed me when he found out about my, admittedly, slower style.

Trish was asked to define a gamer:

Knee Jerk reaction my mind goes to websites. Gamers University.com then D20

Girls. Then it goes to the local game store. And I think smelly dude with butt crack hanging out, socially awkward. Or goth chick. Frankly, I have learned that gamers come in all different shapes and sizes so after all my knee jerk reactions I think, different types of people young and old, and I don't just think console or PC gamer, or just Larp'er or board gamer. I think of all of it. Even casino games. My husband is the ultimate gamer he experiments with every different type of game out there so I have a wide variety of experiences to classify "gamer" and I have 
learned not to stereotype like and think like, 'girls don't game,' even though that's where my mind goes to first.

It is interesting to note that Trish does not wish to stereotype the gamer as predominantly male, but it is what she continues to refer to as her "knee jerk reaction". Additionally, despite her above issues with her husband's opinions of her gameplay, she still considers him as an authority on games. As with other interviewees, there is the pervasive assumption that a gamer is somehow socially secluded or unskilled at social situations. Even gamers tend to consider virtual environments anti-social when the evidence would suggest otherwise.

Trish was asked to elaborate on how she felt about female gamers specifically. Again, she reiterated, "Socially awkward usually defines about 95\% of them.” However, she felt the need to justify such a general statement:

I know many girl gamers and there are some who are very strong and confident and awesome. But most are really introverted, they lose poorly, and they are even worse winners. Frankly 9 out of 10 times, with the group of people I hang out with, I would rather play with the guys. However, I also know girls like me and some of the girls on d20 that are rad as hell, but that doesn't describe the majority.

Seemingly dissatisfied with the vast majority of female gamers she had encountered throughout her gaming career, Trish felt like she shared more in common with male gamers. This is a sentiment I found throughout my interviews with veteran female gamers and one that I find many of the female gamers that I keep in contact with 
still hold. Trish also sees herself as an exception to the rule, again something that seemed to be echoed by other female gamers that felt they had earned their place within, to borrow a term from our intrepid video game designer, the "pirate’s clubhouse".

When it came to male gamers, Trish had equally strong assumptions to make even though she admittedly preferred to play with males.

Ranging from super pompous ass hats to smelly, quiet wall flowers. But for the most part I find that a good majority of male gamers are fun to play with. They are level headed, they will explain whatever you need to know, and good God, if you are playing a new game, let the man explain it! Every woman that has ever tried explaining board game rules to me my brain melted out my head. They are good winners and decent losers -this is the majority [of men].

It sounded like Trish also held onto her perceptions of female players when it came to other types of games as well. I wanted her to elaborate on why she found female gamers so disagreeable and she obliged me with a personal anecdote.

The most memorable moment I had actually was when [my husband] taught me to play Othello. I didn't play a lot of board games up until that point. I mean, sure, I had played Monopoly or Life, but he taught me how to play Othello, then we started playing video games and then we acquired like 400 board games [in] the span of 7 years and have been playing ever since. He was really level-headed when we played Othello - probably because it's not complicated - and it was actually a lot of fun. 
The suggestion by the above excerpt is that her husband was level headed because the game was not complex and easy to explain, thus Trish understood it and was able to play effectively. This is not something I would have said to her in the interview directly, but it is heavily implied by her statements. And she also very adamantly believes that male gamers are better at explaining games than female gamers. This is a troubling statement for a feminist researcher because it implies that this female gamer believes other female gamers (in fact, the vast majority) to be somehow ill-equipped to understand the complexities of gaming and, therefore, cannot properly explain games - any games.

When asked what type of player she liked most independent of gender, she seemed to prefer what she deemed were more mature players and avoided those she felt were dramatic. These latter characteristics she largely associated with being female. In the following excerpt she talks about her own troubles handling authority within the game when she was the one wielding it and what she preferred.

My big thing was damage. When I found a Mage, my main was still my warrior only because she was max level. I don't level quickly, but it was all about blowing shit up. My demeanor was always one of comic or sarcastic asshole. Originally, I was all about helping people and moving up in my guild ranks and being a good little puppet. I actually managed to become guild master of a guild I was in. After that experience, I realized that I didn't want that kind of drama as it lead to issues outside of the game. The game was not a game anymore, it was a job. So, once that phase was over, I played an attractive female who was helpful, but wouldn't take shit. It was an extension of real life for me. I will help anyone 
provided they are being mature and polite. There may be some sarcasm and comedy along the way, but I would never be rude. However, I don't take shit and I have a 3 strike rule. You start drama 3 times and I am done. It's why I did a lot of guild hoping till we started our guild. People interacting together just create drama they can't help it, it happens. Back to blowing shit up? That was therapeutic. Being able to DPS something down in a split second was very gratifying.

Through her experiences with other players, she implied that she would give anyone a chance, but was always cautious. As previously discussed, this preoccupation with "drama" and everything that such a term entails was not something she particularly enjoyed dealing with and would take great pains to avoid. It looked as though playing was an escape for her and a way to channel negativity through, as she said, "blowing shit up”.

Trish was asked about assumptions she made about other players in general. She replied, "Unless I had heard them on Vent, I assumed they were male. If I had heard them on Vent and their attitude confirmed [they were female], like they were clueless and rude... but it was an assumption I made off the bat. I met two women that proved me wrong."

It is interesting to note that Trish introduced me to a joke I had not previously heard with respect to MMOs. She altered the acronym to mean, "Mostly men online role playing girls”. It was poignant and entirely relevant to the conversation. 
When asked what stereotypes she commonly heard with regards to female gamers; not necessarily ones she believed personally, simply what she'd heard others say or read or encountered in any way. She replied, "Stupid, tits equals loot, they role play all the time and are all tee-hee, [and that] they are available even if they tell you they are married.” The stereotype in regards to role playing was one I had not yet heard. However, it would fit with assumptions that female players were adverse to the strategies of MMOs and other such games. Role playing is more about writing, creativity, imagination and description. I could easily see how these would be considered feminine traits, given the breadth of even academic literature in terms of gender differences.

It was important to ask Trish what she thought about these stereotypes, whether she considered them to be true or not and to what extent she felt they accurately reflected the female gamer community,

I'd say they are stereotypes for a reason. You know we can get pissed and say 'don't stereotype us because we truly aren't those people', but a good majority of female WoW players are that way. Hell, I even know a man that role plays a woman that acts like that just to get what he wants from other dudes. He had one guy convinced he was a female and in a relationship until he got on Vent. The guy was never heard from again. This went on for like months!

These "perks" she alluded to when it comes to gender-bending male players is confirmed by the research (Yee, 2005). Trish seemed amused while she was recounting this particular anecdote, as if she thought this was something that was entirely common. 
She seems to be implying that the stereotypes of female WoW players are accurate enough that male players can successfully pretend to be a "real girl".

This led me to ask Trish how she felt about Vent, since it seemed an appropriate lead-in to how she felt about speaking herself and revealing her gender. I was surprised by the answer,

I actually like it... saves me from having to type out crap and it makes the game experience more personal because you can hear inflection and tone. You can get to know someone better by hearing their voice I think.

I then asked Trish if she'd ever been mistaken for a male, to which she quickly replied, "most of the time actually.” She elaborated with an experience she had in a guild she'd previously been part of when she started the game

We had a guild called Legio Gemina... I had been in [it] for probably about 2-3 weeks and told them repeatedly I was a woman and they knew who [my husband] was. When they brought up the TeamSpeak [similar to Venrillo] server I said hello, and I got, 'wow you really do have a vagina!'

Team Speak was the predecessor to Vent and is still sometimes used when a Vent server cannot be implemented. These are programs that allow the players to hear each other's voices and chat while playing the game. It was not surprising to find that even with the addition of a partner to validate her claim that she was indeed a "real girl", none of her guild mates seemed to believe it until she spoke. Trish went on to say, with some pride in her tone, that she believed it was the way she behaved, what she had mentioned 
earlier about being the "sarcastic asshole" seemed to successfully mask her gender and assimilate her, making her "one of the boys".

However, as Trish elaborates, there was a definite downside to her revelation that she was a female player. "After they found out I was a girl, one tried to stalk me coming out to Arizona even," she recalls with a frown. She goes on to explain that her stalker was persistent even after she insisted she was happily married. Eventually, she had to threaten him with pressing charges before he gave up. "He was embarrassed after the threat," she added, even though the incident had clearly unnerved her. This is one of the dark sides of female objectification and sexualization. Because male players are the majority in MMOs - a fact no one disputes- there seems to be a sense of entitlement that goes hand-in-hand with this majority. Therefore, it is not uncommon to hear from female gamers that most of their reluctance in terms of speaking on Vent and revealing their gender boils down to an aversion to being sexualized. Many female players, in passing, have often told me in an off-the-record fashion that they believed their male counterparts all harbored fantasies of sexual interest on the part of any female who would be playing a MMO.

Trish's interview is evidence of the perceived bias of other players affecting communicative and behavioral habits largely because she admits to taking on this persona of the "sarcastic asshole". She is proud to be mistaken for a male regardless of the avatar she chooses. And this is part of this push to shed femininity, to be accepted and being accepted means being as male as possible. Additionally, she also lends support to the 
idea that a male player will gender-bend in order to exploit gender-biased behavior from those male players that assume them to be female.

"Chloe" is a 28 year old single paralegal from New Jersey. Surprisingly, she seemed to have a very post-modern view of gender as it relates to gaming. Chloe admits she is not what one would consider a "stereotypical gamer", and goes on to describe the kinds of avatars she prefers to create.

I prefer avatars that have aspects of sex appeal, girly and are easy on the eyes. Even though an avatar is only in the virtual world, it is an extension of who I am. I do not want to lose attributes that I admire about myself through gaming.

Chloe is a strong, confident woman with a marked self-assurance, and one can easily see that she wants her virtual persona(s) to reflect that about her. She has no compunctions about making a "sexy" avatar because she feels that way about herself. For Chloe, the avatar is very much an extension of herself and her immersion in whatever virtual community she is part of becomes, for the moment, her reality.

Chloe also feels she has a very good sense of what goes on in virtual worlds and what the communities of many virtual spaces are like on the whole. She no longer considers herself a MMO-er, but is an avid player of all types of games including SL.

Gaming is stereotypically considered a man's world. Even when you see a female avatar, there is a high probability that it is a man behind the keys. Then, if you make an avatar that is too 'cute' other female gamers may see you as a novice. You are put down by your own gender, because they feel they need to stand out in 
a man's world. But that is ignorance speaking, which is common throughout most aspects of life. Gaming is no different.

While I was pleased to find so much consistency in the experiences of my survey and face to face respondents, the consistency brought to light a stark realization that these presumably shared views lead to the kind of inequality we find in the physical world, mimicked in the virtual. A bitter sweet feeling takes over when the respondents seem to confirm, quite independently of one another, what the data from various studies seems to suggest: female players are continually trying to prove themselves. Even those that choose to embrace their sexuality do so with the knowledge that the environment they are leaving their virtual footprints within is, as Chloe says, a "man's world”. Additionally, she sheds light on the fierceness of female players that choose not to flaunt their sexuality in-game and their subsequent rejection of those who would, highlighting the point that it is not only male players that carry gender biases, but female players are just as guilty of alienating and judging within their own gender.

When asked how she feels about gamers of the opposite sex, Chloe replied:

Since gaming is considered a male's world, it is the norm to see gamers of the opposite gender. In fact, it's expected. We are both there for the same reason, an outlet, but unfortunately females are considered a guest in the gaming world. Females are becoming a much more common thing, and if I can become a gamer anyone [emphasis mine] can. Men simply need to step to the side and welcome another thing females can do just as well as they do. 
Again, Chloe notes that she is not the stereotypical gamer and that she feels absolutely anyone can fall under the category. Additionally, her response is flavored with feminine empowerment and I get the sense that Chloe very strongly feels that female gamers will eventually be recognized as an integral and permanent part of the gaming community. In fact, she went on to say that, “[w]omen are always breaking molds, and this is just another hurdle they have learned to jump over and adapt to.” Even though her tone is optimistic, there is still some agreement that it is the female player that has to adapt to a world that has been fashioned and shaped by men.

Chloe also spoke to how she feels about gaming in general and how seriously she takes her pastime. This is important to note because of the arguments presented earlier that pertain to the immersive qualities of these virtual worlds, as well as, the judgements that female gamers face.

Some people feel that if a female makes an avatar that is too cute, that they are not a serious gamer. But I take gaming very seriously, with a determination to prove I can play just as well as the men.

Chloe's choices to shape her avatar to Western standard of beauty, to exploit sex appeal, also lend their own support to the hypotheses presented and to some of the research questions asked at the beginning of this study. Her interview indicates that she enjoys the attention for what she considers a well-made avatar. Much of her focus is on aesthetic in order to elicit reactions, thus she is using that perceived bias for her own enjoyment of whatever game she plays. And since she focuses so much on immersion, 
she wants to feel within the games she chooses to play the same way she might want to feel in her physical reality: desirable.

"Ruby" is a 23 year old Production Assistant from London. She responded in a similar fashion to Chloe, claiming that her avatars were, "typically... short, slim and what I deem 'attractive' purely because I do not wish for someone to see an avatar that is new and judge them.” In Ruby's case, similar to Chloe, she felt judged if she was not attractive in the virtual world. Inhabiting an aesthetically pleasing body somehow softened the judgment of being a new player. As with previous discussion of this fear of being a "noob", players will often go to great lengths to try an avoid that title and in Ruby's case that seemed more important than whether or not she was seen as a "real girl”.

This respondent’s experience was actually slightly atypical. Ruby was part of an organization of female gamers that knowingly exploited their femininity for monetary gain. It should be noted that during her time as part of this organization of female gamers, she was playing a very popular console game, Call of Duty, falling under the first-person shooter category, where a player is pitted against either other players or ingame enemies and has to shoot or fight his/her way through gaming areas.

In Call of Duty there are such things as 'clans'. These clans are a group of people, usually friends that can battle other clans. I used to belong to a clan named Ladies2Die4 (L2D4), which was started and grew to have management, funding, and even companies that sponsored them. In this clan, we barely played the game, rather used images of ourselves with products from the people who sponsored us. 
Usually using 'duck faces' and 'pouts' to make us seem more sexual. I ended up leaving the group. However, the success level and money has grown for them, all [because] they are females.

It is important to digress in order to elaborate upon Ruby's explanation. Recent social media trends have seen a backlash against what it seen as women trying to make seemingly mundane pictures more sexual on sites like Facebook and Instagram. The 'duck face' and the 'pout’ Ruby refers to are a plumping of lips in extreme close-ups of women's faces, often exhibited in what is popularly called the 'selfie', a picture taken of oneself for use on a social media website. Several Internet venues, including these social media outlets, are rife with male and female users alike claiming that such sexually suggestive photos are attempts by women to seem more desirable. Thus these types of photos have become the target for Internet humor and backlash, while simultaneously serving as sexually gratifying imagery for a select community of male gamers. This dichotomy is not surprising given that these images are associated with women.

In Ruby's case, she goes on to say that she would take the simplest of photos, add a few filters, make it "pretty" and earn money from something she saw as a simple image. It seemed to bewilder her how willing these men were to pay her for such imagery. When asked to elaborate on how she felt about these men, Ruby smiled and said, “amused, really. I am not the most pretty of people, but the fact I could sell a product due to the fact I gamed made me laugh.”

Ruby felt like this photo manipulation was silly. She made her images fit into a Western standard of beauty and male gamers were then willing to pay for the photos. 
Ruby claimed she finally had to leave the group because she never really had time to do all the promoting that went along with being a L2D4. Promotional material was not just limited to suggestive imagery, but voice chatting and Facebook campaigns. Ruby felt like she never had time to do any actual gaming or, more importantly, work towards her university degree. Thus, she gave up the lucrative group position to pursue her academic and leisurely interests. Nonetheless, it was fascinating to hear that voice chatting was also a cornerstone of the L2D4 promotional campaign. Even in an organized group like this, it is almost as if the novelty of femininity in the gaming world is itself alluring to the male gamer. Indeed, this stereotype of the male gamers' attraction to a female gamer and the sexualization of the female gamer that is the foundation for such organizations as L2D4.

Ruby was then asked to define a gamer, something that was more of a functional definition for her. "A gamer would be someone - typically male - who has at some point owned their own game system... knows the basic difference between an MMO, RPG or game.” Again, she adds that gamers are "typically male”, but the definition is a little more forgiving, allowing any who knows basic differences between games and has owned a system at some point within the label of gamer. When asked to elaborate on some of the stereotypes she associates with the label, she replied, "Geeky, unfortunately... to sit inside and play games all day. You're such a nerd.” Ruby falls in step with most general assumptions made about gamers being anti-social and prone to seclusion. The "nerd" connotation in this case is not so much about mental capacity as it is about the ability to successfully be part of physical society. 
Ruby is similar to Chloe in that her interview seems to reflect a female gamer using the perceived gender biases of other plays to her advantage. Thus, these notions of how their male counterparts will react to their femininity serve to make them accentuate those traits that other female players might want to downplay. One of my initial questions asked what the motivations were for those female players that upheld the status quo of avatar beauty, and my respondents' actions seem to suggest that this is a conscious decision to embrace sexuality.

Ruby defined a female gamer as, "they don't game... typically we pout, preen and talk about how we game.” For Ruby, it was more about communication for the stereotypical female gamer. Stereotypes suggested that female gamers were more prone to "whining" about how they played the game and pouting when they were unsuccessful. This harkens back to the idea that female gamers are dramatic, sparking “drama” and illtidings of an emotional sort for other gamers that simply want to play.

Ruby felt that male gamer stereotypes, conversely, fell towards, “obsessive, brash, and idiotic when it comes to most games.” Ruby elaborated that male gamers tended towards "really getting into" their games, taking it far more seriously than female gamers. Again, she thought it was important to mention that this is how other people feel about male gamers. When I asked her to elaborate on how she personally felt about gamers of the opposite sex, Ruby said they were "mostly easy to manipulate... I could convince a male to play a game a certain way - if strategy based- especially if I am on voice with them.” 
I asked Ruby why she thought it was so easy to manipulate a male player using her voice. She replied simply, “I’m a girl.” Perhaps Ruby’s experiences in L2D4 have colored her perceptions of male gamers on the whole. It can be argued that those she typically encountered with her work in this clan were setting out specifically to find female gamers with the intent to sexualize or fantasize about them. After such an experience, it would be easy to see the rest of the male gaming population as swayed by the simple sound of a female voice. Further, dissemination within gaming populations of such rampantly popular stereotypes can become a self-fulfilling prophecy, as has been previously suggested. In fact, the very act of labeling and the stereotypes that coincide with a particular label make it so that social actors will modify their own behavior to fit the socially accepted definition of the label. Therefore, these male gamers are as much victims of their own propagation of male gamer stereotypes as are their female counterparts.

"Nancy" is a 30 year old Communications Supervisor from Montana. Nancy's definition is more than a little aggressive, reflecting experiences that may be similar to Ruby's in that the male mindset is typically seen as being intrinsically linked to their sexual organs. In fact, most of Nancy's responses during the interview took on an aggressive tone when any suggestion of male gamer flirting was made. Several times, she vehemently asserted that she was married and, therefore, did not engage in any kind of flirtatious banter with other gamers. When pressed, she did admit to some unwanted advances from male gamers, adding, “it’s almost like they think the only reason you're there is to get hit on or to date them or something." 
When asked how she felt about going on Vent, she claimed she was indifferent because she was happily married and did not care what a male gamer might have to say about her revelation that she was female. She was reluctant to elaborate or give me any personal stories of experiences she might have had. When asked about her relationship with her husband when it came to playing WoW together, she would only say that it was one of the things they enjoyed most together and that she felt they were a perfectly complimentary team.

Nancy felt that she avoided most people in WoW, choosing only to play with those she had built closer relationships with along with her husband. "I like doing things myself, I'm stubborn,” she added when asked about why she made such decisions to avoid others players as much as possible. Nancy's interview had that overtone of aggression and her behavior demonstrated that she did not want to be insulted by anyone implying she needed help with her game play in any way. Perhaps this is why her dynamic with her husband is not one that appears to be dominated by his gameplay suggestions.

When asked about female gamers, she felt they were "antisocial, more often than not someone who has weight issues it seems... from those I've come in contact with.” However, she went on to defend a position of neutrality between genders:

They both weave a common thread. A want and need for adventure and fantasy. To indulge in what most find taboo or strange. Behind the mask of an avatar you can be anything or anyone, and the endless possibilities are exciting. 
What was most significant about this challenging interview was Nancy's belief that female gamers are socially challenged because of body image or self-esteem, citing her personal experiences when it comes to female gamers. While pressure to elaborate did not elicit much discussion, her beliefs do reflect this sense of inadequacy that some female gamers hold, even towards their own gender. Standards of beauty, particularly "weight issues”, become a large part of what is associated with the "nerd gamer" stereotype.

“Dorian” is a 29 year old male from New York. Dorian was the only interview I could get with a male player, and much of what he said was in keeping with the accepted stereotypes of male gamers' views of both themselves and the females that play around them. Dorian recounts a lengthy history with video games, "I've honestly been playing video games since I was a small boy. Back when my family bought me my very first Nintendo...” Dorian preferred RPG games, though he has played all types. When asked about WoW specifically, Dorian mentioned he had played the game from about 2006 2012.

Dorian expanded on a lengthy definition of a gamer that mirrored some of the other interviews. In fact, it seems that these trends of Facebook and cellphone app games have served to expand the "gamer" definition for many of my interviewees. His definition is as follows:

A gamer to me... That's something pretty broad now. Originally, I would've told you a gamer is someone who throws themselves into the games they play. Usually those who played only consoles and PCs, doing it generally as a long 
time hobby, but there are a lot of different gamer types in this day and age because of how easily accessible they are. You have mothers and house wives who can play games easily off of Facebook. You have those who play them almost religiously off of cellphones, like Candy Crush. Casual gamers, hardcore gamers and the like exist now. So, to me, a gamer is just a person who freely enjoys that medium, regardless of what device they use to experience it on. When asked about any particular characteristics he associated with gamers, Dorian said, "Those who once they get a hand on one that absorbs them, like a good book they can't just put it down. They tend to actually have the desire to learn more about the games they play.” In general Dorian's answers started off with marked similarities to the female respondents. It was when gender divisions came up that he really started to cater to what one might consider the "traditional" views of the MMO community, specifically the WoW community. I asked Dorian to think about characteristics in terms of gender and he replied with, "When I think of men, I think of more aggressive play styles. When I think of women, the first thing that comes to mind - and you can thank MMOs for this - is free stuff.”

When asked to elaborate, Dorian provided evidence for what was originally hypothesized in this investigation. Male players choosing to play a female avatar did so based on assumptions that they would receive specialized treatment from those players that assumed they were female. In fact, he adds that female players also take advantage of this - seemingly popular - video gaming expectation:

This is a well-known thing in the MMO community, but whenever there is a female character - regardless of if it's a female behind the character or not, and it 
goes double for if they really are female - in the game, the male players tend to have a habit of showering them with free things. Be it in-game currency, items, help via getting them through content. It takes the code of chivalry to a new level. We discussed the proliferation of this stereotype and Dorian added, "You don’t even know the half of it! You have some guys who purposely make female characters just to get free stuff. And it works!” He seemed amused that this stereotype was actually something tangible, something he felt he could see happening around him when he played. These statements also lend support to the idea that choosing to play a female avatar leads to a different experience than if one chose a male avatar.

I then asked him about playing styles of gamers and how he felt they differed based on gender. It was interesting to see Dorian considered men to have "aggressive" play styles, in keeping with the traditional roles of our modern Western society. It truly shows how deeply ingrained these concepts are even when we are presented with a virtual world in which to "perform". In fact, Dorian repeats his previous ideas about male gameplay versus female game play.

"Well, there are always exceptions - and this'll be far more stereotypical to how it is for everyone - but from my own experiences, male play styles always seem to lean to the more aggressive. While female play styles always feel a bit more careful. They tend to focus on trying to watch themselves so they don't mess up, while males tends to be more, balls-to-the-wall in regards to how they deal with situations in game.

Dorian then added that he truly felt that the popular statement "there are no girls on the Internet” was, to some degree, true. It was surprising that he actually admitted that 
this is how he felt. I asked if class or anything else colored his judgment, or if he naturally assumed everyone was basically a male behind the avatar, to which he replied, “Guilty of being male, until proven innocently female. That pretty much sums it up.” I thought it distinctly telling that he would use the word "innocent" to describe a female. As if the act of being female in a game was always deceptive or malicious unless you really were one.

Even Dorian’s avatar choices seemed to coincide with his ideas of typical WoW players and the roles that they seem to fit within:

I think my favorite point was during the expansion, Wrath of the Lich King. I played both on Horde and Alliance side. I always preferred melee characters and tanks. Casters were never really my thing. I enjoyed the 'get up close and personal' game play of someone that was a hard hitter. So, I played a Death Knight...

Although Dorian played a Blood Elf, it was perhaps his admission that he was somehow a natural leader among his peers in-game that may have exempted him from ridicule when it came to avatar choice, leaving him free to choose as he liked, be they the new avatar choices or “classic”. However, it might be argued that his preference for melee and tanking characters is a reflection of this role he seems to embody, a male in a leadership position - one amongst many, playing within a man’s world, perpetuating hegemonic masculinity, assuming dominant positions. Essentially, this is a man performing his gender to what is arguably the pinnacle of masculinity, the role of the alpha male, within the confines of this virtual community. 
To this end, I asked Dorian if a female player had ever revealed herself on Vent and what his reaction was when presented with such a case.

"It happened with me and my friends whenever we'd hear a female behind a character on Vent... the responses went from, 'you're a lie. You can't exist. You must be using a voice mod,' to, 'holy shit, you're actually a female!'

Surprised, I alluded to his earlier comment about his perception that women just don't play this game, or at least, not enough to warrant the benefit of the doubt when someone does claim to be a woman. Therefore, I asked, when he'd clearly spoken to women on WoW, why his ideas persisted. He replied, "it was pretty much... part joke, part all of us knowing how many guys actually 'pretended' to be females, just to get more positive attention... as well as free stuff.”

It always seems to return to the principle of deception. The idea that it proliferates couched within the undeniable truth that male players do, in fact, outnumber female players. I decided to ask about female players that Dorian was, perhaps, exposed to on more than an occasional basis. Thus, our discussion turned to his guild.

Dorian's guild consisted of an average of 30 consistent members, with a female guild leader. He was asked how many of the guild members were female, to which he replied:

Not that many. Most females I know hate other females, anyway. So, [the guild leader] wasn't really the type to jump at the idea of inviting other females into her guild to begin with... I think there was about 3 others that I can remember that were female in that guild. 
This led to a discussion about “drama”, the concept familiar to many WoW players and typically associated with female players, particularly because of the idea that introducing the sex or sexuality of a female into a group of predominantly male participants will complicate the situation past simple play to "relationships" and "connections". It is still a little shocking how incredibly traditional and rigid the WoW community is with their idea of male players and female players. Dorian's take was more universal:

You can't have an online community and not have any drama. It's impossible. Hell, you can't have any legit community be it online or offline and not have drama. It's always bound to happen. What's funny is that's exactly how I got into that guild to begin with. I ran with one of their raids a long time ago by chance. [The guild leader] could be a bit of a hard ass when it came to dealing with people and I was on her Vent at the time, and I was the only guy who would talk back to her to put her in her place. Plus, [I was] doing the top dps in that raid and helping us down content at the same time doing it. That impressed her and she wanted me in her guild. Ever since then, I became sort of known for being her sense of logic once we became closer friends, because any time there was drama, I could always look past it to the bigger picture, and get the drama in check. [That's] why I became an officer so damn fast.

Dorian seems to imply that the guild leader, by virtue of being female, was prone to dramatics. Therefore, despite her notoriety as a "hard ass" when it came to raiding, she still had not cemented her place in the "pirate’s clubhouse" enough to earn her a "Get 
out of drama” free pass. In fact, all her being a "hard ass” warranted, according to Dorian, was the necessity to be "put in her place".

Based on evidence contained in this dissertation, one could argue that the guild leader was attempting to be "one of the boys" and having to overcompensate because she was in a leadership position, but could not escape her femininity completely. To Dorian, she was a female that simply needed a male counterpart to reign her in somehow. While it seems audacious on Dorian's part, it is part of his social upbringing and this is near inescapable even in virtual worlds... and, perhaps, especially, in virtual worlds, where the seeds of our internal norms can be sown and cemented into near perfect ideals. In the real world, it becomes harder to make up ideals, but when we are able to present idealized versions of ourselves hidden behind the mask of an avatar, what is to stop up from acting out a "perfected" version of masculinity, femininity, or even the heterosexual couple as a unit? The implications of such are slightly unnerving to this researcher. 


\section{DISCUSSION AND CONCLUSIONS}

Findings from this research showed varying ideas as it pertains to the avatar itself. In a few cases, there was evidence that the avatar appearance would elicit gender biased behavior from other players. Particularly, this was the major premise of gender bending. Male players gender bend in order to elicit special favors from other players, essentially objectifying their avatar's sexuality and exploiting it for personal gain. This finding suggests that female sexuality is just as easily exploited in a virtual setting as it is in the physical world, solidifying and perpetuation stereotypes that a woman only has value if she can somehow be visually or sexually appealing. It was not clear from the evidence gathered whether or not female players would choose to change the gender of their avatar in order to downplay femininity. Generally, even those veteran female players were not willing to modify avatars from what they considered aesthetically pleasing. In fact, some of the same women downplaying their femininity behaviorally, were just as comfortable with a sexualized avatar. If Yee and Bailenson's (2007) work is to be taken into consideration, part of the allure of playing a sexually appealing avatar might be because the player then feels more confident and appealing.

None of the interview respondents mentioned the clothing being something that

overly concerned them. In general, when it came to WoW, the avatar functioned as just that, a vehicle through which to play. Gendered interactions took place through communication and even deception was something that took place mainly through textual manipulation. 
One of the principles of this investigation was based on the notion that a perceived bias from other players affected communicative and behavioral habits of female players. Female players seemed to downplay femininity in order to fit into the mold and, indeed, those that did felt a unique sense of pride at having - in their eyes successfully managed to carve out their own niche as a WoW player. Oftentimes, these female players, that were typically veteran players, would not only downplay their own femininity, but ridicule those females that did not follow the same path. In fact, these players were more likely to ridicule other female players in general.

To answer the questions of how female players navigate a virtual patriarchy, there is evidence presented in this study that finds female players uphold the patriarchal status quo and navigate by trying to adopt masculine attitudes. Failing to do so may sometimes lead to feelings of inadequacy when playing. In real life settings, where couples play together, these feelings are sometimes expressed more keenly because one is not afforded the comfort of anonymity behind a computer screen.

As previously discussed, male players were shown to have engaged in gender bending because of a belief that playing a female avatar would lead to rewards or special treatment from other players. Through participant observation, it was discovered that some male players did associate a lack of skill with some female players as well as a distinct belief that female players often caused “drama”.

Final Thoughts and Implications

This dissertation was nearly a decade in the making. As my life took twists and turns that I could not have foreseen nor understood, I gained perspective and 
understanding that I value far more than anything material. What I achieved was the ability to know myself and the courage to recognize things about myself that I could never have known had I not taken this journey. I recognize that I identify as a female gamer. Such a realization might not have been as significant to me in the past, but now it takes on a whole new meaning. The female gamer gains a unique experience when in virtual worlds or the Internet. Female gamers are victimized as the very recent \#GamerGate controversy that saw game developer Zoe Quinn as the subject of misogynist attacks both on-line and personal. Female gamers are seen as inferior players as scores of research and surveys have shown, as popular culture continues to promote. Female gamers are sexualized and objectified. Women confront the Internet and find a very different place than their male counterparts, complete with revenge porn and death threats. This environment, while vast and unmapped, is hostile to women, lending a woman no place of refuge within its vastness. Rather, the burden falls on the female gamer to try and shed her femininity, while at the same time preserving it so that she is not too feminine and just feminine enough. The balance is impossible. The pressure is ridiculous.

These investigations have shown that female gamers are consistently aware of a gender-bias that pervades the culture within which they play and the very language they speak, affecting their behavior and their perceptions. This awareness comes with a price, not only affecting the way female gamers behave, but the way they see themselves. For many, it becomes a complex of inferiority linked to femininity. For others, it becomes a struggle to down-play or eradicate all feminine behavior. For so many of us, it becomes a 
festering and poisonous anger that we re-direct to other women and back on ourselves. Our male counterparts are just as victimized, learning through this culture of misogyny that they are entitled to superiority because they identify as male. They learn that women can be sexualized and objectified, that they must also be babied and guided like children. They learn that this is their world and that, at best, women are tolerated and, at worst, they are unwelcome.

And what was most striking about this journey, the nugget of information that I came away with that left me most surprised, was that these virtual worlds are no different than our physical realities. We victimize and undermine women in male-dominated spaces. We force them to change their behaviors, even their styles of dress, to fit into an appropriate mold in order to command power or respect. And even then, the female is in a constant struggle to maintain her tenuous hold on this power that has been bestowed on her. Even more surprising is that we are all responsible for this egregious disparity in gendered relations. That we continue to be responsible for sexism, for racism, for ageism, for victim-blaming, for all the varied emotional abuses human beings can dole out because we simply cannot let go of what is programmed and re-programmed into our consciousness by the society around us. It is the hope of this researcher that recognition of the problem will foster change, because true power is based in knowledge. 


\section{REFERENCES}

Aarseth, Espen

2003 Playing Research: Methodological Approaches to Game Analysis. Digital Arts \& Culture:1-7.

Andersson, Jens, and Anders Holmquist

2004 Real-Time Autonomous Crowds in Graphical Worlds. Lunds Tekniska Högskola.

Atkins, Barry 2006 What are we really Looking at?: The Future-Orientation of Video Game Play. Games and Culture 1(2):127-140.

Boellstorff, Tom 2006 A Ludicrous Discipline?: Ethnography and Game Studies. Games and Culture 1(1):29-35.

Bogost, Ian 2006 Comparative Video Game Criticism. Games and Culture:41-46.

Beasley, Chris 1999 What is Feminism?: An introduction to feminist theory. London: Sage Publications.

Bradley, Caroline, and A. Michael Froomkin 2004 Virtual Worlds, Real Worlds. 49(1):103-146.

Bruhn, John G. 2005 The Sociology of Community Connections. New York, NY: Springer.

Burke, Timothy 2004 the "Narrative-Nudge” Model for Massively-Multiplayer Online Games .

Burnett, Gary 2000 Information Exchange in Virtual Communities: A Typology. Information Research 5(4).

Butler, Judith 1999 Gender Trouble: Feminism and the subversion of identity. New York: Routledge.

Butler, Judith 
2004 Undoing Gender. New York: Routledge.

Cassell, Justine, and Jenkins Henry 2000 From Barbie to Mortal Kombat: Gender and Computer Games.MIT Press.

Castronova, Edward 2005 Synthetic Worlds: The Business and Culture of Online Games. Chicago and London: University of Chicago Press.

Castronova, Edward 2003 The Price of "Man” and "Woman”: A Hedonic Pricing Model of Avatar Attributes in a Synthetic World. CESifo Working Paper.

Castronova, Edward 2006 on the Research Value of Large Games Natural Experiments in Norrath and Camelot. Games and Culture 1(2):163-186.

Castronova, Edward 2002 On Virtual Economies. CESifo Working Paper.

Castronova, Edward 2001 Virtual Worlds: A First-Hand Account of Market and Society on the Cyberian Frontier. The Gruter Institute Working Papers on Law, Economics and Evolutionary Biology 2(1).

Cherny, Lynn, and Elizabeth Reba Weise, eds. 1996 Wired Women : Gender and New Realities in Cyberspace. Seattle, WA: Seal Press.

Chu, Kaitlan Chunhui 2004 Gender Reactions to Games for Learning among Fifth and Eighth Graders. Ph.D. dissertation, Michigan State University.

Combs, Nathan 2004 The Intelligence in the MMOG: From Scripts to Stories to Directional AI. Other Players.

Corneliussen, Hilde G. 2008 World of Warcraft as a Playground for Feminism. In Digital Culture, Play, and Identity: A World of Warcraft Reader. Cambridge, MA: MIT Press.

Darling-Wolf, F. 2004 Virtually Multicultural: Trans-Asian Identity and Gender in an International Fan Community of a Japanese Star. New Media \& Society 6(4):507-507-528. 
Delwiche, Aaron

2003 MMOs in the College Classroom. The State of Play: Law, Games and Virtual Worlds.

Dibbell, Julian

1998 My Tiny Life: Crime and Passion in a Virtual World. New York, NY: Henry Holt and Company.

Drexler, P.

2013. Are women mean or just stating the facts? $C N N$ Retrieved

from http://www.cnn.com/2013/11/22/opinion/drexler-womencompetition/index.html?hpt=hp_c3

Ducheneaut, Nicholas, Robert J. Moore, and Eric Nickell 2004 Designing for Sociability in Massively Multiplayer Games: An Examination of the "Third Places" of SWG. Other Players.

Ducheneaut, Nicholas, and Robert J. Moore 2004 Gaining More than Experience Points: Learning Social Behavior in Multiplayer Computer Games.

Elverdam, Christian, and Espen Aarseth 2007 Game Classification and Game Design: Construction through Critical Analysis. Games and Culture 2(1):3-22.

Eneman, Marie

2003 Dereth and its Inhabitants: A Study of Asheron's Call with a User-Centric Perspective. MSc Thesis in Interaction Design.

Etzioni, Amitai 2007 The Community Deficit. Journal of Common Market Studies 45(1).

Etzioni, Amitai 2005 Communal Considerations. The American Experiment Quarterly:16-16-17.

Etzioni, Amitai 2004 A Communitarian Position for Civil Unions. In Just Marriage. Mary Lyndon Shanley, ed. Pp. 63-63-66. Oxford University Press.

Etzioni, Amitai, ed.

1998 The Essential Communitarian Reader. Rowman \& Littlefield.

Etzioni, Amitai, and Mackenzie Baris 2005 A Communitarian Perspective on Sex and Sexuality . International Review of Sociology 15(2):215-215-241. 
Etzioni, Amitai, and Oren Etzioni

1999 Face-to-Face and Computer Mediated Communities, a Comparative Analysis. Information Society 15(4):241.

Friedman, Elisabeth Jay 2007 Lesbians in (Cyber)Space: The Politics of the Internet in Latin American onand Off-Line Communities. Media Culture \& Society 29(5):790.

Gans, Herbert J. 1962 The Urban Villagers: Group and Class in the Life of Italian-Americans. New York, NY: The Free Press of Glencoe.

Giddens, Anthony

1971 Capitalism and Modern Social Theory. Cambridge University Press.

Ginossar, Tamar 2008 Online Participation: A Content Analysis of Differences in Utilization of Two Online Cancer Communities by Men and Women, Patients and Family Members. Health Communication 23(1):1-1-12.

Grimes, Sara M. 2006 Online Multiplayer Games: A Virtual Space for Intellectual Property Debates? New Media \& Society 8(6):969-990.

Grimmelmann, James 2004 Virtual Worlds as Comparative Law. 49(1):147-184.

Gudelunas, D. 2005 Online Personal Ads: Community and Sex, Virtually. Journal of Homosexuality 49(1):1-1-33.

Gupta, Sumeet, and Hee-Woong Kim 2004 Virtual Community: Concept, Implications, and Future Research Directions.

Hartmann, T., and C. Klimmt 2006 Gender and Computer Games: Exploring Females' Dislikes. Journal of Computer-Mediated Communication 11(4).

Haverbeke, Marijn 2004 Internet-Based Social Contracts. Ph.D. dissertation, .

Hayes, Elisabeth 2005 Women and Video Gaming: Gendered Identities at Play. Games, Learning and Society Conference. 
Hearn, Jeff

2006 The Implications of Information and Communication Technologies for Sexualities and Sexualised Violences: Contradictions of Sexual Citizenships. Political Geography 25(8):944-944-963.

Hian, Lee Bee, Sim Li Chuan, Tan Mon Kiat Trevor, and Benjamin H. Detenber 2004 Getting to Know You: Exploring the Development of Relational Intimacy in Computer-Mediated Communication . Jornal of Computer-Mediated Communication 9(3).

Kendall, Lori

2002 Hanging Out in the Virtual Pub: Masculinities and Relationships Online. Berkeley, CA: University of California Press.

Kendall, Lori 1996 MUDder? I Hardly Know 'Er! Adventures of a Feminist MUDder. In Wired Women: Gender and New Realities in Cyberspace. Lynn Cherny and Elizabeth Reba Weise, eds. Seattle, WA: Seal Press.

Klastrup, Lisbeth 2008 What Makes World of Warcraft a World?: A Note on Death and Dying. In Digital Culture, Play, and Identity: A World of Warcraft Reader. Cambridge, MA: MIT Press.

Krzywinska, Tanya 2008 World Creation and Lore: World of Warcraft as Rich Text. In Digital Culture, Play, and Identity: A World of Warcraft Reader. Cambridge, MA: MIT Press.

Lastowka, Greg 2006 Law and Games Studies. Games and Culture 1(1).

Lenski, Gerhard E. 1982 Human Societies: An Introduction to Macrosociology.McGraw-Hill, Inc.

Leonard, David J. 2006 Not a Hater, just Keepin' it Real: The Importance of Race- and Gender-Based Game Studies . Games and Culture 1(1):83-88.

Lin, Wen-Kung, Chou-Kang Chiu, and Yuan-Hui Tsai 2008 Modeling Relationship Quality and Consumer Loyalty in Virtual Communities. Cyberpsychology and Behavior 11(5):561-561-564.

Lindley, Craig A. 2002 Conditioning, Learning and Creation in Games: Narrative, the Gameplay Gestalt and Generative Simulation . 
Lorber, Judith

1994 Paradoxes of Gender. New Haven: Yale University Press.

Lowood, Henry

2006 Game Studies Now, History of Science then. Games and Culture 1(1):78-82.

MacCallum-Stewart, Esther

2008 "Never such Innocence again": War and Histories in World of Warcraft. In Digital Culture, Play, and Identity: A World of Warcraft Reader. Cambridge, MA: MIT Press.

MacKinnon, Catharine A.

1989 Toward a Feminist Theory of the State. First Harvard University Press.

Malaby, Thomas M.

2007 Beyond Play: A New Approach to Games. Games and Culture 2(2):95-113.

Malaby, Thomas M.

2006 Parlaying Value: Capital in and Beyond Virtual Worlds. Games and Culture 1(2):141-162.

Marchand, Marianne H. and Jane L. Parpart

2003 Feminism/Postmodernism/Development. New York: Routledge.

McGonigal, Jane

2003 A Real Little Game: The Performance of Belief in Pervasive Play.

McRae, Shannon

1996 Coming Apart at the Seams: Sex, Text and the Virtual Body. In Wired Women: Gender and New Realities in Cyberspace. Lynn Cherny and Elizabeth Reba Weise, eds. Seattle, WA: Seal Press.

Miller, Toby

2006 Gaming for Beginners. Games and Culture 1(1):5-12.

Newlands, Allison, Anne H. Anderson, and Jim Mullin 2003 Adapting Communicative Strategies to Computer-Mediated Communication: An Analysis of Task Performance and Dialogue Structure. Applied Cognitive Psychology 17:325-348.

O'Brien, Jodi

2003 Writing in the Body: Gender (Re)Production in Online Interaction. In Communities in Cyberspace. Marc A. Smith and Peter Kollock, eds. New York, NY: Routledge. 
Ondrejka, Cory

2006 Finding Common Ground in New Worlds. Games and Culture 1(1):111-115.

Pearce, Celia 2006 Productive Play: Game Culture from the Bottom Up. Games and Culture $1(1): 17-24$.

Powell, Abigail, Barbara Bagilhole, \& Andrew Dainty. 2008. How women engineers do and undo gender: Consequences for gender Equality_406411..428 doi:10.1111/j.1468-0432.2008.00406.x

Raessens, Joost 2006 Playful Identities, Or the Ludification of Culture. Games and Culture 1(1):5257.

Rellstab, Daniel H. 2007 Staging Gender Online: Gender Plays in Swiss Internet Relay Chats. Discourse \& Society 18(6):765-765-787.

Rheingold Howard 1993 The Virtual Community: Homesteading on the Electronic Frontier. Cambridge, Massachusetts: The MIT Press.

Rowe, Aimee Carrillo 2005 Be Longing: Toward a Feminist Politics of Relation. NWSA Journal 17(2):15.

Simon, Bart 2006 Beyond Cyberspatial Flaneurie: On the Analytical Potential of Living with Digital Games. Games and Culture 1(1):62-67.

Smith, Jonas Heidi 2003 Avatars You can Trust - A Survey on the Issue of Trust and Communication in MMOs . Game Research.

Snowraven

(2010, Feb 14) Re: A Seemingly Random Question... [Online forum comment]. Retrieved from http://www.mmo-champion.com/threads/1263547-A-SeeminglyRandom-Question?p=20218024\&viewfull=1.

Squire, Kurt 2006 From Content to Context: Videogames as Designed Experience. Educational Researcher 35(8).

Thurer, Shari L.

2005 The End of Gender: A Psychological Autopsy. New York, NY: Routledge. 
Turkle, Sherry 2005 The Second Self: Computers and the Human Spirit. Twentieth ed. Cambridge, Massachusetts: The MIT Press.

Turkle, Sherry 1999 Cyberspace and Identity. Contemporary Sociology 28(6):643-643-648.

Turkle, Sherry 1997 Multiple Subjectivity and Virtual Community at the End of the Freudian Century. Sociological Inquiry 67(1):72-72-84.

Turkle, Sherry 1997 Computational Technologies and Images of the Self. Social Research 64(3):1093-1111.

Turkle, Sherry 1995 Life on the Screen: Identity in the Age of the Internet. Reprint ed. New York, NY: Simon and Schuster.

Turkle, Sherry 1994 Constructions and Reconstructions of Self in Virtual Reality: Playing in the MUDs. Mind, Culture, and Activity 1(3):158-158-167.

Tychsen, Anders, Michael Hitchens, Thea Brolund, and Manolya Kavakli 2006 Live Action Role-Playing Games: Control, Communication, Storytelling, and MMO Similarities. Games and Culture 1(3):252-275.

Weber, Max, Alexander Morell Henderson, and Talcott Parsons 1997 The Theory of Social and Economic Organization. reprint ed.Simon and Schuster.

Williams, Dmitri, Scott Caplan, and Li Xiong 2007 Can You Hear Me Now? the Impact of Voice in an Online Gaming Community. Human Communication Research 33(4):427-449.

Wittenburg, Georg 2004 Modeling and Classifying Cheating in Online Multiplayer Games.

Yee, Nick 2005 Motivations of Play in MMOs: Results from a Factor Analytic Approach. Electronic document, http://www.nickyee.com/daedalus/motivations.pdf, accessed April, 2008. 
Yee, N., \& Bailenson, J.

2007. The proteus effect: The effect of transformed self-representation on behavior. Hastings Center Report, 33(3), 271-290.

Yee, Nick

2014. The Proteus Paradox. Yale University Press. 


\section{APPENDICES}


Appendix I - Web-based Survey Questionnaire

$$
\text { World of Warcraft Female Identity Survey }
$$

Are you.... 1. Male 2. Female

How old are you?

Which type of server do you play most on... 1. PvE 2. PvP 3. RP

Please tell me what features of MMORPGs you consider most important.

Scale: Not Important, Somewhat Important, Important, Very Important

1. Customization of the appearance of the avatar

2. User friendly gaming interface

3. Advanced interaction with the game environment

4. Advancing stages of difficulty/challenge

5. Friendly community (i.e. Forums, Chatting)

6. Co-op opportunities (i.e. Group Quests, Raids)

7. Player versus Player

8. Player versus Environment

9. Role-play 
Do you belong to a guild? a. Yes b. No, but I did once c. No, and I never have

If c, explain.

Do you usually play in an 1) all guild group or 2) PUGs or 3) mixed guildies and PUG?

How many avatars do you currently play? a. 1, b. 2-5, c. 6-9, d. 10 or more

What class type do you prefer to play? a. healers, b. melee, c. tanking, d. ranged dps

Of your avatars, how many are female? __ How many are male?

Is the best healer you know a male or a female avatar?

Is the best melee character you know a male or a female avatar?

Is the best ranged dps character you know a male or female avatar? 
How many of your guild mates are actual females?

Do they largely play female avatars?

How often do you group with players who are female? a. Always b. Often c. Seldom d. Never

Do you raid weekly/monthly/sometimes/never?

If you raid, do you raid mostly in guild groups or PUGs?

All raid groups try to achieve a workable balance of classes. But, talking about your personal playing preferences, is there a type of PLAYER that you try to avoid in raid groups? Any particular playing characteristics that you absolutely HATE?

Do you associate these characteristics more with a. female players, b. male players, c. neither, d. both equally 
What player characteristics do you LOVE when raiding with a group?

Do you associate these characteristics more with a. female players, b. male players, c. neither, d. both equally

Do you notice any difference in the play style of male players versus female players in raids, quests, festivals or when simply conversing? Explain.

Now I want to know what you think about the use of gender and interactions through MMORPGs and WoW.

Scale: Strongly Disagree, Somewhat Disagree, Somewhat Agree, Strongly Agree

1. I assume most players to be male, whether or not the avatar is female.

2. I think most players have created an avatar of the opposite sex.

3. I have, at some point, created an avatar of the opposite sex.

4. I think there are more male WoW players than female WoW players.

5. I think female gamers prefer more aesthetically pleasing avatars.

6. I think younger gamers prefer more aesthetically pleasing avatars.

7. I prefer creating more aesthetically pleasing avatars.

8. I judge the skill of other players based on their avatar choice.

9. I judge the gender of other players based on their avatar choice. 
10. I think guilds are stronger when there are equal amounts of male and female players.

11. I think female gamers prefer player versus player.

12. I think female gamers prefer player versus environment.

13. I think female players are more likely to choose healing classes.

14. I think female players are more likely to choose pet-based classes.

15. I think female players are more social when it comes to chatting.

16. I think female players take greater part and enjoy the WoW festivals (The Feast of Winter Veil, Midsummer Fire Festival, etc.) more than male players.

17. I am comfortable speaking on a voice chat system such as Ventrillo when participating in group activities in-game.

18. I am often mistaken by other players as being of the opposite sex.

19. I try to quickly reveal my gender to my guild or group partners.

20. I am more comfortable playing with gamers of the opposite sex.

21. I am more comfortable playing with gamers of the same sex.

22. I think more popular MMOs have a more aggressive community.

23. I think less popular MMOs have a more helpful community.

24. I am comfortable asking questions in MMO forums.

25. I am comfortable revealing my gender in MMO forums. 
Appendix II - Semi-structured Open Ended Interview Questionnaire Tell me about your own gaming habits...

Probe: How long have you been playing video games?

Probe: How long have you played/did you play World of Warcraft?

Probe: Describe your main or the avatar you typically make.

Probe: What, if any, are the reasons for those choices?

What do you consider to be the definition of a "gamer"?

Probe: What characteristics do you associate with the term "gamer"?

Probe: What characteristics do you associate with a female gamer? A male gamer?

Describe how you feel about gamers of the opposite sex?

Probe: Why do you feel that way?

Probe: What memorable experiences have led you to feel that way? 
With World of Warcraft specifically, describe the players you choose to group with the most. Describe those you choose to avoid.

Probe: Tell me about some experiences you have had with these players to lead to your decision.

What are your feelings about female players in World of Warcraft?

Probe: Why do you feel that way?

Probe: What experiences have led you to feel that way?

What assumptions do you make when you encounter a female avatar?

Probe: Are there any assumptions when they are of a particular class? What assumptions?

Probe: How about male avatars?

Are there any stereotypes associated with female players that you are aware of?

Probe: What are they?

Probe: How true do you feel these stereotypes are?

Probe: Are there any experiences you have had that speak to those stereotypes? 
Have you ever had experiences with gender-bending players, that is, players that play a female avatar and are male or vice versa?

Probe: Describe those experiences.

If female respondent: How do you feel about communicating on Vent?

Probe: Have there ever been instances where someone has expressed some emotion at finding out your gender through Vent? Please explain that experience.

Probe: Has someone ever believed you to be male and been surprised when you revealed (either on Vent or through chat) that you were female? Please explain that experience. Why do you think that happened?

If male respondent: Have you ever thought a character was played by a male of female and the voice on Vent surprised you?

Probe: How did you react? Describe the situation.

Probe: Has someone ever believed you to be female and been surprised when you revealed (either on Vent or through chat) that you were male? Please explain that experience. Why do you think that happened? 


\section{CONNIE M. VIAMONTE}

1999-2002

B.A. in Anthropology/Sociology

Florida International University

Miami, FL

2004-2009

Teaching Assistant

Florida International University

Miami, FL

2004-2006

M.A. in Comparative Sociology

Florida International University

Miami, FL

2009-2011

Adjunct Faculty (part-time)

Florida International University

Miami, FL

2009-2010

Research Associate (part-time)

Camillus House, Inc.

Miami, FL

2012-present

Adjunct Faculty (part-time)

Florida International University

Miami, FL

\section{PRESENTATIONS}

2007 - Presentation of Resistance and Redevelopment at the American Anthropological Association 2007 Conference in Washington, D.C.

2009 - Presentation of Female Identity in the Massive Multi-player On-line Gaming Community of World of Warcraft at the Eastern Sociological Society 2009 Conference in Baltimore, MD

2009 - Successful defense of dissertation proposal presentation of Female Identity in the Massive Multi-player On-line Gaming Community of World of Warcraft

2010 - Presentation of Female Identity in the Massive Multi-player On-line Gaming 
Community of World of Warcraft at the $10^{\text {th }}$ Annual Women, Sexuality, and Gender Student Conference at Florida International University in Miami, FL.

2011 - Presentation of Female Identity in the Massive Multi-player On-line Gaming Community of World of Warcraft for Florida International University virtual classroom in Second Life.

2012 - Presentation of Dissertation Research of Female Identity in On-line Gaming Community of World of Warcraft for Cyberaesthetics and narratives Conference at University of Miami in Miami, FL 